\title{
Blast Tests of Expedient Shelters in the DICE THROW Event
}

Cresson H. Kearny

Conrad V. Chester

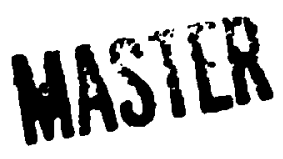


ORNL-5347

Dist. Category UC-41

Contract No. W-7405-eng-26

ENERGY DIVISION

Solar and Special Studies Section

BLAST TESTS OF EXPEDIENT SHILTERS IN THE DICE THRON EVENT

Cresson H. Kearny

and

Conrad v. Thester

Date Published: March 1978

Research sponsored jointly by the Defense Civil Preparedness

Agency and the Division of Biomedical and Environmental

Research, Department of Energy, under contract with the

Union Carbide Corporation.

OAK RIDGE NATIONAL LABORATORY

Oak Ridge, Tennessee 37830

operated by

UNION CARBIDE CORPORATION

for the

DEPARTMENT OF ENERGY

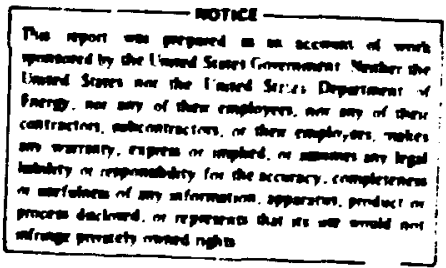


ConTENTS

Page

LIST OF FIGURES . . . . . . . . . . . . . . . . . . vil

LIST OF TABLES . . . . . . . . . . . . . . . . . . . xi

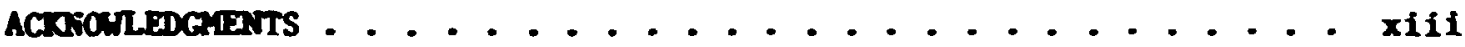

ABSTRACT . . . . . . . . . . . . . . . . . . 1

1. BACTGROUID AND SCOPE .................... 1

2. PRINCIPAL OBJECTIVES .................... . . 3

3. IXSTRUAERTATIOA USED AND TEST DATA RECOVERED .......... 3

3.1 Blast Overpressures . . . . . . . . . . . . . . 3

3.2 Elastic and Pernanent Defornations ........... 4

3.3 Blast-Wind Scouring ................. s

3.4 Blast Danage to Structures ............... 5

4. SMALL-POLE SHELTER AT 53 psi ................ 5

4.1 Purpose ................... 5

4.2 Construction ................. 8

4.3 Test Results ................... 12

4.4 Conclusions and Recomendations ............ 16

5. UNHODIFIED RUSSIAN POLE-COVERFD TRENCH SHELTERS AT 20

AND 6.7 psi . . . . . . . . . . . . . . . . 17

5.1 Purpose ................... 17

5.2 Construction ................. 17

5.3 Location and Test Results . . . . . . . . . . 18

5.4 Conclustons . . . . . . . . . . . . . 22

6. LOG-COVERED TRENCH SHELLTER AT 53 psi . . . . . . . . 23

6.1 Purpose . . . . . . . . . . . . . . . 23

6.2 Construction . . . . . . . . . . . . . . 23

6.3 Test Results . . . . . . . . . . . . . . 27

6.4 Conclusions and Recomendations . . . . . . . . . . . 28

7. LOG-COVERED TRENCH SHELTER AT 31 pS1 . . . . . . . . . . 29

7.1 Purpose . . . . . . . . . . . . . . . . 29

7.2 Construction . . . . . . . . . . . . . . . 29

7.3 Test Results . . . . . . . . . . . . . . . 29

7.4 Conclusion and Recommendations ............. 31 


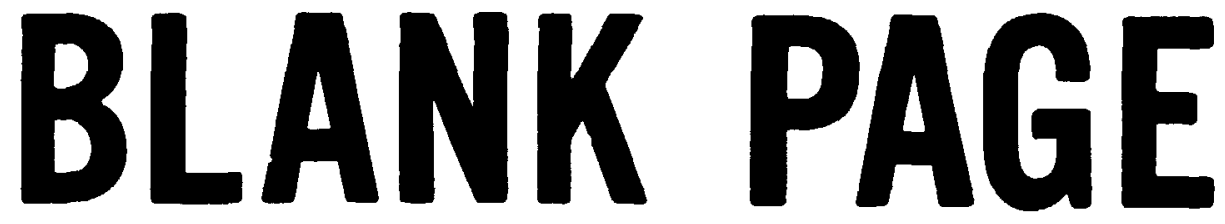 \\ BLANK PAGE}

,

, 
8. DOOR-COVERED EARTh-ROLL SHELTERS AT 15 AND 5.8 psi . . . . . 31

8.1 Purpose . . . . . . . . . . . . . . . 31

8.2 Constructicn .................. 31

8.3 lest Results ..................... 32

8.4 Conclusions and Recomendations . . . . . . . . . 35

9. RIDGE-POLE SHELTERS AT 15 AND 5.8 psi ............ 36

9.1 Purpose . . . . . . . . . . . . . . . . . 26

9.2 Construction . . . . . . . . . . . . 36

9.3 Test Results . . . . . . . . . . . . . . . 38

9.4 Conclusions and Recomendations ............. 41

10. DOOR-COVERED TRENCH SHELTERS AT 31 AND 15 f.Si . . . . . . 42

10.1 Purpose . . . . . . . . . . . . . . . 4?

10.2 Construction .................. 42

10.3 Test Results .................... 42

IÛ. 4 Conclusions and Recomendations ........... 45

11. CHINESE "MAN" SHELter at 20 psi . . . . . . . . . . . 45

11.1 Purpose... . . . . . . . . . . . . . 45

11.2 Construction ................... 46

11.3 Test Results .................... 49

11.4 Conclusions and Recomendations ............. 51

12. RUG-COVERED TRENCH SHELTERS AT 15 AND 5.8 psi . . . . . . 51

12.1 Purpose . . . . . . . . . . . . . . . 51

12.2 Construction ................ 52

12.3 Test kesults . . . . . . . . . . . . . 53

12.4 Conclusions and Recommendations . . . . . . . . . 54

13. SCALE MOdels of SHELTERS . . . . . . . . . . . . . . 54

13.1 Purpose and Construction ............. . . 54

13.2 Test Results ................. 55

13.3 Conclusions .................. 60

14. BLAST-HURLED DEBRIS .................... 60

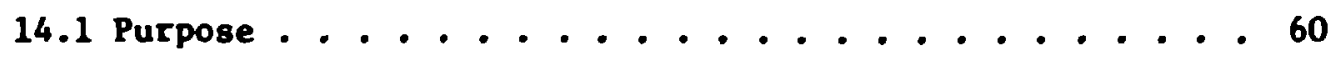

14.2 Test Results . . . . . . . . . . . . . . . 61

14.3 Conclusions and Recomendations............ 62 
15. BLAST-WTRD SCOURING ................. 63

15.1 Purpose and Method of Measurements .......... 63

15.2 Test Results ................... 63

15.3 Conclusions and Recomendations ............ 64

16. EXPEDIENT UATER STORAGE ................. 64

16.1 Purpose . . . . . . . . . . . . . . . . 64

16.2 Construction and Test Results .............. 64

16.3 Conclusions . . . . . . . . . . . . . . . . 67

17. EXPEUIEAT VETTILATION OF BLAST SHELTERS . . . . . . . . 68

17.1 Putpose . . . . . . . . . . . . . . . . . 68

17.2 Observations, Cunstruction, and Test Results ...... 68

17.3 Conclusions and Recomendations . . . . . . . . 70

18. LIMITATIONS OF THESE DICE THRON TESTS . . . . . . . . . 71

18.1 Limitations nue to Size . . . . . . . . . . . . 71

18.2 Blast Tests of Scale Modeis .............. 73

18.3 Earth Stability ... . . . . . . . . . . . 73

18.4 Fire Dangers . . . . . . . . . . . . . . 73

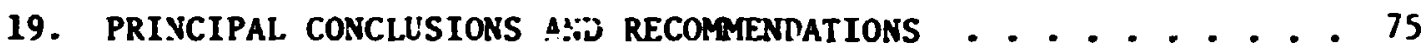

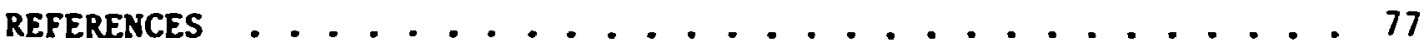




\section{LIST OF FIGURES}

Fieure

Page

1.1 The 628 tons of NTrO ready for detonation ......... 2

1.2 Vies of the rising mushroon cloud taken from an observation post .................... 2

4.1 Plan and elevation of Sall-Pole Shelter ......... 6

4.2 Piccorial vies of Seall-Pole Shelter . . . . . . . . 7

4.3 Nafling tare-strip hinges to expedient blast door . . . . . 9

4.4 Expedient blist door that can be closed and secured In $4 \mathrm{sec} . . . . . . . . . . . . . . . . . . . .1010$

4.5 Vertical cross section through an overlapping-flaps blast valve ........................ . 11

4.6 Blast-protector logs around blast door ........... 11

4.7 Sall-Pole Shelter after being tested with blast coors closed . . . . . . . . . . . . . . . . 13

4.8 Hovement of upper part of Sall-Pole Shelter . . . . . 14

4.9 "Puffed-up" part of the floor of Sall-Pole Shelior . . . 14

4.10 Expedient bed-sheet hamock, useful to avoid severe shock effects . . . . . . . . . . . . . . 15

5.1 Poles covering Russian Pole-Covered Trench Shelter . . . 17

j.2 Russian Pole-Covered Trench Shelter in stable earth.... : 9

5.3 Dumies being struck by air blast and surtains . . . . . 2C

5.4 Du ies at 20-psi range after ground shock collapsed earth walls.................. 20

5.5 Wrecked entry of Russian Pole-Covered Trench Shelter at $20 \mathrm{psi}$.................... 21

5.6 Dugy knocked off bench in Russian Pole-Covered Trench Shelter ...................... 21

6.1 Comparison of Russian way and Chinese way of positioning poles... . . . . . . . . . . . . 23

6.2 Hewing square sides on a 108 .............. 24

6.3 Expedient triangular blast door ade of pine poles . . . 25

6.4 View of the sane triangular blast door . . . . . . . . 26

6.5 Broken pole of triangular door seat . . . . . . . . . . 26

6.6 Postest condition of expedient triangular blast door . . . . . . . . . . . . . . . . . 27

6.7 Postshct view of the caved-in caliche walls........ 28 


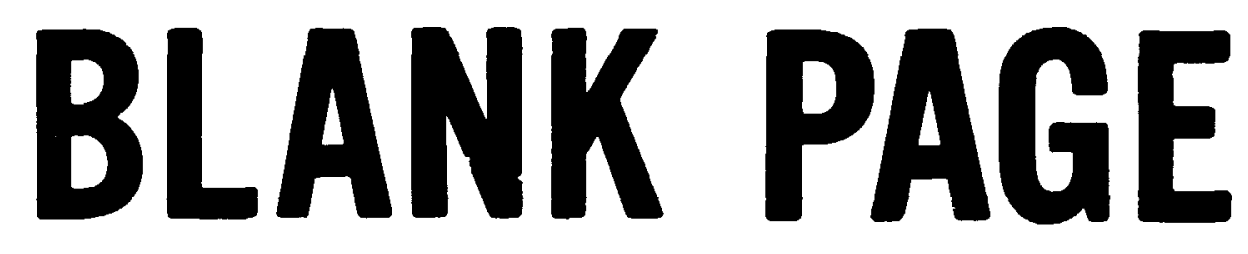

(1) 
7.1 Seniexpedient blast door ande of a 30-gal steel drun . . 30

7.2 Serious wall caving at 31 psi (predicted 30 psi) . . . j0

8.1 Bed-sheet "earth-roll" walls $36 \mathrm{in}$. apart before rest ...................... 31

8.2 Door-Covered Earth-Roll Shelter, tested at 15 and $5.8 \mathrm{psi}$. . . . . . . . . . . . . . . . 33

8.3 Northward-facing entry ... if Door-Covered Earth-Roll Shelter ...................... 34

8.4 Interior of Door-Covered Earth-Roll Shelter . . . . . . 34

8.5 Posttest Interior of Door-Covered Earth-Roll Shelter . . 3j

9.1 Alnost copleted frane Ridie-Pole Shelter . . . . . 36

9.2 Ridge-Pole Shelter tested at 15 and $5.8 \mathrm{psi}$. . . . . . 37

9.3 Covering the frane of a Rdje-Pole Shelter . . . . . . 38

9.4 Post test interior of .1dge-Pole Shelter at 15 psi . . . . 39

9.5 Postcest exterior of 1/10-scale Ridge-Pole Shelter at 15 psi . . . . . . . . . . . . . . . . 39

9.6 Collapsed entrance facing away from ground zero ...... 40

9.7 Postblast view of the entry of the Ridge-Pole Shelter . . . 40

10.1 Door-Covered Trench Shelter tested at 31 and $15 \mathrm{psi}$. . . 43

10.2 Photo of Door-Covered Trench Shelter at 31 psi . . . . . 44

10.3 Postblast interior of Door-Covered Trench Shelter ..... 4t

11.1 Chinese "Man" Shelter tested at $20 \mathrm{psi}$......... 45

11.2 Completed frane of m:tnese "Man" Shelter . . . . . . . 46

11.3 Undanaged interior, showing earth bench on one side . . . 47

11.4 The lowest part of the vertical triangular entry . . . . 47

11.5 Posttest undanaged triangular blast door ........ 48

11.6 Undanaged triangular blast door, partly open ...... 49

11.7 Covering the 11mb-covered pole frame with bed sheets... 49

11.8 Posttest view of opening ... of triangular vertical entry .................... 50

11.9 Postshot condition of ... triangular vertical entry . . . 50

12.1 Construction of Rug-Covered (or Tarp-Covered) Trench Shelter ................. 52

12.2 Taming earth over edge of a side trench ......... 53

12.3 Duplng earth on side of rug before mounding earth .... 53 
12.4 Demolished Rug-Covered Trench Shelter at 15 psi . . . . . 54

13.1 One-half-scale Clinese "Man" Shelter tested at 31 psi . . . 56

13.2 One-tenth-scale roos of Chinese "Man" Shelter at 31 psi ................... 57

13.3 Construction of one-half-scale Loz-Covered Trench Shelter .................... 58

13.4 One-tenth-scale Small-Pole Shelter, pretest at 106 psi ........................ 59

13.5 One-tenth-scale Swall-Pole Shelter, posttest at 106 psi .................... 59

14.1 Some of the fireplace-size logs hurled from a roodpile ..................... 61

14.2 Postcest condition of the side facing ground zero . . . . 62

16.1 Vertical sectirn of cylindrical water storage pit . . . . 65

16.2 Cylindrical water storage pit lined . . . . . . . . 65

16.? Postshot view of plastic-lined water storage pit . . . . 67

17.1 Expedient shelter ventilating pump . . . . . . . . . 69

17.2 Expedient KAP $(20 \times 24$ in) tested in the Chinese "Man" Shelter................... 70

18.1 Parts of a blast door and its blast-protector logs . . . 75 


\section{LIST OF TABLES}

Table

Page

3.1 Overpressures at various distances . . . . . . . . 4

15.1 One-kiloton blast-wind scouring ............63 


\section{ACKONOWLEDGENTS}

The authors wish to express their indebtedness to the following:

The Defense Nuclear Agency and many of its of ficers and other personnel for authorizing Oak Ridge lational Laboratory's participation in DICE THROW and for installing most of the ORNL shelters and other test items.

Donald Richmond of the Lovelace Foundation for the use of anthropomorphic dusies.

Julius Meszaros of the Ballistic Research Laboratory for the highspeed movie camera that recorded blast effects on dumies and shelter walls; also John Wisotski of Denver Research Institute for the Installation and operation of this camera.

P. R. Barnes for his work on blast pressure gauges and shelter installation.

M. E. Fish for making the one-tenth-scale shelter models.

G. A. Cristy and Ruby N. Thurmer for their editorial helf.

Edwin N. York of the Boeing Company and Lawrence Dresner (Oak Ridge Y-12 Plant) for their final manuscript reviews and helpful criticisms. 


\section{ABSTRACT}

To deteraine the worst blast environments that eight types of ex,edient shelters can withstand, we subjected a total of 18 shelters tc the $1-k^{\prime}$.ioton blast effects of Defense Nuclear Agency's DICE TRROW min event. These expedient shelters included two Russtan and two Chinese types. The best shelter tested was a Small-Pole Shelter that had a box-1fke roon of Russian design with ORNL-designed expedient blast ent-ies and blast doors adder. It was undamaged at the 53-psi peak overpressure range; the pressure rise inside was only $1.5 \mathrm{psi}$. An umodified Russian Pole-Covered Trench Shelter was badly damaged at 6.8 psi. A Chinese "Man" shelter, which skillfully uses very small poles to attain protective earth arching, survived 20 psi, undamiged. Two types of expedient sheltecs buitt ci materials found in anc around most American homes gave gond protection at overpressures up to about 6 psi. Rug-Covered Trench Shelters were proved unsatisfactory.

Hater storage pit\} lined with ordinary plastic tras'. bags were proven practical at up to $53 \mathrm{psi}$, as were triangular expedient blast doors made of poles. At 53 psi, expedient blast valves installed in blast doors successfully protected the expedient air pump and allowed it to continue to force sufficient air through the shelter. However, after the blast the reopened valves allowed so much wind-blown sand to enter the shelters that it became obvious that blast valves installed in blast doors will not give adequate protection against the entry of fallout.

\section{PACKGROUND AND SCOPE}

Civil defense research at Oak RIdge National Laboratory has stressed the developmeni of: protection against blast and ilre effects, even in the design of expedi,nnt fallout shelters. Well-constructed expedient shelters w111 permit their: occupants to survive at least 7 psi. in contrast, most frame buildfngs are badly damaged by blast and ary be destroyed by fire at the 2-risi overpressure range from a large-yleld weapon, at great hazard to anyone taking, shelter in them. Since the area covered by 7 psi 18 is: iy one-quarter that covered by 2 psi by a single weapon, the lifesaving potential of good expedient shelters, built unattached to buildings, is worth working hard to attain. Another reason is that even expedient shelters, if their walls are skillfully shored and their entrances equipped with expedient blast doors, can readily be built so 


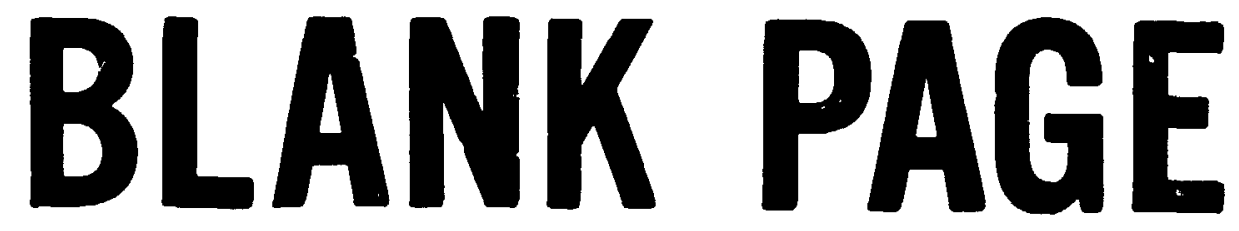


as to protect occupants against all blast effects at peak overpressure ranges several times as high as 7 psi. Therefore, in 1973 ORN participated in Defense Nuclear Agency's (DNA's) MIXED COMPANY Event. This test subjected various expedient shelter designs to the effects of an explosion of 500 tons of TNT. All of the ORNL expedient shelters survived with little or no damage at overpressures up to $29 \mathrm{psi} .^{l}$ As a resuit, it was decided that the wost promising designs should be subjected to b]ast effects severe enough to indicate the worst blast environments that these $\therefore: 21$ ters are capable of withstanding.

The main event of DMA's recent DICE THROW series afforded the required blast enviroment. This event was a 628-ton ANFO (ammonium nitrate-fuel cil) explosion, the largest planned detonation of a conventional explosive in history. The 1,256,000 lb of ANFO is shown in Fig. 1.1, stacked in the desert at White Sands Missile Range, New Mexico. This shot was detonated on October 6, 1976, and produced air-blast effects about equivalent to a 1-kiloton nuclear surface burst.

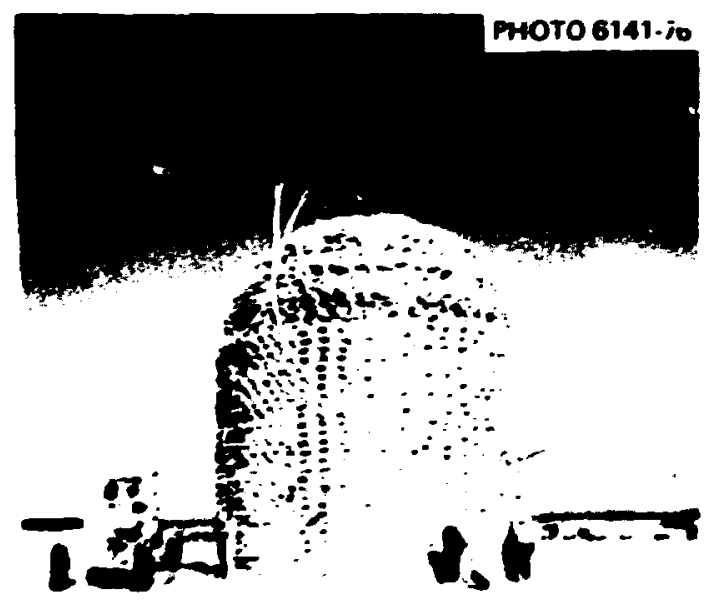

PHOTO 6391.76

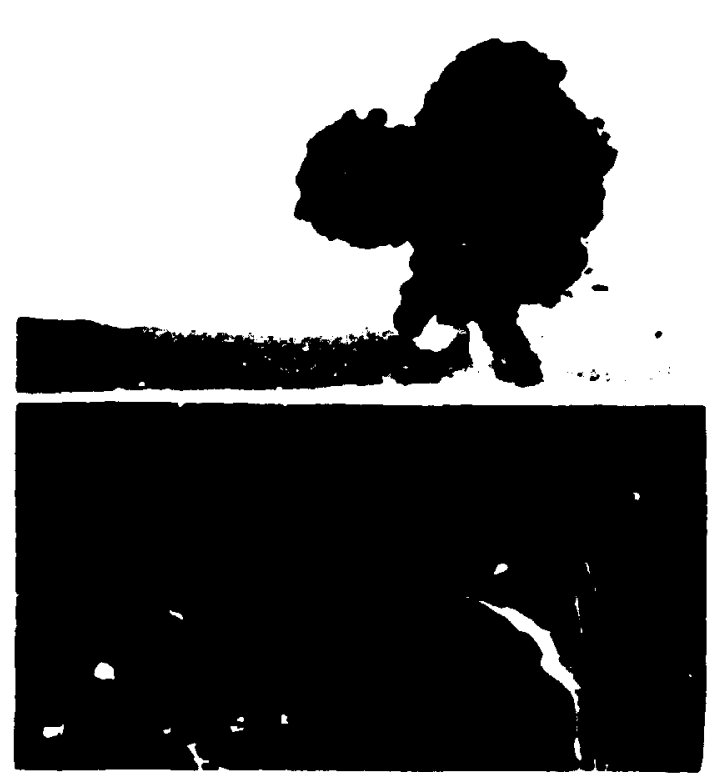

P18. 1.1. The 628 tons of ANFO ready for detonation.

Fig. 1.2. View of the rising mushroom cloud taken from an observation post 3 miles away.

Figure 1.218 a photo taken 3 miles away from ground zero and shows the mushroow cloud while 1 wes still rising. The winds of the negative 
phase were still blowing a sheet of dust and sand inward toward the rising sten of the cloud. Eighteen expedient shelters (in. luding four half-scale models) were subjected to the blast effects at overpressures ranging from 53 to 5.8 psi, and expedient life-support equipnent (mosty placed inside shelters) was exposed to overpressures of 53 to 1 psi. Several one-tenth-scale models of shelters were also tested, at overpressures of up to 180 psi.

\section{PRINCIPAL OBJECTIVES}

The principal objectives of ORN's participation in DICE THROW were:

2.1. Co obtain field data useful in making more reliable estimates of the practical limitations of promising expedient shelcer designs and expedient life-support equipment, as regards their capabilities for withstanding all blast effects from large explosions;

2.2. to observe the relative effectiveness of several different ways of utilizing earth arching and trench-wall shoring to increase the blast protection afforded by lightly constructed shelters, in order to develop improved shelter designs that can be built using only widely available materials.

\section{INSTRUMENTATION USED AND TEST DATA RECOVERED}

\subsection{Blast Overpressures}

Blast overpressures were measured by yielding foil membrane blast gauges. ${ }^{2}$ These passive gauges were developed at ORHL and performed well at the lower overpressures (1ess than 7 psi). However, the ORNL gauges that were installed adjacent to principal shelters to measure overpressures above 7 psi all rer.orded overpressures 28 to $60 \%$ higher than those recorded by the transducers at the same radial distances from groind zero on DNA's adjacent Gauge line No. 1. Therefore, we have used the DNA measurements for all the aboveground overpressures to which the ORNL shelters were subjected, except for the DNA measurement at the predicted 100-pst range, which was obviously far too low. 
The distances from ground zero to the shelters, the predicted overprrssures, and the measured overpressures at these distances are shown is rable 3.1.

Table 3.1. Overpressures at various distances

\begin{tabular}{ccccc}
\hline \multirow{2}{*}{$\begin{array}{c}\text { Distunce from } \\
\text { ground zero } \\
\text { (ft) }\end{array}$} & $\begin{array}{c}\text { Predicted } \\
\text { overpressures } \\
\text { (psi) }\end{array}$ & $\begin{array}{c}\text { Dik Gauge } \\
\text { Line No. } 1\end{array}$ & $\begin{array}{c}\text { ORNL } \\
\text { gauges }\end{array}$ & $\begin{array}{c}\text { Overpressure } \\
\text { value used }\end{array}$ \\
\cline { 3 - 5 } 440 & 100 & 66 & 106 & 106 \\
540 & 50 & 53 & 68 & 53 \\
640 & 30 & 31 & 43 & 31 \\
740 & 20 & 20 & 32 & 20 \\
820 & 15 & 15 & 24 & 15 \\
1140 & 7 & 6.7 & 10.5 & 6.7 \\
1370 & 5 & 5.8 & 6 & 5.8 \\
\hline
\end{tabular}

To simplify this report, only a few references to distances from ground zero or predicted overpressures wili be made. Measured peak overpressures will be used (e.g., "53 pst," "31 psi").

The ORNL pressure gauges liside the shelters recorded low overpressures. All these gauges functioned well. However, the records of two overpressures inside the st.elters at the 31-psi overpressure range were subsequently lost. All the ORNL pressure gauges were recovered, and all but the two above-mentioned overpressures they recorded inside the shelters are used in this report.

\subsection{Elastic ind Permanent Deformations}

Elastic and permanent deformations of the roofs and some other parts of the shelters were measured by pasaive mechanical devices. 1 Over 907 of these functioned effectively. Linear measurements of distances between parts of a shelter were taken before and after the bl ist. 


\subsection{Blast-Wind Scouring}

Blast-wind scouring of the earth wounded over shelters and around entryways was detemined by driving 12-in. steel spikes into the earth until their heads were flush with the ground and measuring their exposures after the blast. (The duration of the blast winds is proportional to the cube root of weapons yield; ${ }^{3}$ thus the dept:t of scouring by larger weapons can be estimated.) Also, preblast and postblast depths of earth over and around shelters vere recordid.

\subsection{Blast Danage to Structures}

Blast danage to all structural parts of shelters and to the earth valls of unshored shelters and of water storage pits were determined prinarily by observation. Nunerous photographs were taken, both before and after the blast, :o record blast danage - the nost important part of the cest data.

\section{SMALL-POLE SHELTER AT 53 pSi}

\subsection{Purpose}

The Small-Pole Shelter (see Figs. 4.1 and 4.2) has been developed for construction by unskilied workers in wooded areas (in stable or unstable earth, below or above giound). It provides excellent protection against radiation and much better protection agai:st blast than does an unshored trench shelter or any poorly shored sielter. Untrained groups of families, using only muscle-powered tools, have succeeded in building this type of shelter in less than $48 \mathrm{hr}$ elapsed time from the time they received the instructions. ${ }^{4}$ A 24 -man section of an infantry platoon of the 82nd Airborne Division, with no prior training and using only muscle-powered tools, built a 24-man model, without benches or bunks, in 18 elapsed hours. 5 All of these models had cnly one entry. The Russian-sized ventilation duct at the other end, that provided only about $10 \mathrm{~cm}^{2}$ of cross-sectional area per occupant, was found to result in dangerously inadequate cocling during sumertime tests in Tennessee. 


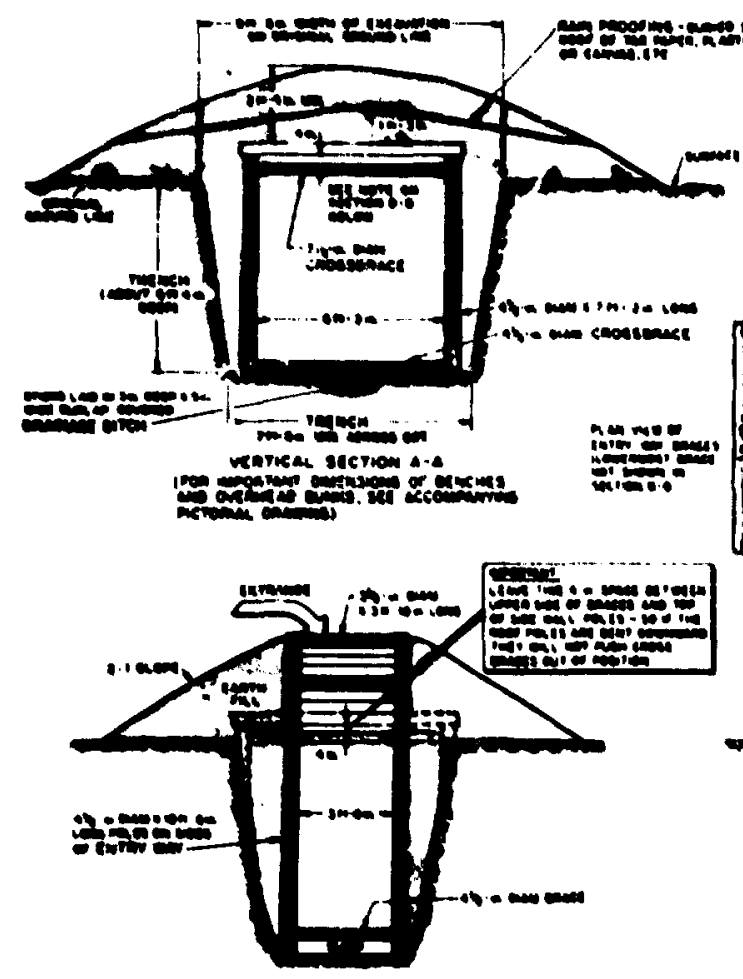

varicen secrom 0-0

".min".

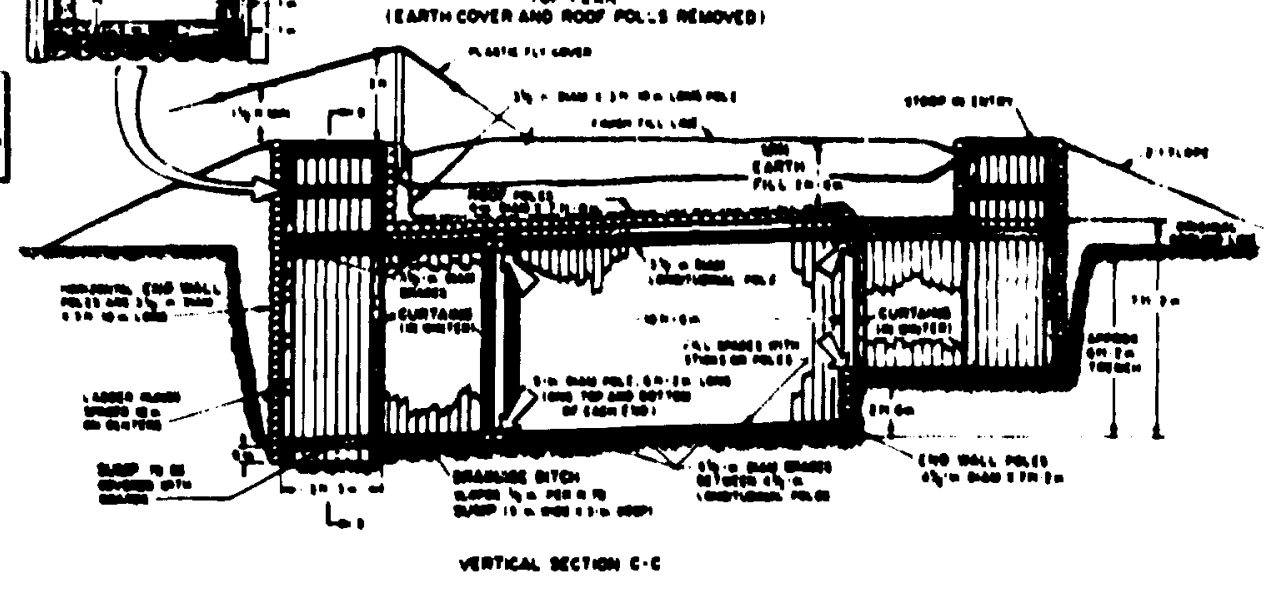

F1g. 4.1. Plan and elevation of Small-Pole Shelter. 


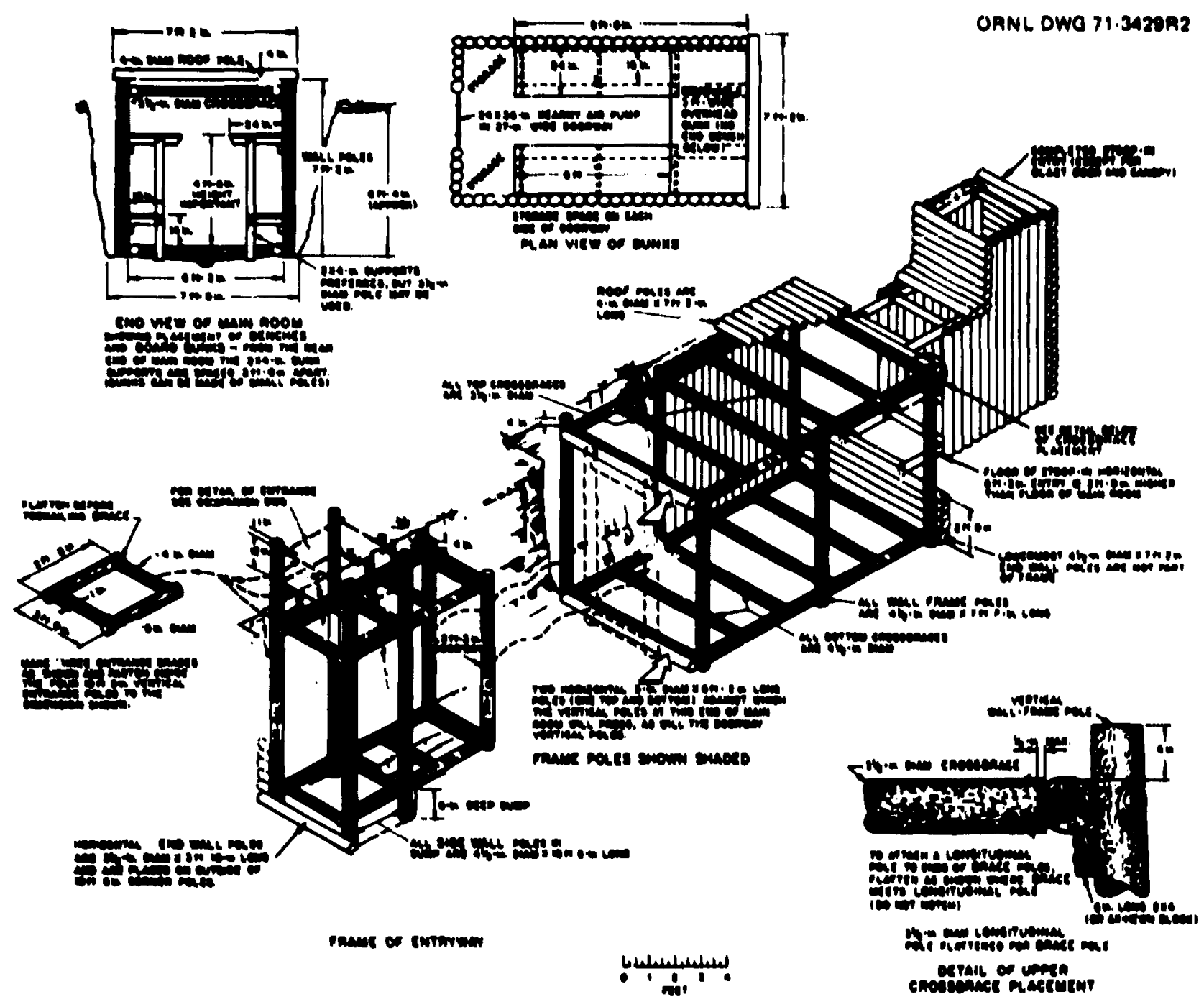

F18. 4.2. Pictorial view of Small-Pole Shelter. 


\subsection{Construction}

The anin roon and the horizontal part of the entryway at the east end vere of unodified Russian design, 6,7 except that the excavation in the nard caliche was ade i ft deeper than the final level of the shelter floor. Then this bottion 2 ft was backfilled with dry, sandy earth. This soft earth under the vall poles pernitied then to be pusbed down sufficiently under blast laading to throw nost of the laad onto the resultant earth arching that blast overpressure sets up over a jielding structure.

A previous ODI analysis ${ }^{8}$ of the survivability of this shelter Indicated that without the protection of earth arching it would withstand an overpressure from a 200-kfloton weapon of about 15 psi with blast doors closed. This analysis assuned the use of green hardwood poles, the strengths of wich were determined in the ORIL materials laboratory. The roof poles and wall poles of all the ORIL pole shelters In DICE THRON were ponderosa pine. In this shelter the poles averaged about 5 in. In diameter, including their bark. The 12-occupant shelter room was 10-1/2 ft long, as 11lustrated by Figs. 4.1 and 4.2.

The horizontal part of the entryway at the south end was only 4-1/2 ft In helght, with 1 ts floor 2-1/2 ft above the floor of the and roon and the east-end entryway.6,7 This height proved adequate, and this stoop-in entryay required significantly less material and labor to bulld than did the Russian-type horizontal entryway with $6 \mathrm{ft}$ of headroon. (An unodified Ruesian Small-Pole Shelter has only a smal chiney-1ike air duct at one end; ond tests had proved that this sall air duct would provide such inadequate ventilation that fatalities fron excessive heathundity could result in warn or hot weather after a day of full occupancy.) The vertical entryways were of odul design, 7 as shown in P1ge. 4.1 and 4.2, except that they extended $5 \mathrm{ft}$ above the cellings of the horizontal entryways. (The Russian inclined stairway-entrance had been found to be weak and not suitable for the installation of a blast door.)

The roof poles of this boxlike shelter were at ground level. The length of this shelter was perpendicular to the radius from ground zero. To provide adequate shielding against the initial nuclear radiation to 
be expected at the approximately 50-psi overpressure range fron smaller nuclear weapons, the roofs of the shelter roon anc its entryways were covered with $5 \mathrm{ft}$ of counded earth. For adequate protection against Initial radiation from a tactical weapon (through the entries), each entryay should have been at least $10 \mathrm{ft}$ long. For protection against radiation from strategic weapons, the entries actually bullt would be satisfactory, and only 3 ft of earth cover would give a protection factor (PF) of over 500 .

The need for blast doors on fanily shelters has long been recognized.9,10 opd blast cests ${ }^{1}$ had demnstrated the effectiveness of expedient blast doors with protector logs around the at overpressure ranges up to $29 \mathrm{psi}$, and since the present Soviet nuclear arsenal could subject over half of all Anericans, if In their normal areas, to serious blast dangers, we included three new designs of expedient blast doors ir. our DICE THRON tests.

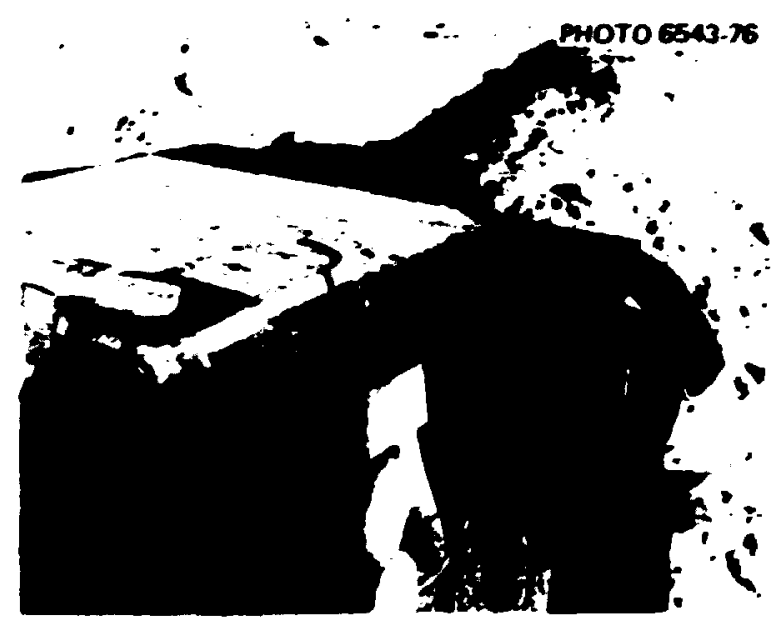

Fig. 4.3. Ralling tire-strip hinges to expedient blast joor tested at the 53-psi overpressure range.

Both entrances of the Sal1-Pole Shelter were protected by expedient blast doors (see Figo. 4.3 and 4.4). Each door weasured $48 \times 42$ in. and each was aade of five thicknesses of $3 / 4-1 \mathrm{n}$. exterior plywood. The plywood sheets were glued together with waterproof resin and natled together from boch sides, on a rectangular spacing of $4 \mathrm{in}$. In each direction, with lio. 16 (4-in.) coaced natls. Expedient hinges ade of strips cut from the worn treads of autombile tires were nalled to the 

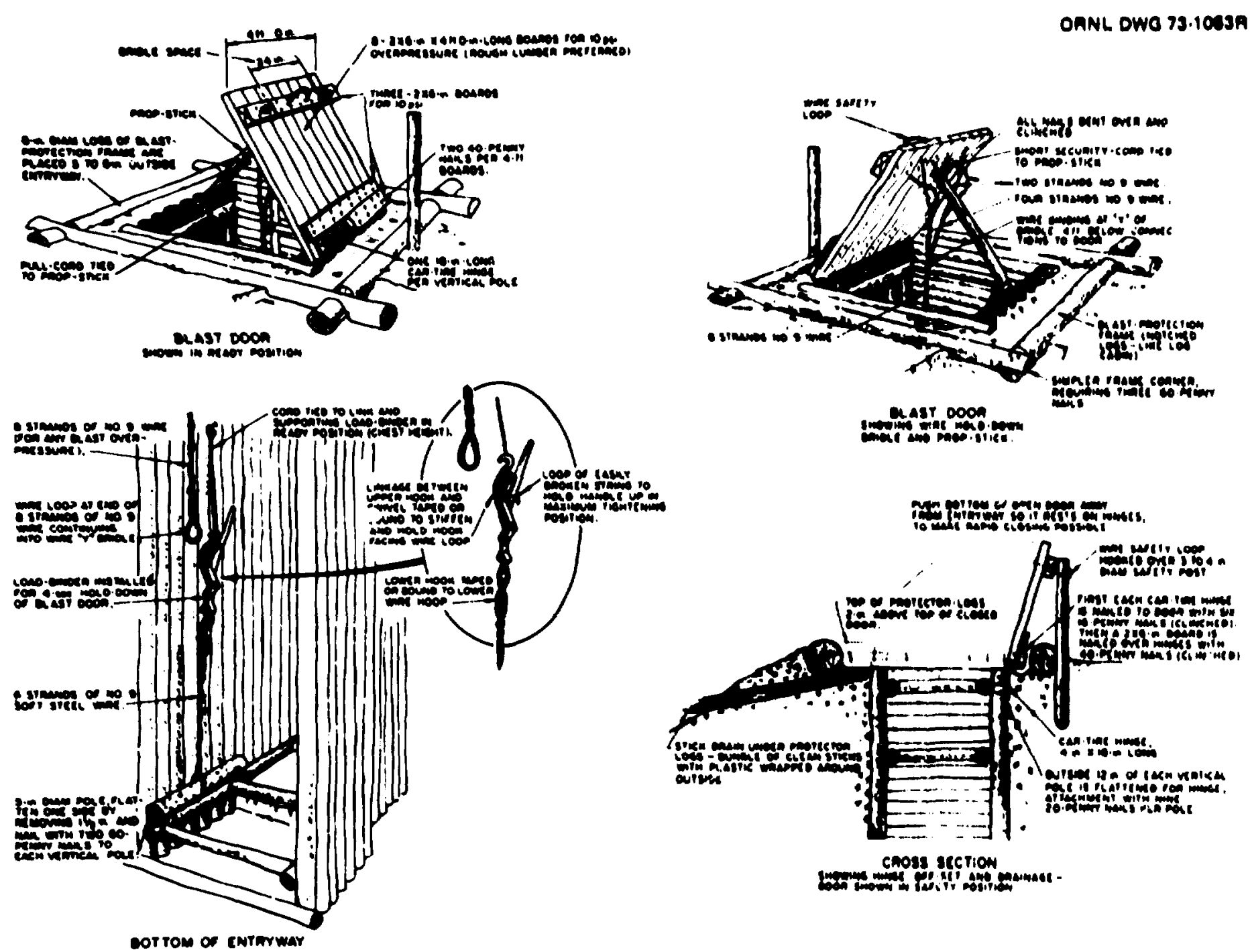

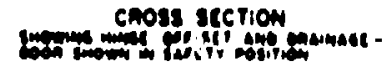

Fig. 4.4. Expedient blast door that can be closed and secured in 4 sac. The expediant blast doors tested at DICE. THROW were all of stronger construction than this door made of boarde. This door was damaged but still intuct after being subjected to about 17 pal in the main explosion of DNA's MIXED COMPANY Event. 
door and to vertical poles of the entry. A door was hinged on its side nearest ground zero with five hinges nalled with 5-in. nails to the five vertical poles of this side of its vertical entry. Each hinge was a 24-in.-long strip of worn, wide-tread automobile tire, 4 to 6-1/2 in. wide and 1/4 to $1 / 2 \mathrm{in}$. thick, measured in the grooves of the tread. Each strip was nailed to its door with twelve 5-in. nails, driven in about 3-1/2 in., with their heads bent away fron the hinge line.

After seeing the bright light fron a nuclear explosion, an alert shelter occupant can close and secure this type of door within $4 \mathrm{sec}$. This 19 fast enough to effect the closure of the door before the arrival of the air-blast shock wave from an 8-wegaton or larger weapon at the 20-psi or less overpressure range, but not fast enough at the 53-psi range. Therefore, if this shelter is to afford protection against tactical weapons, it should be equipped with expedient blast valves of che tire-strip type (Fig- 4.5), installed in separate intake and exhaust stafts. This type of valve installed in an air shaft $2 \mathrm{ft}$ above its bcttom, has been blast tested without being damaged at 65 psi. I

C.RIAL DWG 73-2229

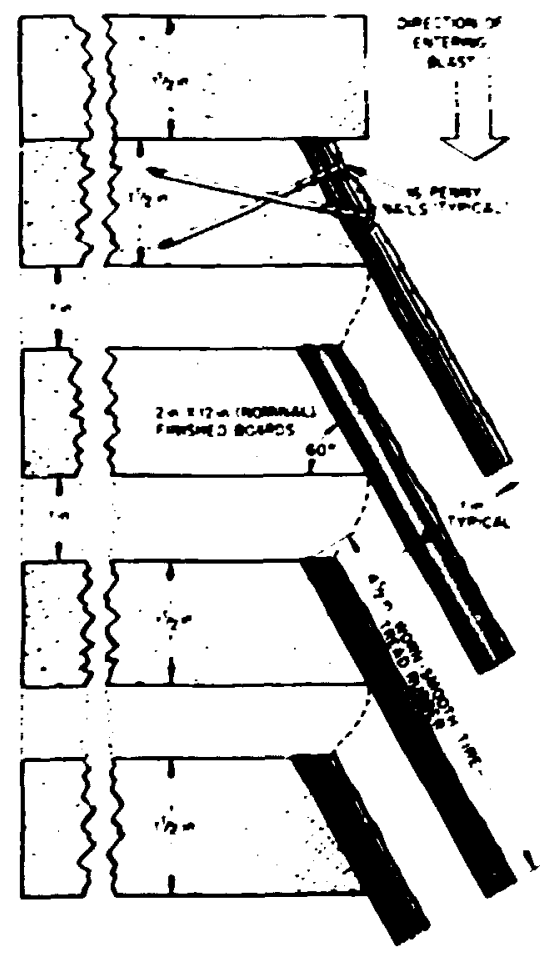

Fig. 4.5. Vertical cross section through an overlappingflaps blast valve. The tested valve had four open-air slots, each $1 \mathrm{in.} \mathrm{high} \mathrm{and} 10 \mathrm{in.} \mathrm{wide.}$ The overall width of the housing was $18 \mathrm{in}$.

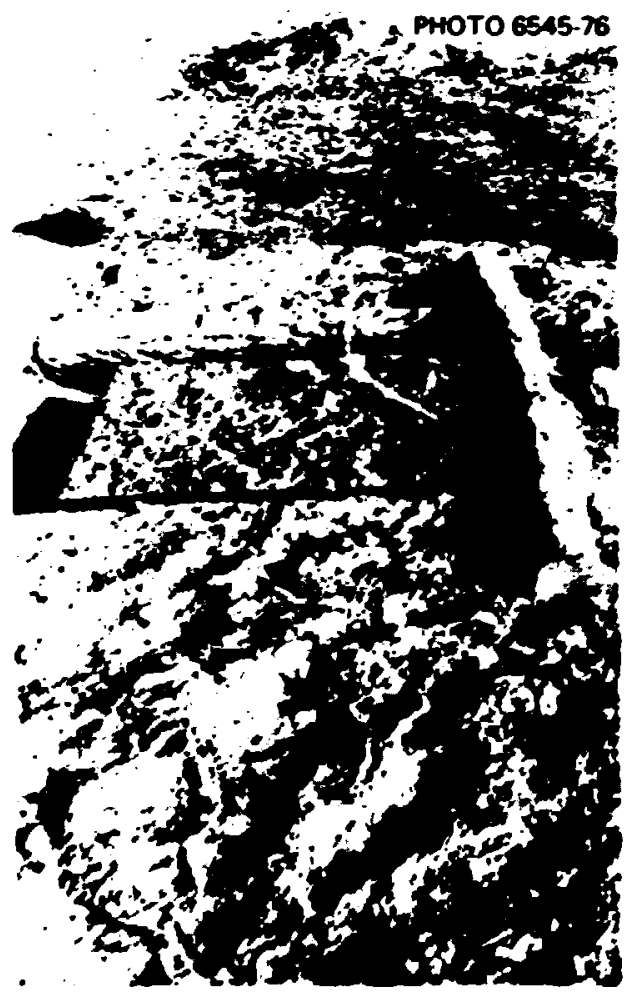

Fig. 4.6. Blast-protector logs around blast door after these logs were moved by blast effects at the $5^{2}$-psi overpressure range. 
Each blast door was surrounded with blast-protector logs which had been notched and spiked together and vere evenly spaced around the door (see P1g. 4.4). These logs (about $8 \mathrm{in}$. In dianeter and $8 \mathrm{ft}$ long) had been placed with their upper sides about 2 in. higher than the top of the closed blast door. Hithout blast-protector logs, the reflected shock overpressure against a vertical side edge of this type of door could be sereral tines as great as the free-field peak overpressure. 11 At the 53-psi ovarpressure range, this reflected peak overpressure. that would wove the closed door horizontaliy, could be as weh as 77,000 $1 \mathrm{~b}$. We belleve that the door hinges and hold-down attachnents of an expedient door could not withstand this great a horizontal force. Furthermore, stout blast-protector logs give an aboveground blast door some protec ion against the heavy objects that in most areas would be hurled by a large nuclear blast.

\subsection{Test Resulto}

P1gure 4.6 shows the four blast-protector logs around the north-end door after the blast. This explosion produced a measured peak overpressurs of about 53-psi and a calculated peak blast-wind veloctty of about 1000 ph at this range (1.e., 540 ft from ground zero). The blast winds blew away up to $12 \mathrm{in}$. of the dry earth previously piled around the blast-protector logs. The shock wave and dynamic drag effects shifted these four logs from their original positions. In its final position, the $10 \mathrm{~g}$ nearest ground zero was 80 close to the hinges that the door could be opened from the inside to an inclination of only about $60^{\circ}$.

If this door and Its protector logs had been subjected to the same overpressure from a large surface burst that would have produced dynamic dreg and blast-wind effects of wuch longer duration, the door might have been janed in its closed position by the shifted logs. If long, strong etakes had been driven prior to the blast 80 as to secure the logs, their movement would have been reduced. However, for maximum blast protection against nuclear weapons, this whole shelter should have been poeftioned deep enough in the earth so that its blast doors would have been only a few Inches above ground level, with the earth surrounding 
the blast-protector logs sloped up around them at an angle of about $10^{\circ}$. (The slope angle of this nound was $36^{\circ}$.) Or the earth wounded over the whole shelter should have all its slopes less than $10^{\circ}$ If the earth is dry and sandy.

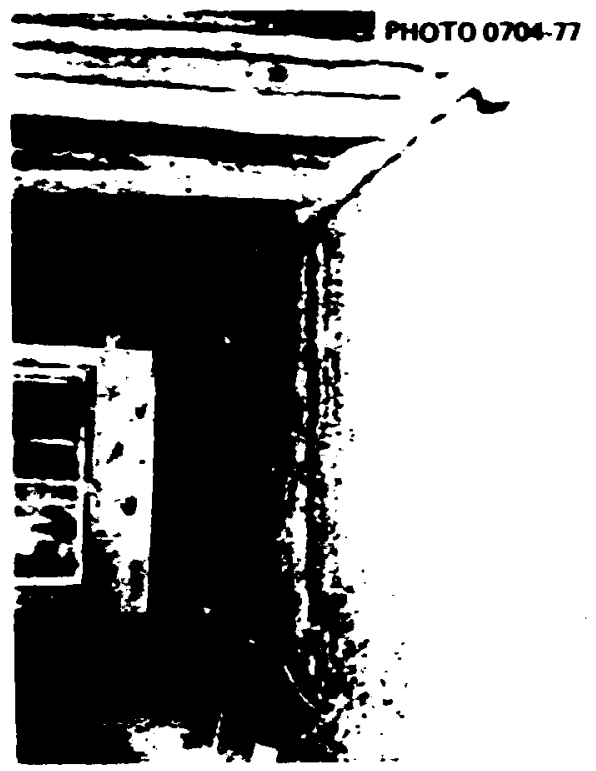

Fig. 4.7. Small-Pole Shelter after being tested with blast doors closed at the 53-psi overpressure range. Note the slightly damaged expedient shelter ventilating pump in the stoop-in entryway. Two wen worked about 5 min to replace the four blown-loose flaps, the onily damage.

The pole frame and plywood blast doors of the Small-Pole Shelter were essentially undanged by the blast effects at the 53-psi overpressure range (see Fig. 4.7). However, occupants would have been injured If they had been standing with the fr heads close to the celling, which was rapidly depressed when pressure on the roof poles caused the wall poles to be punched down into the soft, backfilled earth supporting them. This downard movement of the roof and walls varied from a minimum of 2 in. In the southwest corner to a maximum of 6-1/4 in. In the northeast corner. Figure 4.8 shows the movement at the center of the room, where the upper part of the shelter was moved 4-1/4 in. away from ground zero and 4-3/16 in. downard, relative to the "fixed" vertical pust to which the lower part of the damaged deflection gauge was attached. Furthermore, about $15 \%$ of the floor area "puffed up" from 2 to $8 \mathrm{in}$. above 1 ts original elevation.

Figure 4.9 shows hew the floor "puffed up" aboist $6 \mathrm{in}$. In the northeast corner of the shelter in the east entryway; pressurized earth caused some earth to "flow" up into the closed room, in which the measured peak 
Fig. 4.8. Movement of upper part of Small-pole Sheiter away from ground zero due to blast effects at 5j-psi overpressure range.
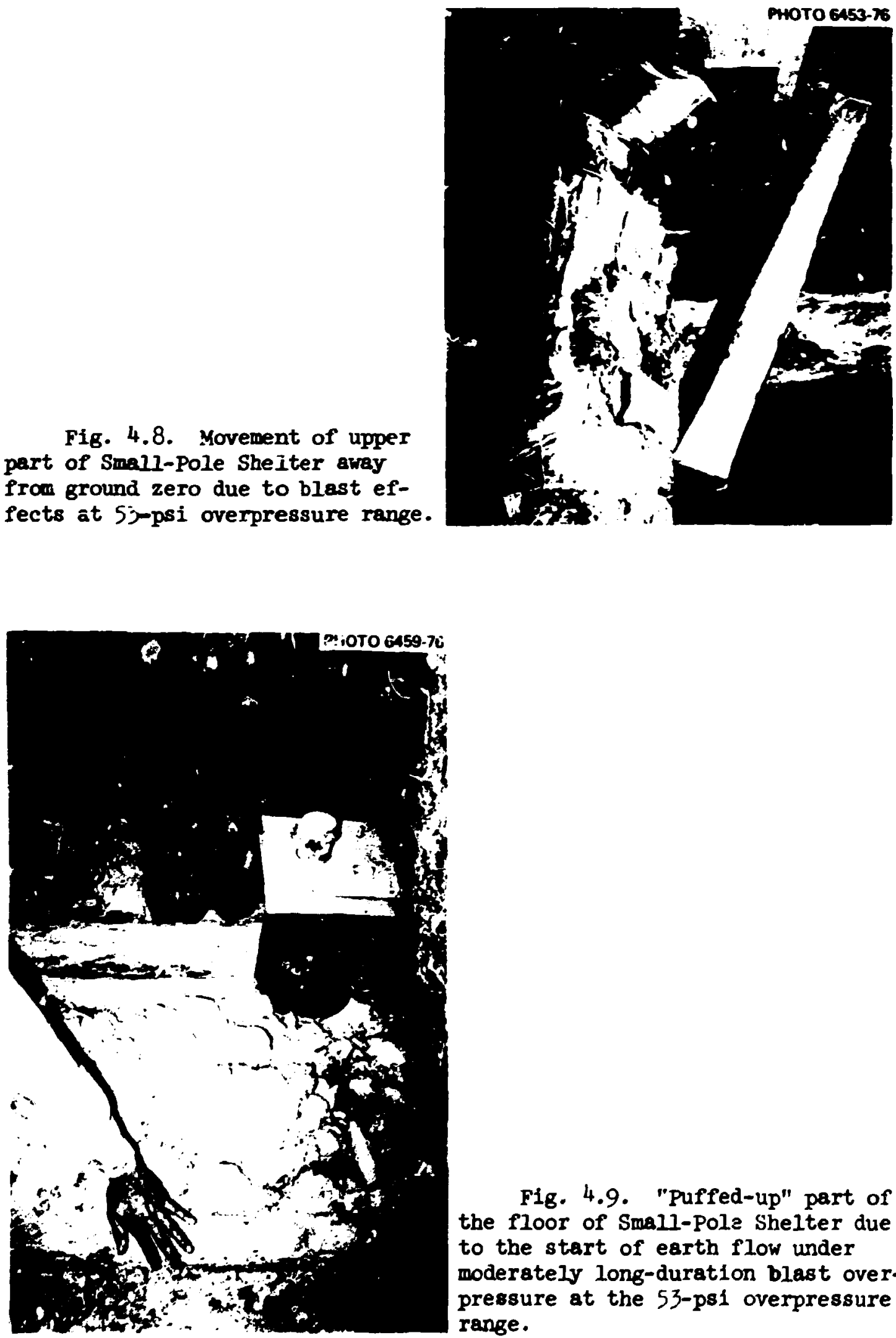

Fig. 4.9. "Puffed-up" part of the floor of Small-Pole Shelter due to the start of earth flow under moderately long-duration blast overpressure at the 53-psi overpressure range. 
overpressure was only 1.5 psi. About 857 of the floor area was undisturbed, as was the floor in front of the man's hand resting on the cross brace. Neither the blast gauge resting on the brace pole in the corner nor the smals expedient fallout meter on top of it was moved.

If a perscn had been standing on the floor when it was "puffed up" suddenly, possibly his legs could have been injured. To prevent possible injuries due to an intact celling moving very rapidly dowmard and/or the floor woving upward, occupants could recline in expedient bed-sheet hamocks ${ }^{12}$ slung from tine upper horizontal brace poles of the main shelter room, as shown in Fig. 4.1C.

The whole roof, the upper horizontal braces, and the upper ends of the wall poles were all dispraced 3 c ut 4-1/4 in. to the west (away from ground zero) by the blast effects on the 5-ft-hinh moind of shielding earth over the shelter. The sides of this mound sloped about $36^{\circ}$; its width on cop averaged about $10 \mathrm{ft}$. (If this dry mound had been subjected to the blast effects of a megaton or larger nuclear weapon at the same 53-psi overpressure range, the much greater impulse and longer-duration drag effects might have caused the earth mound to be displaced far enough to wreck the underlying pole shelter - especially since the longduration blast winds would have scoured away most of the cover of very dry, loose earth. Even a mound of wet erth, which is much less vulnerable to loug-duration blast-wind scouring. might have been displaced far enough to cause serious or disastrous structural damage.)

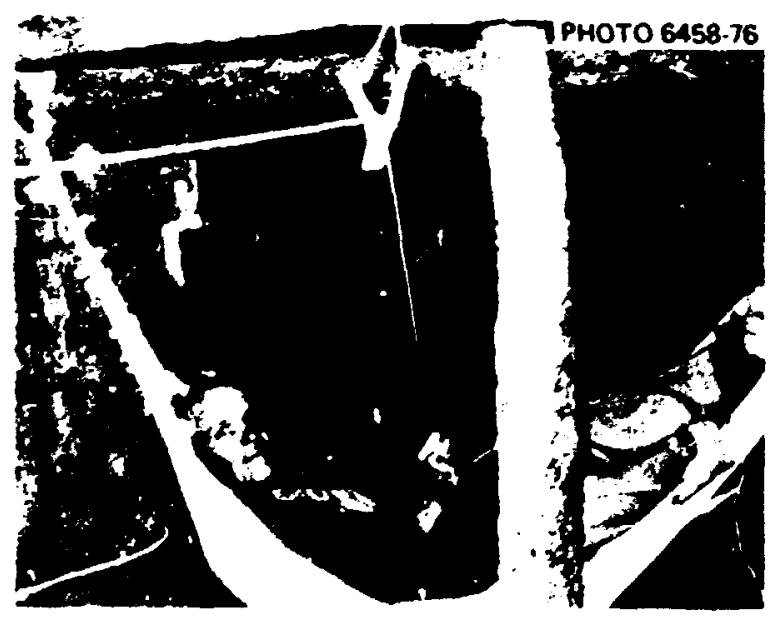

Fig. 4.10. Expedient bed-sheet hammock, useful to avoid severe shock effects in a shelter at high overpressure ranges. The man is operating an expedient shelter ventilating pump via an expedient pulley equivalent, a greased forked stick suspended on strings. 
The maximu overpressure neasured inside the shelter was 1.5 psi not enough to be haruful. Less than half of this pressure inc: case was due to the sudden reduction in the volume of the shelter room which was described above. The rest was caused by blast wind that blew through cracks between the poles near the top of the vertical entryways. These cracks appeared after the initial blast wind had scoured away soveral inches of the covering earth and torn away the polyethylene film that, with the essential help of small-scale earth arching, had kept earth from being forced between the cracks by the peak overpressure.

There was no danage to any of the life-support equipsent in this shelter, except for quickly repairable damage to the expedient shelter ventilating purp (RAP) ${ }^{13}$ pictured in Fig. 4.6. (Without the protection of closed blast doors, a KAP or any other pump securely installed in an entry would be wreciad by the entering shock wave and blast winds, even at ranges as $10 \mathrm{w}$ as 3 to $4 \mathrm{psi}$. Without forced ventilation, belowground shelters cannot be fully occupled in warm or hot weather. However, a KAP can be installed so that a shelter occupant can detach it and wove it out of the way in the few seconds between seeing the very bright light from a large nuclear explosion and the arrival of the shock wave at lower overpressure ranges. ${ }^{13}$ )

\subsection{Conclusions and Recommendations}

4.4.1. A Small-Pole Shelter built in stable ground and equipped with blast doors can give reliable protection against the blast effects of small tactical weapuns up to about the 50-pst overpressure range.

4.4.2. A modification of this shelter with a continuots pole floor under the wall poles shoild not fall as a posstble result of a large amount of pressurized and destabilized earth flowing up into it through its floor when subfected to the long-duration overpressures and large wovements caused by a megaton explosion.

4.4.3. In order to prevent the above modification from seriously reducing the capability of the shelter frame to yleld under blast loading and thus promote protective earth arching, a Smoll-pole Shelter should be blast tested with all its poles covered with readily crushable 
material, such as small tree limbs. Then this material should be covered with fabric or plastic before placing earth around and over the protected shelter.

4.4.4. Swall-Pole Shelters modified in these ways should be subjected to the effects of blast simulating at least a 100-kiloton explosion at the 50- and 100-psi overpressure ranges, when installec in a trench dug in unstable earth, deep enough so that its blast doors are only about a foot above the original ground level.

\section{UARODIFIED RUSSIAN POLE-COVERED TRENCH SHELTERS AT 20 AND 6.7 psi}

\subsection{Purpose}

Two Identical unmodified Russian Pole-Covered Trench Shelters were tested at the 6.7- and 20-psi overpressure ranges, in order to make a more accurate estimate of the blast proterition afforded occupants of this common type of Russian expedient shelter. This unshured "dugout" is recommended for construction in stable earth.

\subsection{Construction}

The two unmodified Russian Pole-Covered Trench Shelters were of the design detailed in the 1969 Sovfet civil defense handbook ${ }^{14}$ except that the entrance stainays vere at right angles to their lengths, a modification recommended in both the 1972 and 1976 Russian shelter-butlding manuals.15,16 Figure 5.1 shows most of the roof noles in position before

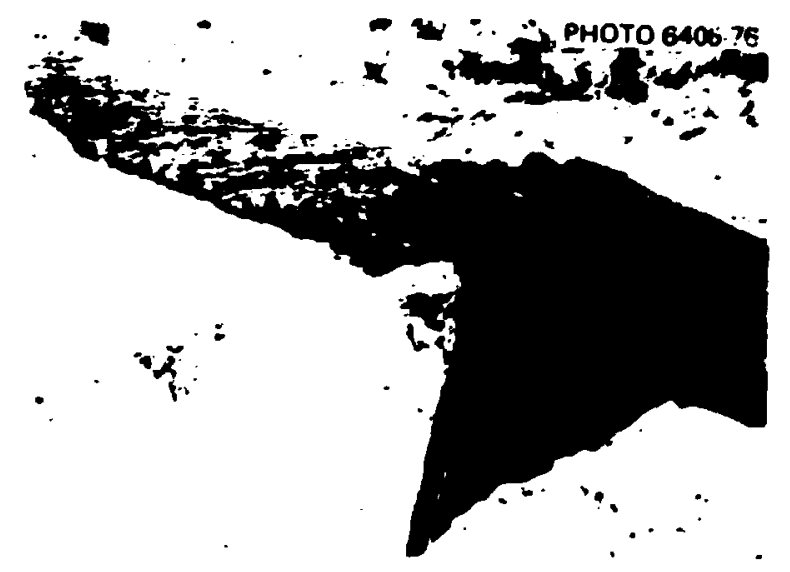

Fig. 5.1. Poles covering Russian Pole-Covered Trench Shelter at 20-psi overpressure range, with uncompleted stairway opening facing away from ground zero. 
the shelter was covered with 4-mil polyethylene and with earth aounded 30 in. deep. A total of 62 lodgepole pine poles, each $7 \mathrm{ft}$ long, were laid side by side across the 31-ft-long trench (not including the rightangle entry stainway shown in the foreground of Fig. 5.1). Figure 5.2 gives the details of this simple fallout shelter.

\subsection{Location and Test Results}

A Soviet civil defense handbook 6 states that within "the zone of complete destruction" the overpressure exceeds $0.5 \mathrm{~kg} / \mathrm{cm}^{2}(\sim 7 \mathrm{psi})$ and that all residential and industrial buildings and ali fallout shelters will be destroyed. (This limitation obviously does not apply to the Russian "hasty shelters" built of prefabricated concrete or steel corponents. Typical Russian expedient fallout shelters are of light construction and are not designed to withstand blast effects.) Therefore, one uneodifled Russion Pole-Covered Trfoch Shelter was built at the forecast 7-psi overpressure range (6.7 pol was measured). Because of the almost rocklike caliche earth, an identical shelter was built at the 20-psi range, to see if occupants might survive more seve:e blast effects than those at the 7-psi range. Neither shelter had 1 blast door.

In the shelter at $20 \mathrm{psi}$, two anthropomorphic dumies (supplied by the Lovelace Foundation) were seated side by side just Inside the inner curtain (see Figs. 5.2 and 5.3). A novie camera was installed by Denver Research Institut? for the U.S. Army's Ballistic Research Laboratory. This camera was farther inside the shelter, mounted on a concreted-inthe-ground post. This camera took $400 \mathrm{frames} / \mathrm{sec}$; the four photographs of Fig. 5.3 were taken in $1 / 100 \mathrm{sec}$. The first photograph shows only a slight movement of the innermost blanket-curtain. The second shows the earth valls beginning to crumble under the forces of a ground shock wave, Induced by the airwave slap overhead before the airborne shock wave reached these walls or the dumies. The third and fourth photographs show the inne:most blanket-cur': in being torn, revealing the torn outermost curtain, that was darker colored, being blown behind and against it. The collapsing walls trapped the two dumbies before the entering blast wind, which was shown by the four wovie frames to have a velocity of about $180 \mathrm{mph}$, could blow them over. (The blast wind peaked at about 470 uph outside this shelter.)

Pigure 5.4 shows the dumles trapped by the collapsing walls. 


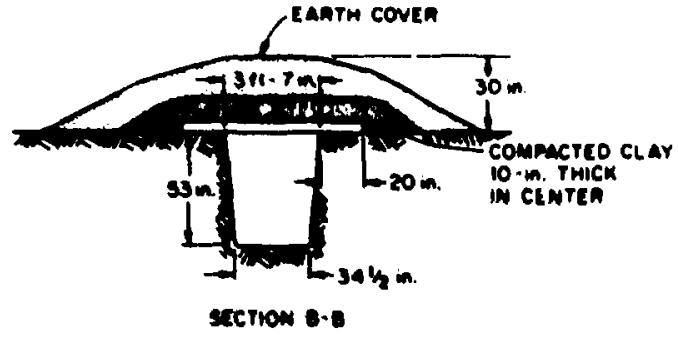

LOOS LENOTHWISL

To racmen

ats.o.m. oin

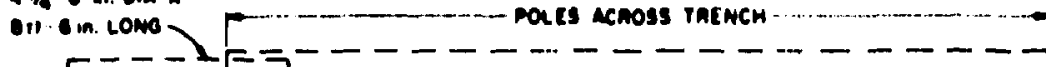

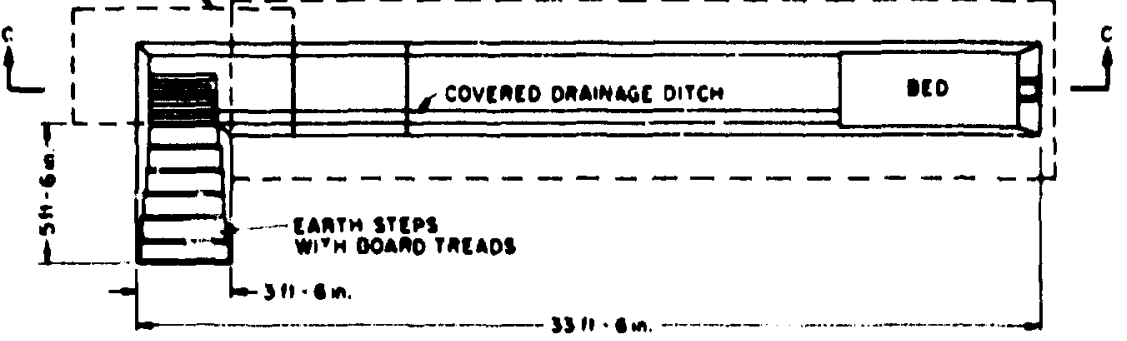

LAN VIEW

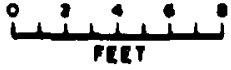

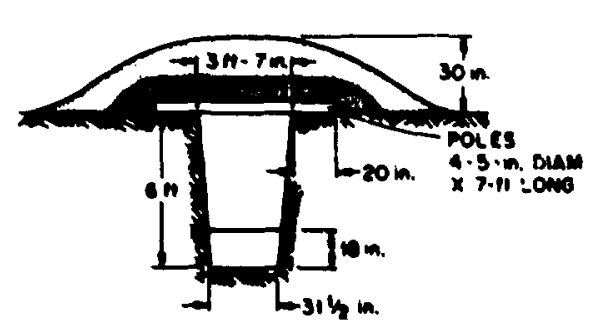

Section A-A

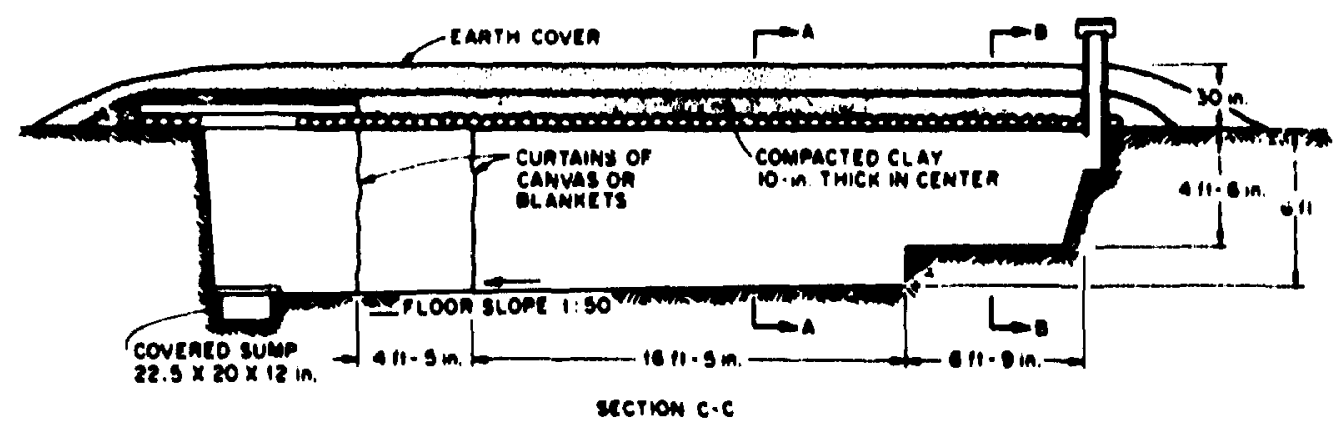

F18. 5.2. Russian Pole-Covered Trench Shelter in atable earch. 

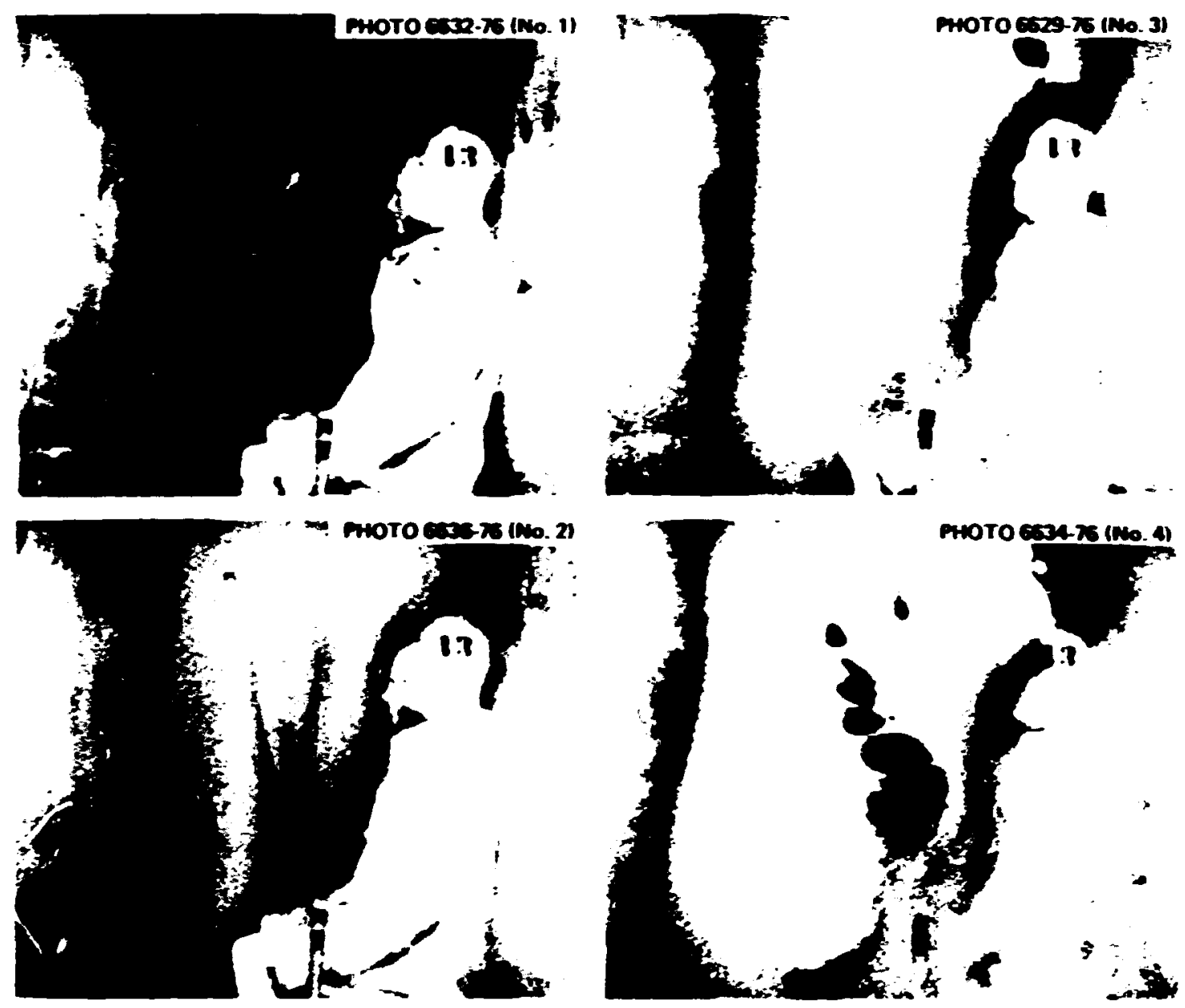

Fig. 5.3. Dumies being struck by alr blast and curtains traveling about $180 \mathrm{mh}$. Note the walls collapsing under groundshock stresses before the arrival of the airborne shock wave.

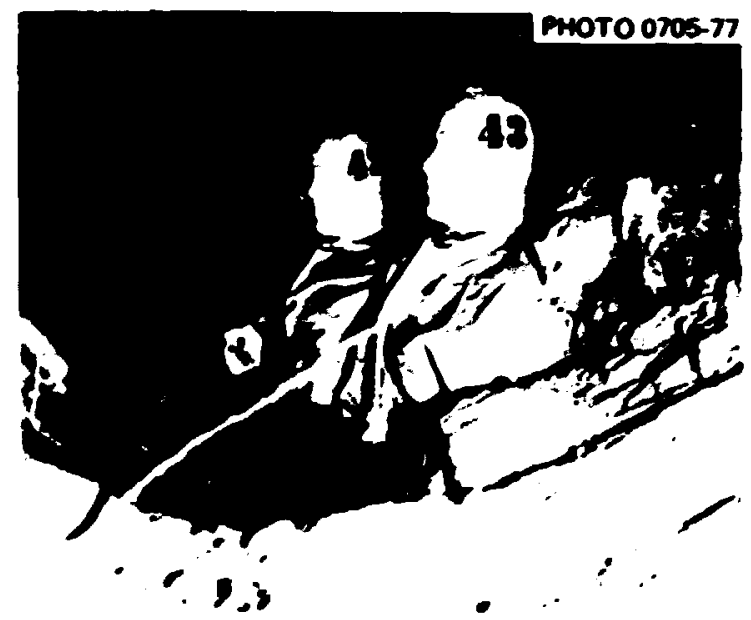

F18. 5.4. Durmes at 20-psi range after ground shock collapsed the earth walls of shelter. Their steel "bones" and foints prevented then from being knocked down and burted. 
Because their strong steel joints did not pernit these dunies to bend forward, the collapsing walls did not bend then forward, knock thea down, and bury thex, as would have been the fate of two nen. Note the unbroken roof poles.

The neasured overpressure inside this shelter was 7 psi - high enough to break sone persons' eardrums. (If this shelter had been subjected to the blast effects of a megaton weapon at the 20-F ;i range, the maxiwerpressure inside the shelter would have been almost 20 psi.)

The entry was wrecked and wch of its covering earth was blown avay, as illustrated by Fig. 5.5. The ventilation duct was broken off.

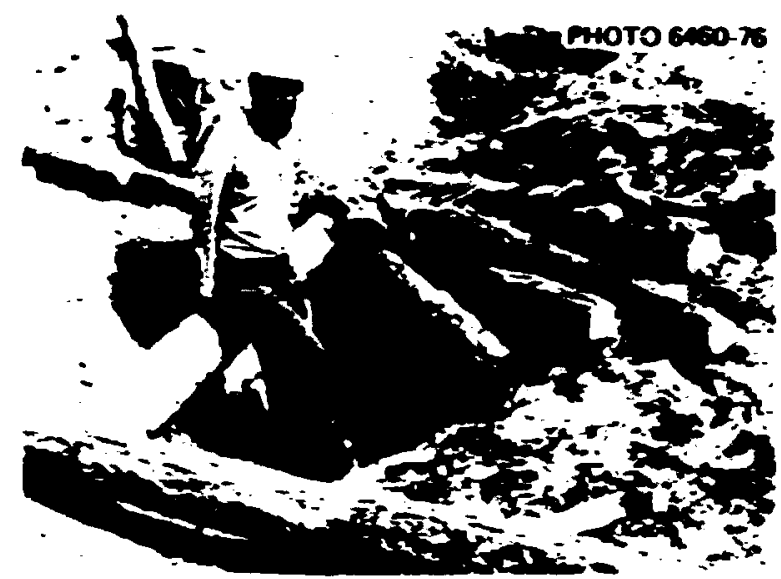

Fig. 5.5. Wrecked entry of Russian Pole-Covered Trench Shelter at 20 psi.

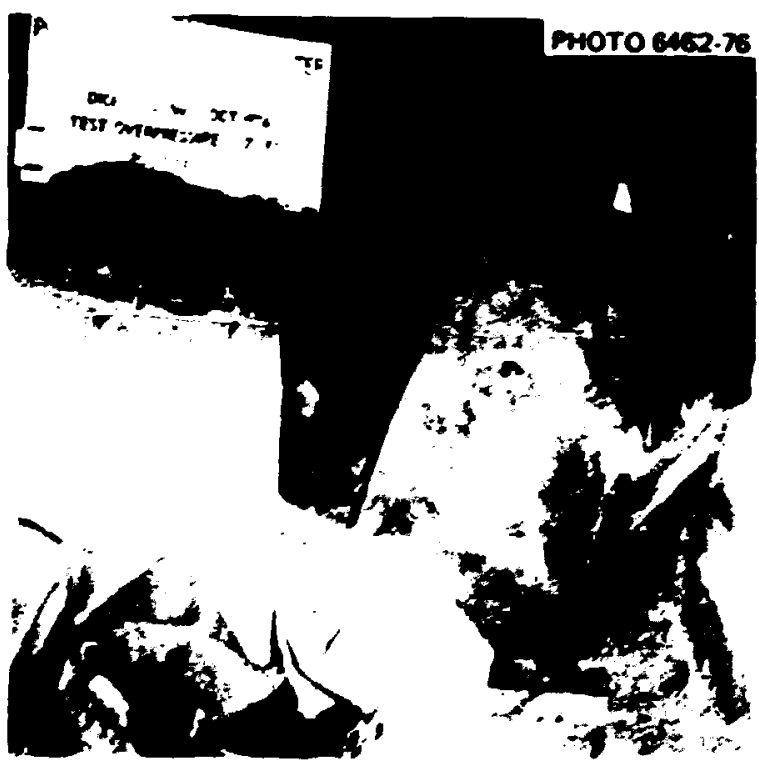

Fig. 5.6. Dumy knocked of $f$ bench in Russian Pole-Covered Trench Shelter at the 6.7-psi overpressure range. 
At the 6.7-psi range, an Identical shelter suffered serious daage. Chunks of hard caliche veighing up to about $400 \mathrm{lb}$ were broken off the very stable earth walls and would have injured shelter occupants. A dum seated on a fixed bench next to the blanket-curtains vas knocked off the beach by the shock wave and the entering blast winds (see Fig. 5.6).

\subsection{Conclusions}

5.4.1. In soils typical of nost inhabited areas, if a shelter of this design vere subjected to the blast ef fects of a wuch larger explosion at the 7-ps: overpressure range, the Russian estimte of "total destruction" would probably prove to be realistic. As specified for Russian shelters, this shelter room and entryay are of stand-up height. (The authors believe that "total destruction" in this sense neans the shelter vould be so badly danazed as to be uninhabitable - not that all occupants would be proptly killed.)

5.4.2. Earth arching in adequately thick earth cover over pole roofs prevents the poles from being broken by overpressures far in excess of the pressures such roofs could withstand if uncovered.

5.4.3. Stresses due to ground shocks and earth waves would be the predoninant causes of fallure of unshored trench shelters subjected to the blast effects of large explosions.

5.4.4. To reduce the damage to unshored trench walls caused by the vertical pressures exerted by the roof poles on the trench walls, whenever boards are avallable they should be laid on the ground to serve as oud 81118 supporting the roof poles close to their ends. (In DKA's MIXED COMPAN blast test, ${ }^{1}$ an ORIL Pole-Covered Trench Shelter was essentially undamaged after being tested closed at the 12-psi overpressure range. This shelter was $54 \mathrm{in}$. deep, $42 \mathrm{In}$. wide, and had 7-ft roof poles resting on $2 \times 6 \mathrm{in}$. mud sills. However, in MIXED COMPANY the ground-shock effects were not as severe as in DICE THRON.) 


\section{LOG-COVERED TREICH SHELTER AT 53 pai}

\subsection{Purpose}

We constructed an unshored trench shelter with its roof poles positloned in two different ways and located at the predicted 50-psi overpreasure range because:

1. We anticipated that the extrenely stable, rocklike caliche at the test site vould result in unshored trench walls being so strong that they would not collapse under the ground-shock stresses produced at the 50-psi range by 1-ktloton blast effects.

2. We were confident that effective earth arching in the thick ear covering vould prevent the breaking of roof poles.

3. We were interested in comparing the effectiveness of the Russian and the Chinese way of roofing a trench with poles or logs.

\subsection{Construction}

This shelter was bullt with half of its 12-ft-long roon having its roof poles positioned in the Russian anner at ground level (see Figs. 5.1, 5.2, and 6.1). The other half of the room had its roof poles positioned in a recomended Chinese manner 17 (i.e., about 28 in. below ground level). Figure 6.1 shows the vertical cross sections of these

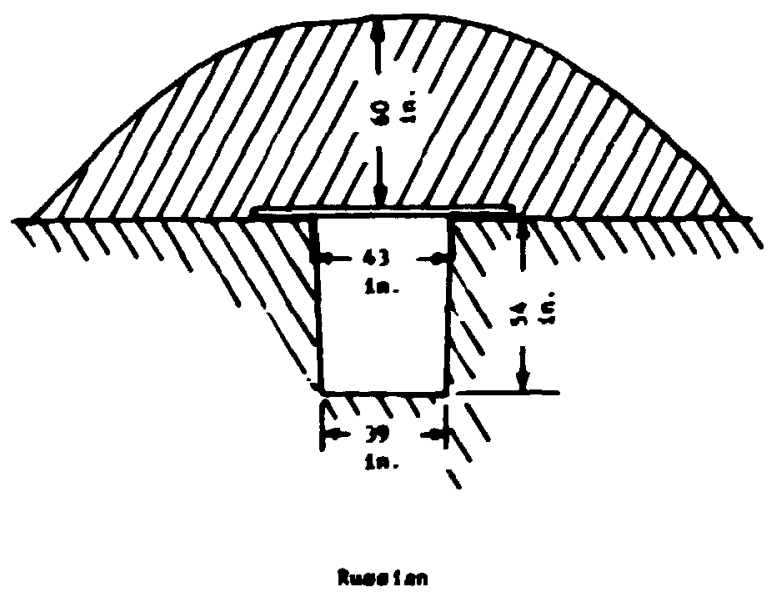

OANL DWG 77.10330

Fig. 6.1. Comparison of Russian way and Chinese way of positioning poles to roof a trench shelter. Note that the Chinese way requires about 357 less earth to be moved in order to make a 5-ft-thick covering - about the thickness specified in a Chinese handbook for shielding against initial nuclear radiation. 
two halves as wodified from the original designs in order to perait a better comprison between the nerits of the two different ways of positioning roof poles. (The roon of the Russian half was ande $16 \mathrm{In}$. less in height than in the original Russian destgn, and the Chinese half was ande 4 in. less in width than specified in the Chinese handbook. 17) As shown in Fig. 6.1, the Chinese half was built with its roof poles resting on earth shelves $28 \mathrm{in}$. below ground level, cut into the hard callche. All roof poles (logs) vere ponderosa pine. The poles averaged about 5 in. In dianeter, not including their bark; all vere cut $7 \mathrm{ft}$ long. Earth was nounded about $5 \mathrm{ft}$ above ground level over this whole shelter. This resulted in about 4-1/2 ft of earth covering the roof lozs of the Russian half and about $6 \mathrm{ft}$ covering the roof logs of the chicese half. Blast-wind scouring resoved a foot of this wounded dry, loose earth. If blast-wind scouring by a very large explosion had blown away almost all the dry earth wounded above ground level, the Chinese shelter would still have had adequate cover to provide good fallout protection.

The vertical parts of the two entries to the shelter were of a newly developed design with triangular cross sections. The expedient blast doors were of a new triangular type. This design (see Figs. 6.2 and 6.3) was developed in order to: (1) use green poles cut from

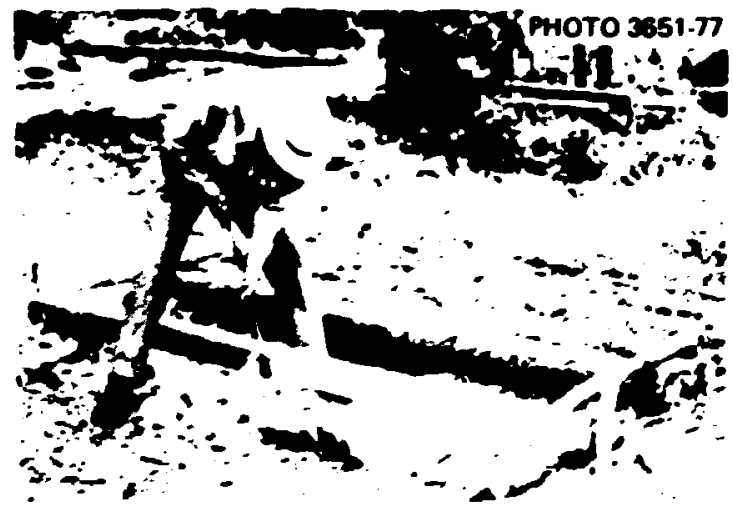

P1g. 6.2. Hewing square sides on a log. The hewer had first secured the $10 g$ by nalling two small poles to the unhewn logs on the ground and to the already hern upper side of the 108 , near its ends. Then he had agde vertial ax cuts about 3 to $4 \mathrm{in}$. apart and at angles of about $45^{\circ}$ to the surface of the log. He had made these multiple cuts almost as deep as he planned to make the centerline of the finished flat side. The hewer is show cutting of flong strips, producing a vertical flat side at right angles to the already hew, horizontal upper oide. 


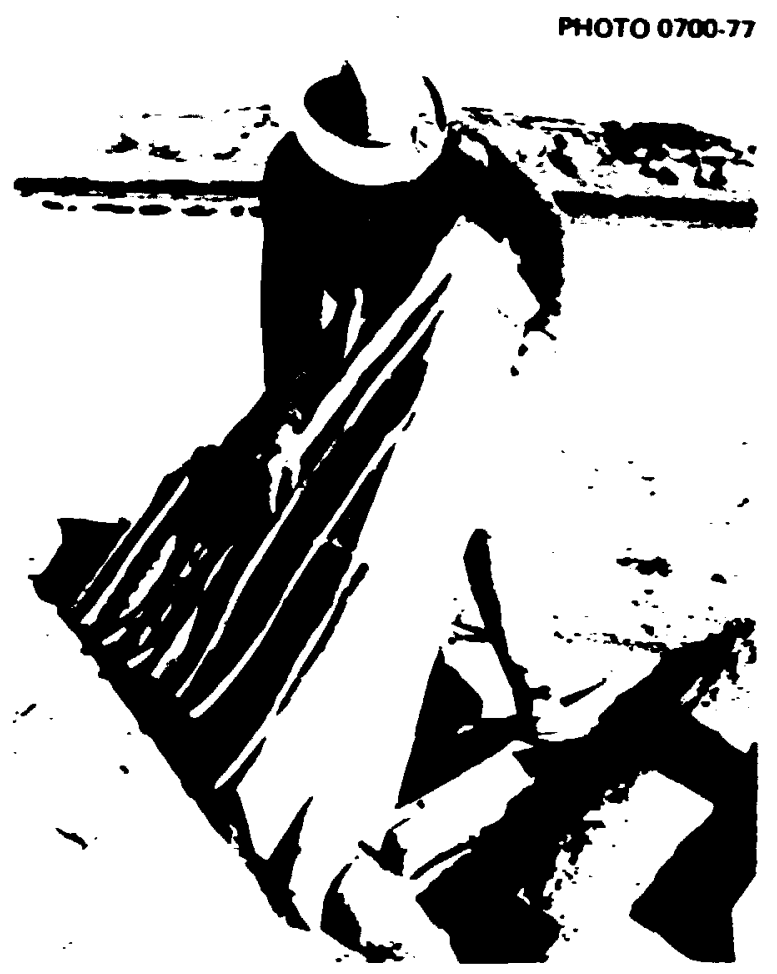

Fig. 6.3. Expedient triangular blast door made of pine poles. The auto-tire flap valves over the 1-1/2-in.-wide spaces between the poles were undamaged by the blast effects at the 53-psi overpressure range. Ground zero was to the lef $t$, in prolongatton with the hinge pole of the door. Blast effects had moved the three connected blastprotector logs, preventing the door from being opened fully.

ordinary trees to make a tight-closing expedient blast door that takes advantage of the fact that three intersecting straight lines determine a plane, (2) require only widely available hand tools and common materials (e.8., auto tires, nails, and some wire or rope, in addition to poles), and (3) make practical the use of a triangular vertical shelter entry, which has a smaller cross-sectional area than does a rectangular vertical entry big enough for the same sized person to use and shows promise of requiring less materials to meet a given level of blast protection.

Few modern Americans know hor to hew flat sides on a 108 or pole, a skill required to build blast-tight blast doors out of green trees. But most persons who can swing an ax jiould be able to learn quickly if shown instructions for hewing such as those given in Pig. 6.2.

The triangular blast doors tested at $53 \mathrm{psi}$ are shown in Figs. 6.3, $6.4,6.5$, and 6.6 . 


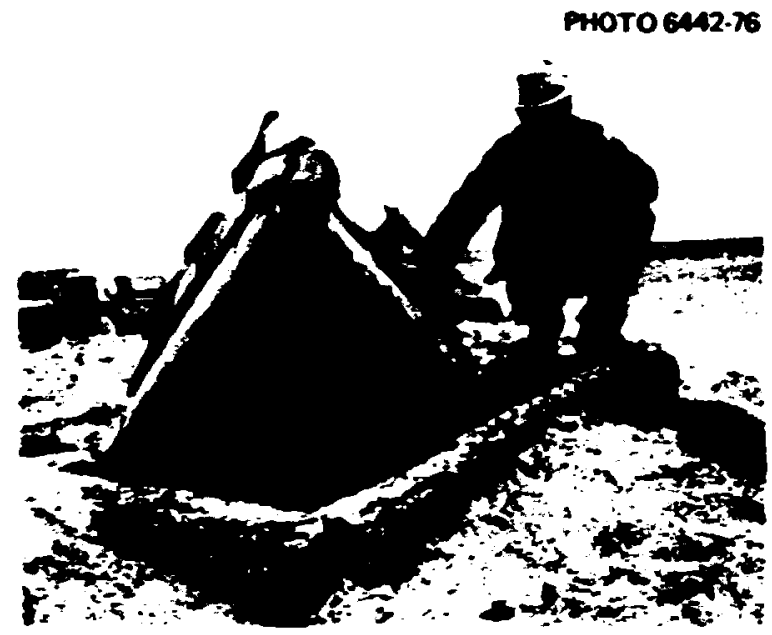

F18. 6.4. View of the same triangular blast door, looking in a direction perpendicular to the radius from ground zero. The hinge pole, originally 7 in. In diameter after peeling, had been flattened on its top and back side. The two other poles, $8 \mathrm{in}$. In diameter, had been flattened cn their bottom, top, and inner sides. All three outer poles were notched and nalled together. Note the slots between the doorcovering poles.

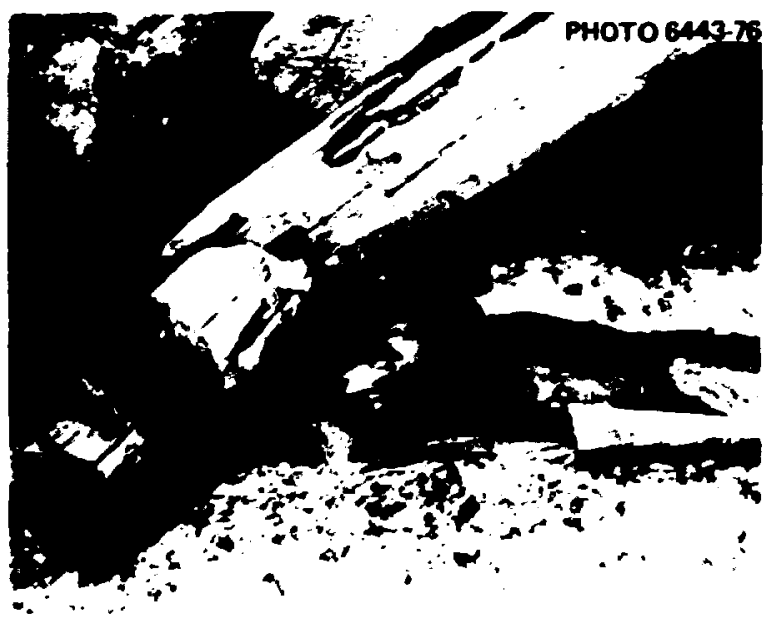

Fig. 6.5. Broken pole of triangular door seat. This pole was broken by differential movements of the earth mounded over the shelter. The man's hand rested on the unbroken hinge pole. 


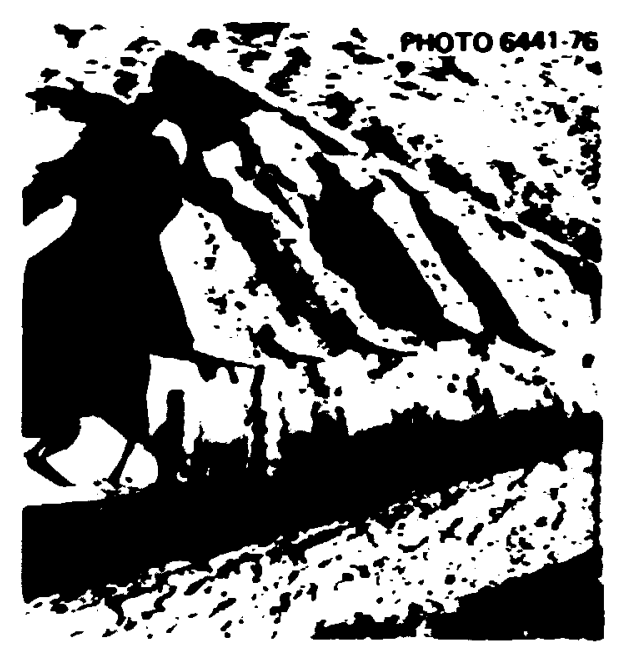

Fig. 6.6. Posttest condition of expedient triangular blast door. Some flap valves had been janed shut, and much earth and sand had been deposited.

\subsection{Test Results}

Figures 6.2 and 6.3 show the triaingular blast door on the south end of the shelter, undanaged after the blast. Note that one of the three blast-protector logs (the 108 in the lower left corner of the photograph) has been pushed by the blast up against the ininge pole of the blast door. The door was undanaged. (If a door of this type and size was not protected by blast-protector logs and if at the 53-psi overpressure range a blast shock wave struck one of its 8-in.-thick edges perpendicular to the plane of this edge, the door could be subjected to a peak horizontal force of about 90 tons.) itowever, the movement of the earth mound had broken the door-seat pole on which the man's foot is shown resting in Fig. 6.3. Figure 6.5 shows the break wore clearly.

Both of the triangular blast doors were undamaged. The expedient blast valves on the blast doors were closed by the blast, and abrist $75 \%$ opened after the blast, permitting adequate ventilation wth ar expedient pump, a KAP. The overpressure inside the Chinese half was $1.5 \mathrm{psi}$, and the overpressure directly under the north door was $3 \mathrm{ps} 1$. The results of this tes+ Indicate that the use of expedient blast valves over the 1-1/2-in.-wide cracks of this blast door is impractical. Most of the flap valves opened before the strcng blast after-winds subsided. These winds plus the natural desert winds blew so much dirt and sand through 
the valves and into the shelter that a serious fallout entry problem could exist after a nuclear blast. Figure 6.5 shows the blast door at the north end of the shejter before it was opened after the blast. Much earth and sand had been leposited on it by the subsiding blast winds.

although not one roof pole of any part of this shelter or any other shelter was broken or cracked, the ground-shock ef fects collapsed the walls of the Russian half of this shelter so badly (see Fig. 6.7) that all occupants would have been killed. Damage to the Chinese half was much less serious, although hundreds of pounds of caliche, some chunks weighing up to $20 \mathrm{lb}$, were broken of $f$ the edges of the shelves supporting the roof logs. The roof deflection gauge in the Chinese half recorded a maximum transient dowmard deflection of 1-1/2 in. and a permanent deflection of $7 / 8 \mathrm{in}$.

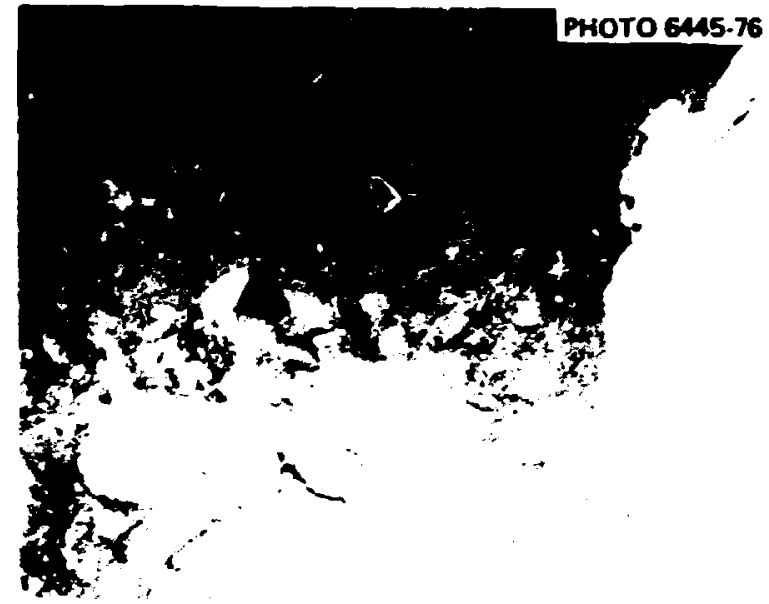

Fig. 6.7. Postsho: view of the caved-in caliche walls of the "Russian" half of the Log-Covered Trench Shelter at 53 psi.

\subsection{Conclusinins an 1 Recommendations}

6.4.1. Under the longer-duration blast effects of a large nuclear explosion, vertical entries protected by steep-sided earth mour.is rising several feet above original grade level would probably be wrecked by the combined effects of blast-wind scouring and dynamic drag.

6.4.2. Blast doors should be posftioned only about a foot above ground level, and earth should be mounded with slopes of $10^{\circ}$ or 1 ess. 
(Unfortunately, such deeper excavation, even in softer earth, wight make construction within $48 \mathrm{hr}$ impractical for builders having only hand tools.)

6.4.3. Triangular blast doors made of poles can readily be built to withstand 50-psi blast effects, but should be made solid and as nearly dust-tight as practical. Separate ventilation shafts with blast valves should be provided, with the blast valves positioned about $2 \mathrm{ft}$ irom the bottom of each shaft.

6.4.4. Persons building expedient shelters to provide protection against nuclear blast effects should build well-shored shelters with blast doors and blast valves whenever practical.

\section{LOG-COVERED TRENCH SHELTER AT 31 ps}

\subsection{Purposi.}

A near counterpart of the Loz-Covered Trench Shelter that was tesced at 53 psi was tested at 31 psi, in order to determine at what overpressure range this type of shelter, if built in extremely stable earth, will survive. Also we wished to test a semiexpedient design of steel blast door on a shelter entrance at approximately 30 psi.

\subsection{Construction}

This shelter was constructed the same as the Log-Covered Trench Shelter at $53 \mathrm{psi}$, except that protectirg its sir.jle entry it had a semiexpedient blast door made of about $65 \%$ of a 30 -gal steel ofl drum. Rubber-tire hinges and rubber-tire seals made a snug closure between the door and the upper part of the vertical entry. The upper $2 \mathrm{ft}$ of the vertical entry was made of two thicknes:es of 2 -in. boards nailed together (see Fig. 7.1).

\subsection{Test Røsults}

Although the blast effects loosened some of the bolts of the steel blast door, tore the metal in several places, and produced other damage indicating that it was on the verge of fallure, it did not fail. 


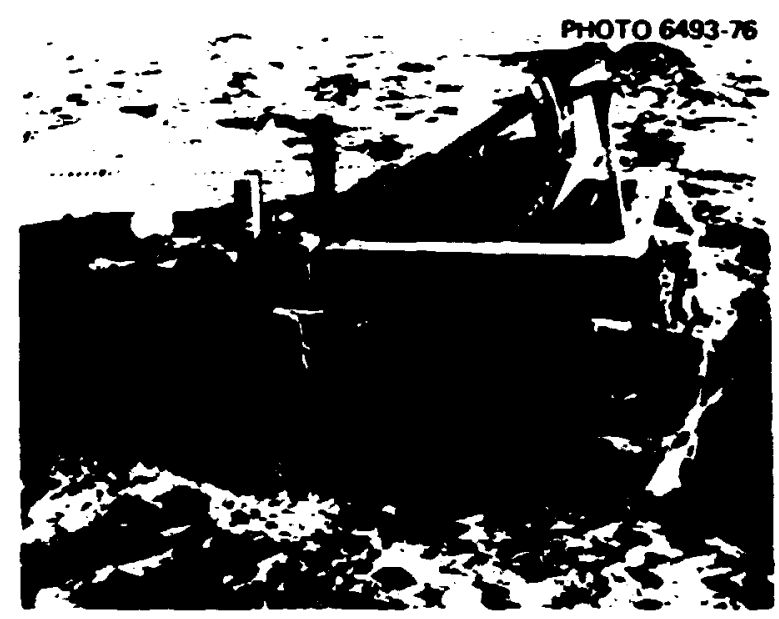

Fig. 7.1. Semiexpedient blast door made of a 30-gal steel drum, badly damaged at 31 psi but still blast-tight. Blast-uind scouring had removed up to $17 \mathrm{in}$. of the dry earth mounded around this entrance and blown away its single blast-protector log.

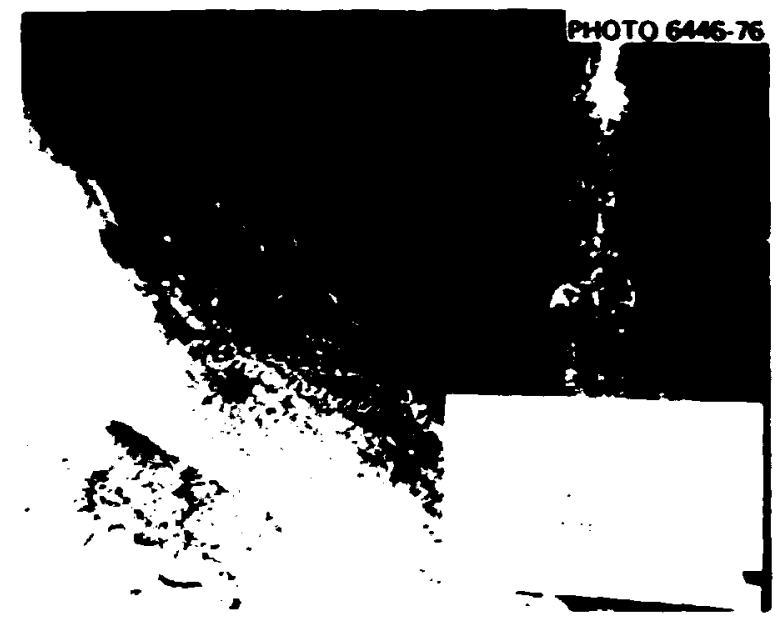

F1g. 7.2. Serious wall caving at 31 psi (predicted 30 psi). The beam deflection gauge on top of the post showed a $2-1 / 2-1 n$. lowering of the enter roof $10 \mathrm{~g}$.

Figure 7.2 pictures the interior of the Chinese half of the shelter after the blast had broken hundreds of pounds of caliche of $f$ the very stable walls and lowered the roof poles from an estimated maximum of up to $6 \mathrm{In}$. at some lower ends on the side nearest ground zero to a minimum of about an inch at some of their opposite ends. This lowering did not cause the roof to collapse. No poles were cracked in any part of this shelter. The walls of the Russian half collapsed so badly that all occupants would have been burled. 


\subsection{Conclusion and Recomendations}

7.4.1. Even in extremely stable earth, an unshored trench shelter at 31 psi would give inadequate blast protection against even a sall cactical nuclear weapon.

7.4.2. The steel-drum blast door is not as blast resistant as pole or plywood blast doors that require materials mucn less difficult to find and that require less skill, tools, and time to build.

\section{DOOR-COVERED EARTH-ROLL SHELTERS AT 15 AND 5.8 psi}

\subsection{Purpose}

Two of these aboveground small fallout shelters, ${ }^{7}$ made of interior hollow-core doors, bed sheets, and other materials available in tens of millions of American homes, were tested at the 15- and 5.8-psi overpressure ranges in order to determine whether the shelters would afford better blast protection than would typical homes.

\subsection{Construction}

Each shelter was built with its long axis on a radius from gro:Ind zero. Figure 8.1 shows the interior of the shelter at the 15-psi range before the explosion. The vertical stick toucning a roofing door is a

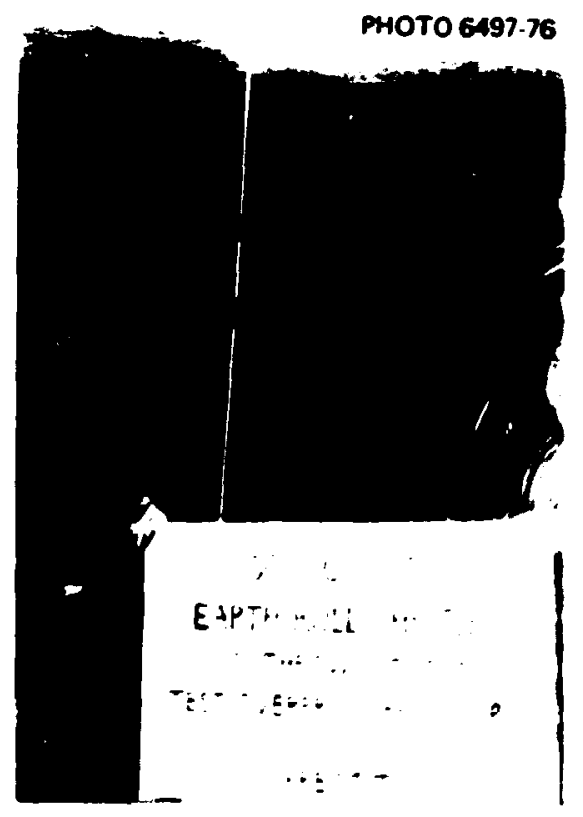

Fig. 8.1. Bed-sheet "earth-roll" walls 36 in, apart before test. 
roof deflection gauge, with its upper end consisting of nothing but a thin cylinder of household aluninum foil, an unzatisfactory device if exposed to blast wind. Figure 8.2 gives details of the construction of these shelters.

\subsection{Test Results}

Figure 8.3 is a posttest picture of the northward-faring entry of the shelter at the 15-psi overpressure range. This photograph also shows part of the northward-facing side of this shelte:. The blast winds scoured only abuut $1 \mathrm{in}$. of earth fron the top of this shelter, apparently because its long, flat top extended in the same direction that the blast winds blew. Note the proof of the toughness of polyestercotton pillowcases used to make 100-1b sandbags. The sandbag in the foreground was blow about $7 \mathrm{fL}$ by the approximately 370-mph blast wind without being broken.

To the surprise of most observer;, earth arching above the roof doors prevented any of them from being broken in by the blast effects. The doors were not broken in, even though the lower $1 / 8-1 \mathrm{n}$. plywood veneer of three of the six doors was troken. Figure 8.4 pictures the interior of the shelter at the 15-psi overpressure range after the blast effects outside had caused the sandy soll inside the bedsheet "earthrolls" to "flow" inward rapidly. The width of the shelter was reduced from $36 \mathrm{in}$. to a minimum of $14 \mathrm{ln}$. No additional earth movements were observed during the two weeks following this test. This unanticipated earth "flow" within the "earth-rolls" did not tear any of the pieces of bedsheet cloth. The velocity of earth "flow" was not measured. However, we belleve that such earth "flows" take place only while earth is destabllized by ground-shock effects. Judging from the pressure-time measurements cited in the following paragraph, the drastic reduction in the widh of this shelter occurred in less than second - too short a time to permit a shelter occupant sitting with back against a wall to avold belng crushed.

Pressure-t1me measurements on the adjacent DNA Gauge LIne No. 1 showed that only about $40 \mathrm{msec}$ elapsed between the peak overpressure of 14.9 pei recorded at the same distance ( $820 \mathrm{ft})$ from ground zero, and 


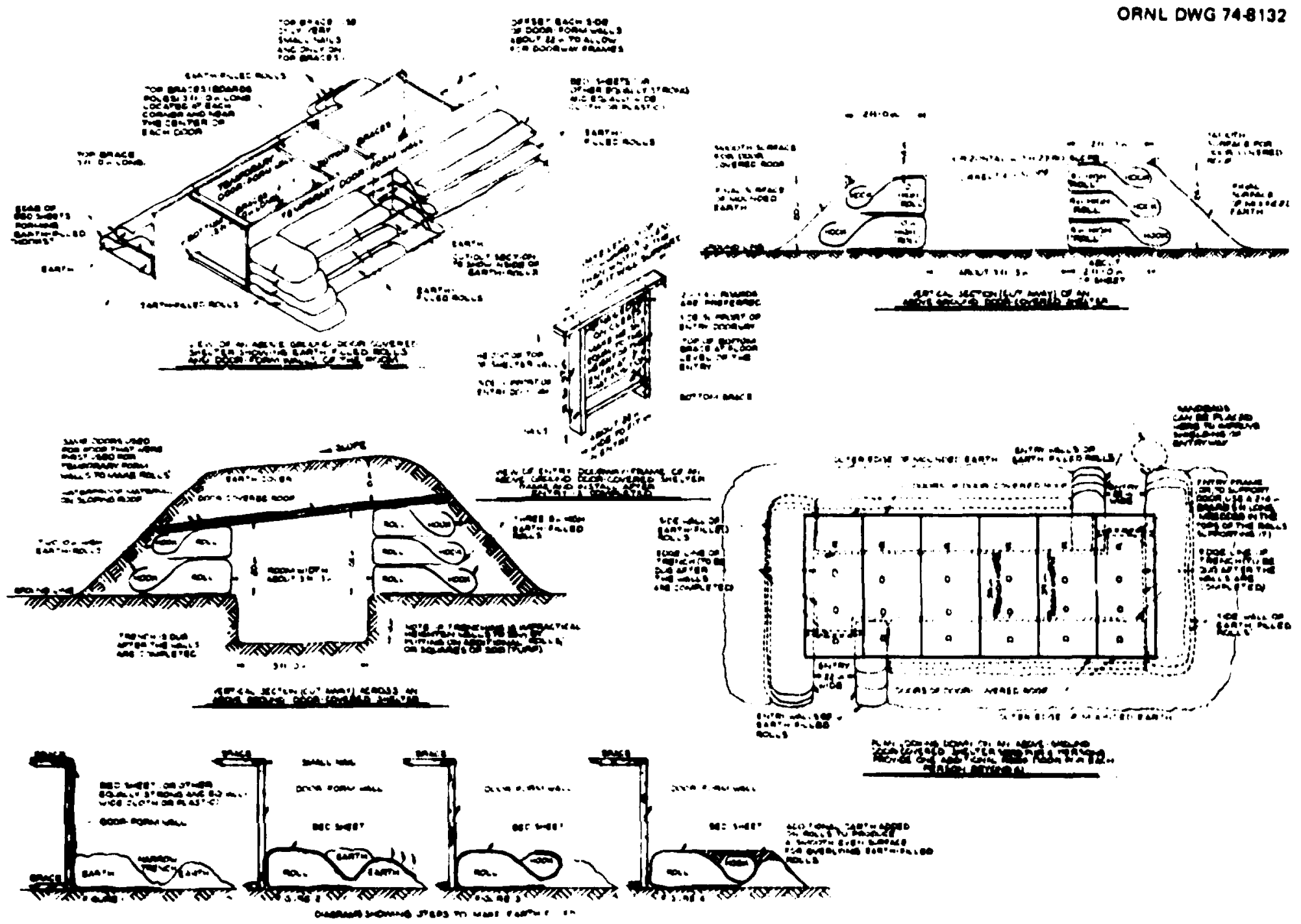

F18. 8.2. Door-Covered Earth-Roll Shelter, tested at 15 und 5.8 psi. 
mºto 6A83.75

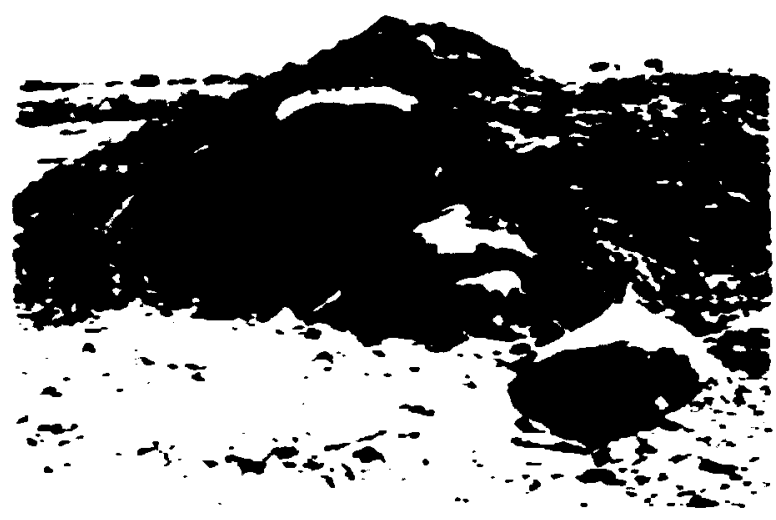

Fig. 8.3. Northward-facing entry (at right angle to the direction to ground zero) of Door-Covered Earth-Roll Shelter at the 15-psi overpressure range. This is a posttest photograph.

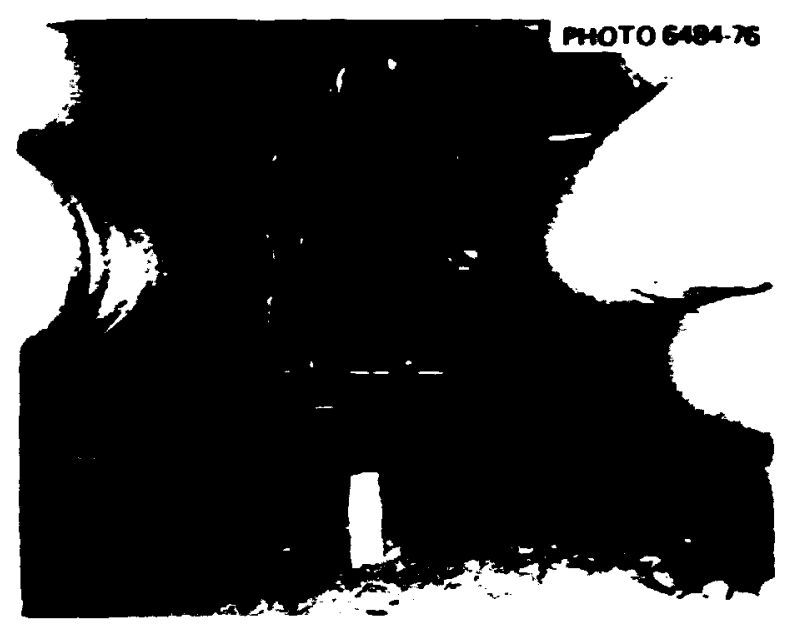

Fig. 8.4. Interior of Door-Covered Earth-Roll shelter after 15-psi blast effects had reduced width of shelter from $36 \mathrm{in}$. to a minimu of $14 \mathrm{in}$. near its center.

its reduction to $6 \mathrm{psi}$, the maximum overpressure recorded inside this shelter by the ORIL pressure gauge show in the foreground of Fig. 8.4 . The gauge that had been installed to measure the roof ionlection was blow away by the entering shockwave and blast wind. The reduction in celling height appeared to be 1 ess than $1 \mathrm{in}$. In this part of the shelter, but up to about $4 \mathrm{in.}$ in other parts.

At the 5.8-psi overpressure range, the Door-Covered Earth-Roll Shelter was still habitable for weeks after the test. Figure 8.5 


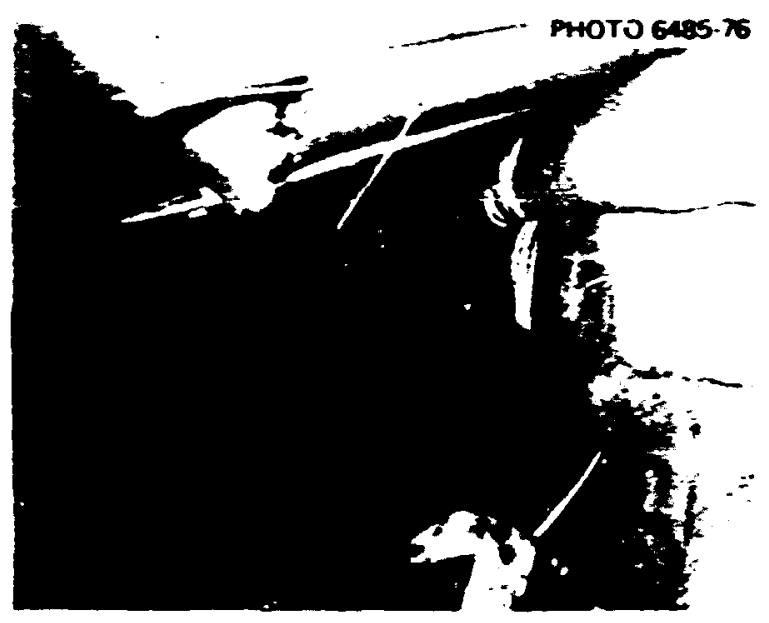

Fig. 8.5. Postcest interior of Dnor-Covered Earth-Roll Shelter at 5.8-psi overpressure range. The lower 1/8-in. veneer of the doors had been badly broken by impact before the test, due to a front-end loader having dumped tons of earth onto this yielding roof.

shows that at 5.8 psi the walls were not forced inward by the blast effects. The unbroken upper 1/8-in. veneer plies of the doors held as flexible membranes, and earth arching was set up in time to prevent this sh.leer's roof from being collapsed either as a result of initial aechant sed earth loading or due to the 5.8-psi blast effects.

The peak overpressure measured inside this shelter was 3 psi, abou: half the 5.8 psi measured outside on DNA's adjacent Gauge Line No. 1 . The blast winds, which peaked outside at about 17 , mph, scoured away only a fraction of an inch of the shielding ear'h.

\subsection{Conclusions and Recomentat fons}

8.4.1. Door-Covered Earth-Rc1l Shelcer obvlously is imprectical for use as a blast-protective she]ter against blast effects considerably less than those at the is-psi overpressure range froe even a very small nuclear weapon.

8.4.2. If this fallout shelcer with a procection factor of at: :east 200 had been bulit in a typical suburb and had been subjected to the b'ast winds fron a megaton weapcn at the same 5.8-psi overpressure range, it aight have been damaged or destroyed by blast-hurled pleces of houses and/or trees. 
8.4.3. Jotwithstanding the hazards inherent in the use of this or any other lightly constructed aboveground shelter in a blast area, occupants of this simpe shelter would have a decidedly better chance of surviving than would people inside typical suburban howes, which would be dewolished by the blast effects at $5.8 \mathrm{psi}$.

\section{RIDGE-POLE SHELTERS AT 15 AKD 5.8 p8I}

\subsection{Purpose}

In wooded areas having the water table or rock too close to the surface for below-ground expedient shelters to be practical, untrafned families with feu tools have been able to build Ridge-Pole Shelters in less than $48 \mathrm{hr} .12$ No prior blast testing of this type of shelter. which has its side poles merely leaning against its ridge pole, had been carried out anywhere (see Fig. 9.1).

\subsection{Construction}

Two identical Ridge-Pole Shelters were built, each having the dimensions shown in Fig. 9.2. One was tested at the measured 15-psi overpressure range and the other at the 5.8-psi overpressure range. Each was positioned with its ridge pole perpendicular io a radius from ground zero, with one of its two crawlin entries facing ground zero

PHOTOGMOS-76

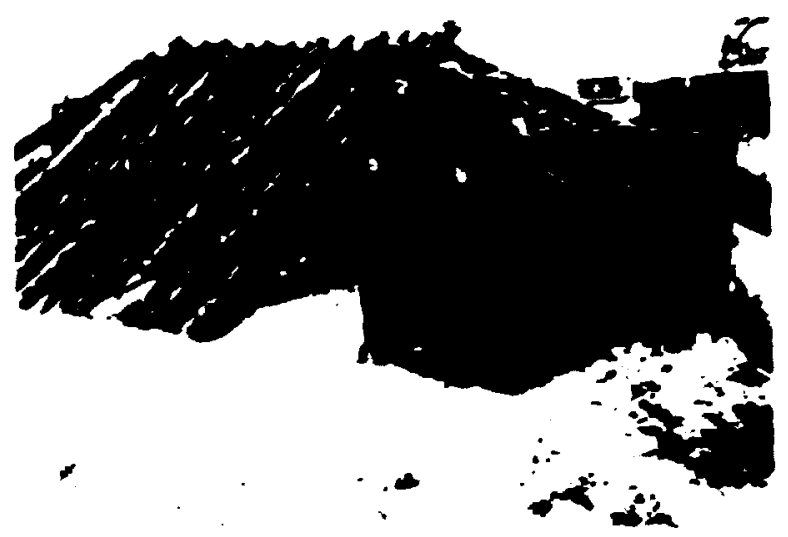

Fi8. 9.1. Almost completed frame of Ridge-Pole Shelter at 15 ps1. Only the outermost roof pole of the entry had been placed on 1 ts wall poles. 


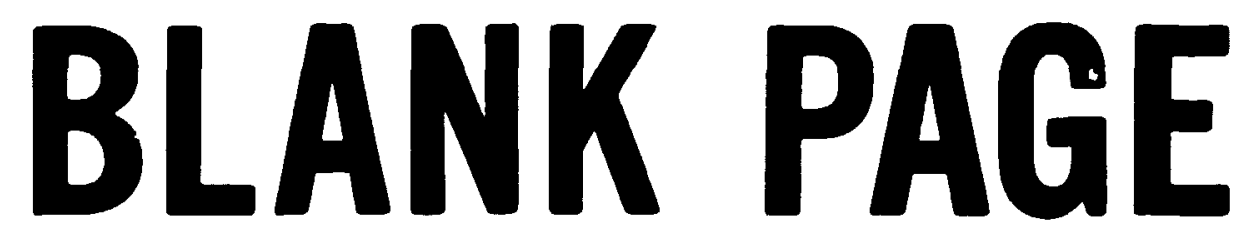




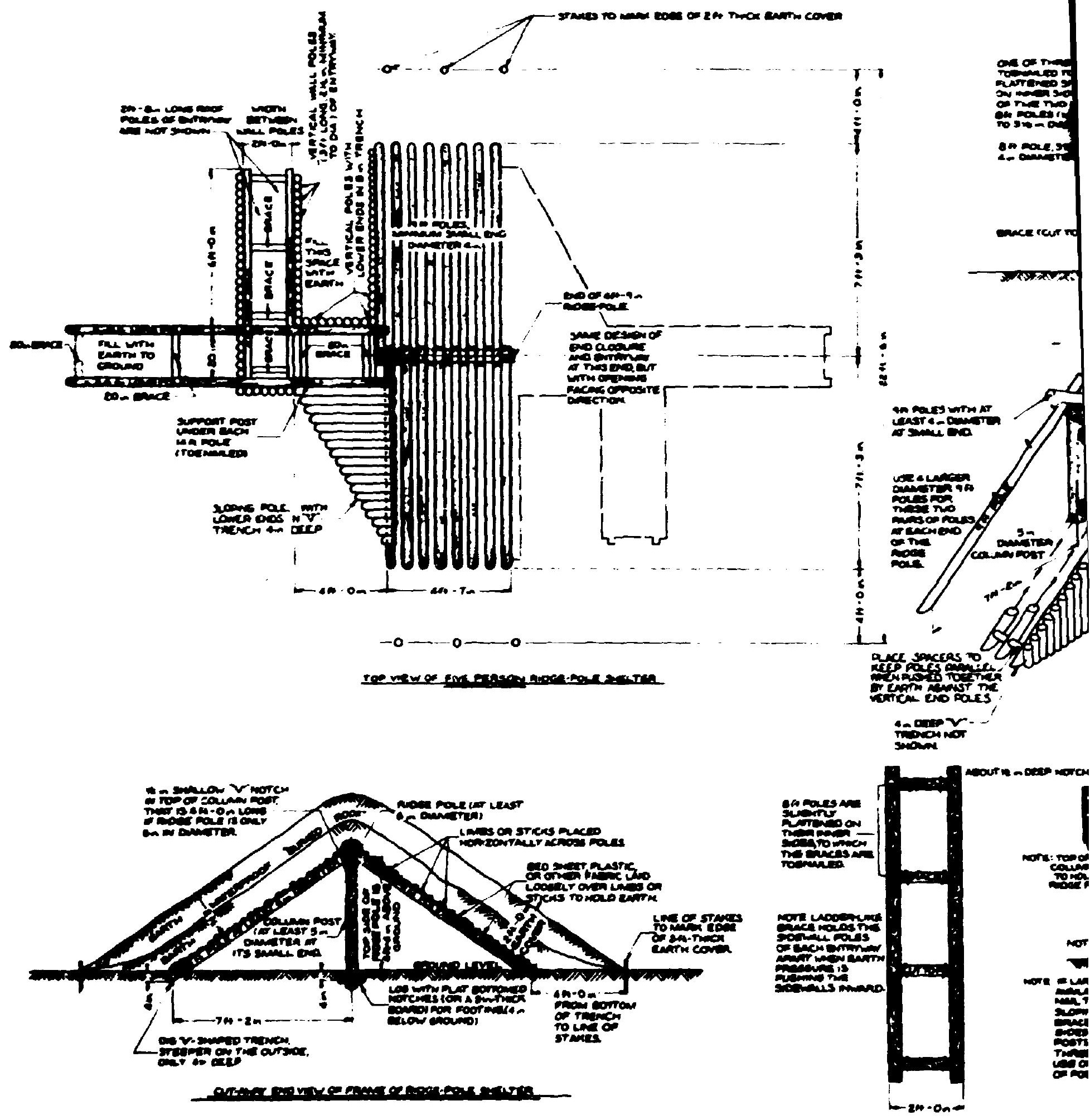

F18. 9.2. Ridge-Pole Shelter tested at 15 and $5.8 \mathrm{pgt}$. 


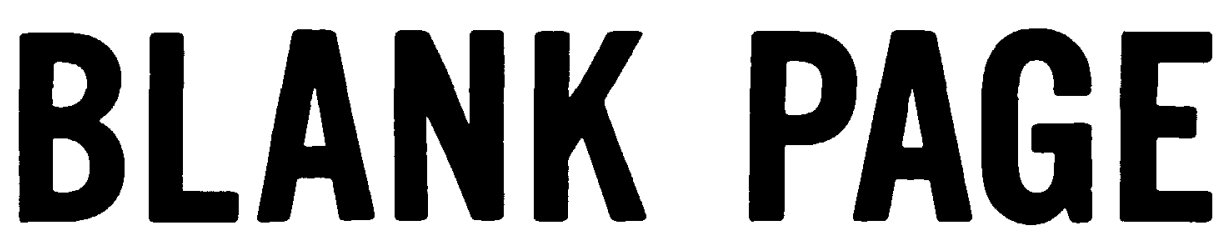




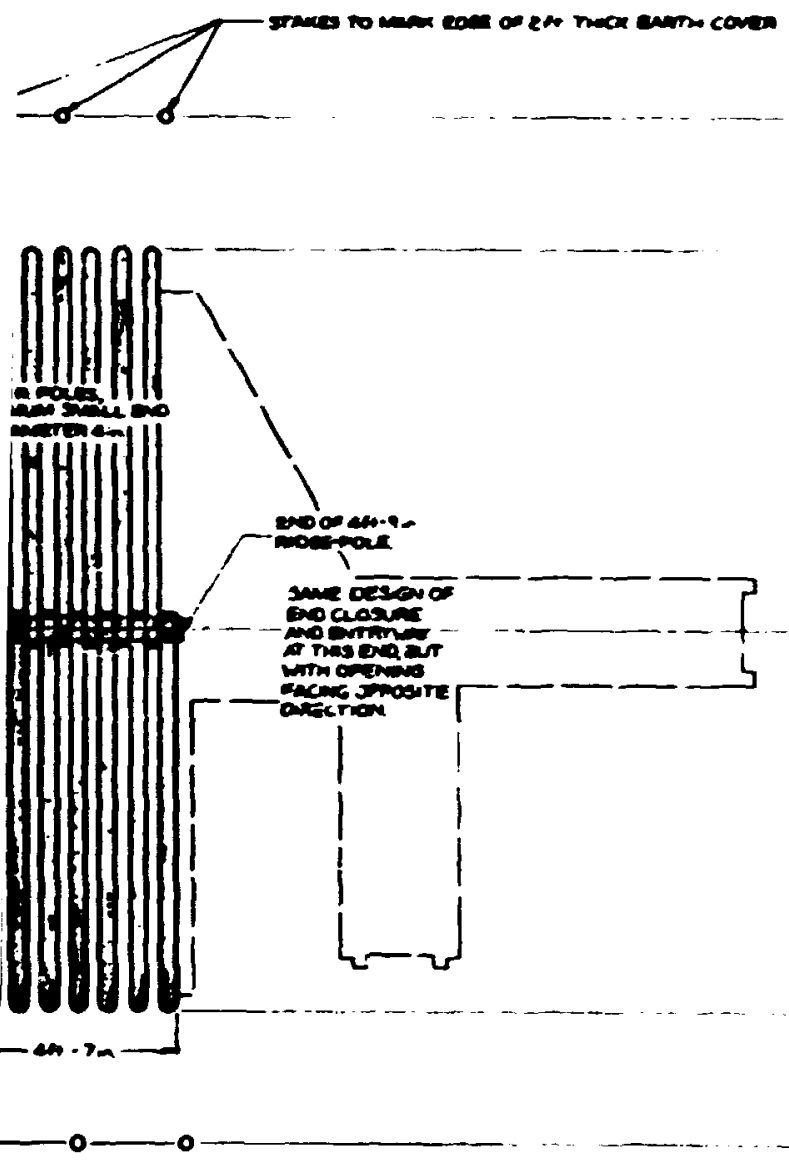

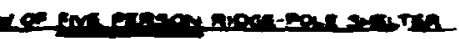

,

8

$\vdots$

1

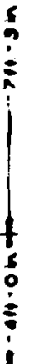

ance sacens to 2 pos - cram constion vinch cro pars

- activer...' rocernor solom

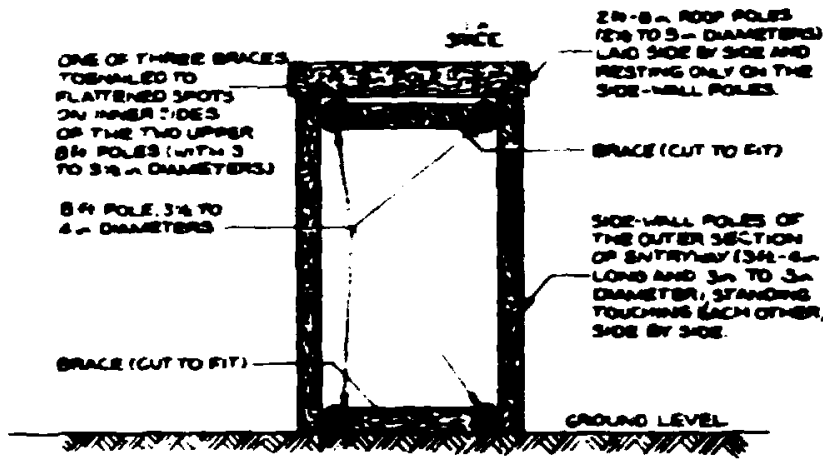

- 24.0n

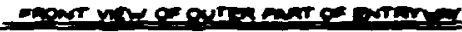

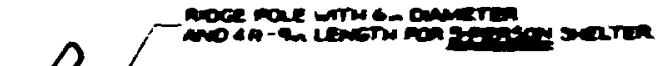
icasriang mantan

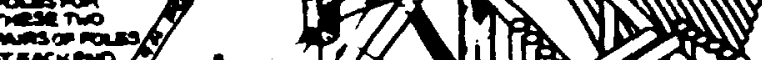

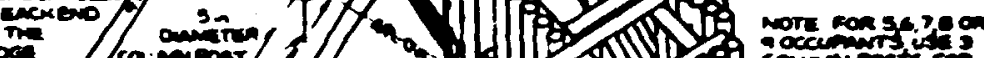
wat
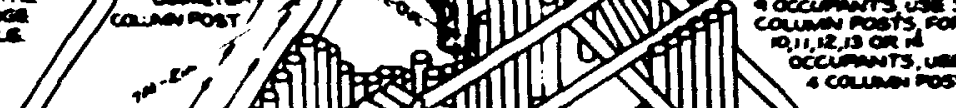

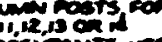

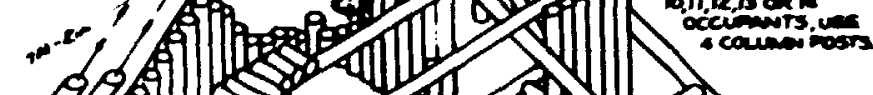

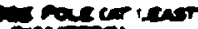
Einaming
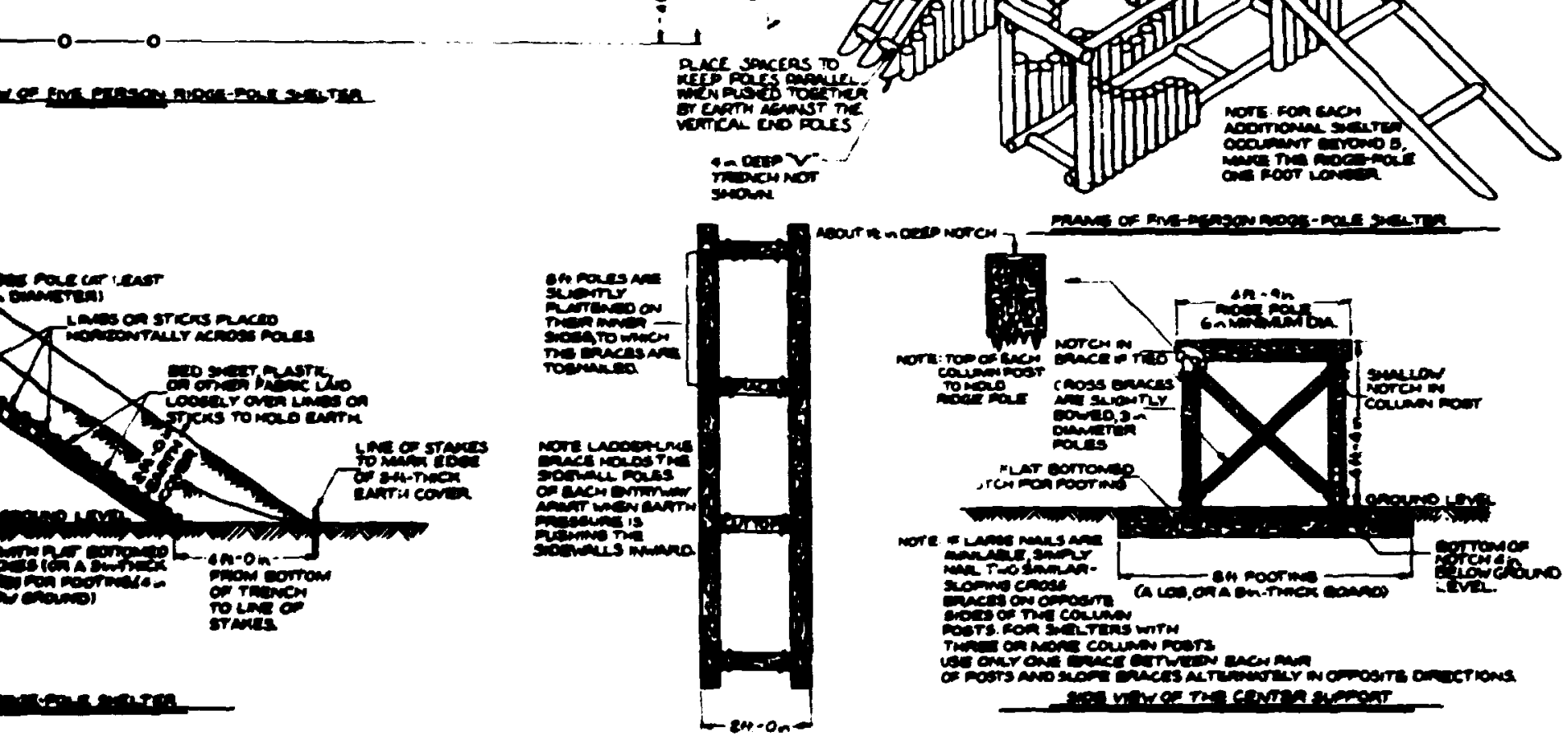

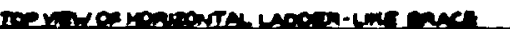

tested at 15 and $5.8 \mathrm{psi}$. 


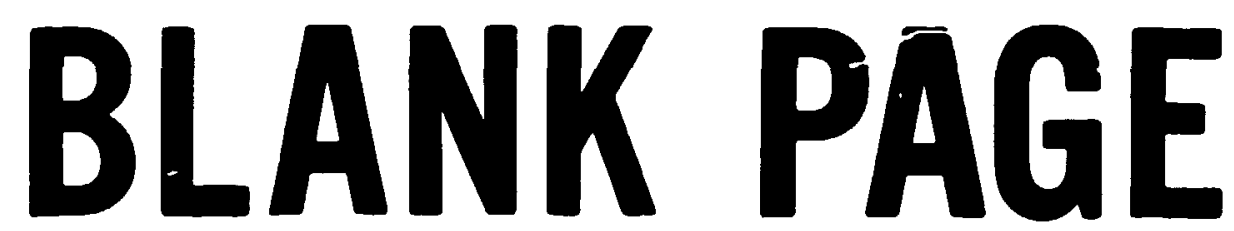


and the other entry facing in the opposite direction. Figure 9.1 shows the alwst rompleted pole frame, plus a temporary brace pole steadying the entrance. The pole frame was next covered witl; small, leafy limbs (Fig. 9.3), which in turn were covered with 4-mil polyethylene. Then a covering of dry, sandy earth $2 \mathrm{ft}$ thick was placed over the whole shelter, with earth-filled potato bags retaining the earth over the entrances.

PHOTO 6476.76

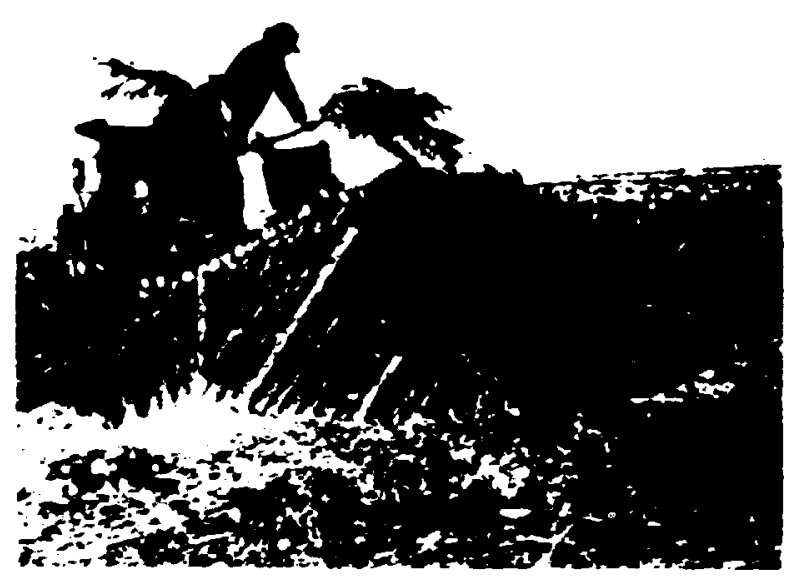

Fig. 9.3. Covering the frame of a Ridge-Pole Shelter with salt cedar limbs.

\subsection{Test Results}

\subsubsection{At 15 psi. Contrary to our expectations that the blast} effects would collapse the mair, room, the main room was undamaged (see F1g. 9.4). The ridge pole was moved only $3 / 4$ in. away $f: 0 m$ ground zero. However, up to $9 \mathrm{in}$. of earth was scoured of $f$ the top of the slialter. In three places the underlying plastic over the ridge was broken; as a result, dry, sandy earth fell thrcugh the roof poles in these places, producing holes several inches acrois, open to the sky.

The serfousness of what would be the amount of blast-wind scouring by a l-megaton explosion (which at a gi"en overpressure range would produce blast winds lasting ten times as long as the j-kiloton blast winds at DICE THROW) is indicated by the removal of all shielding earth from the ground-zero side of a 1/10-scale model of this Ridge-Pole Shelter, also tested at 15 psi (see Fig. 9.5). 


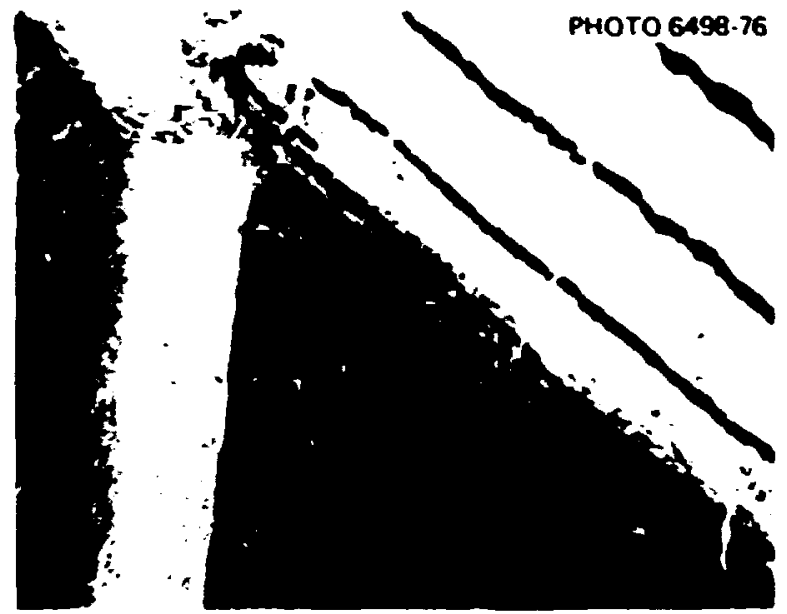

Fig. 9.4. Posttest interior of Ridge-Pole Shelter at 15 psi. The main room was undamaged; the ridge pole had been moved only $3 / 4$ in. away from ground zero.

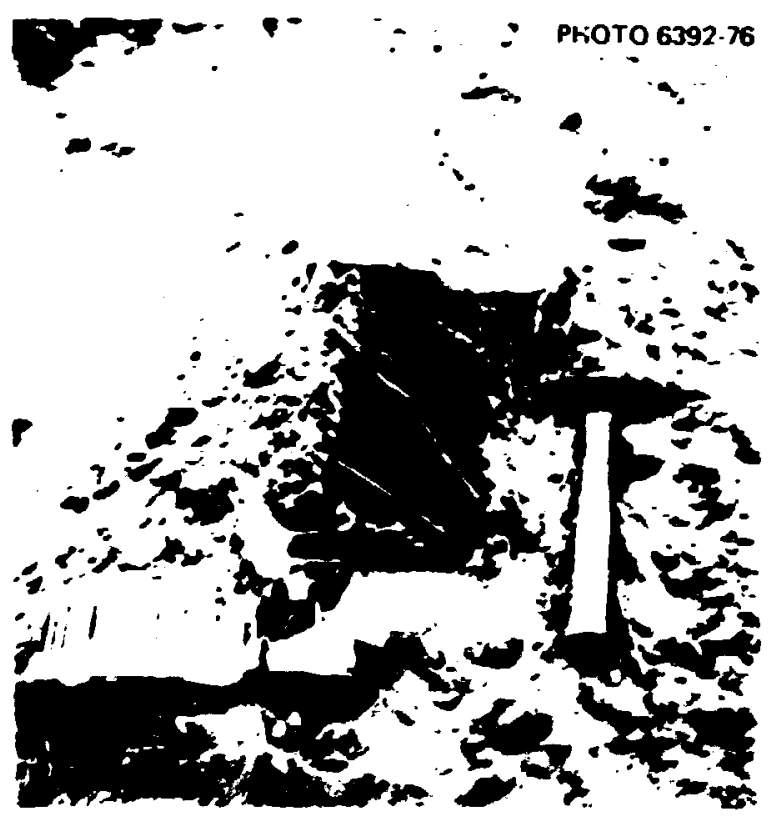

Fig. 9.5. Posttest exterior of 1/10-scale Ridge-Pole Shelter at 15 psi. Scouring by the blast winds had removed practically all the earth, plastic, and twigs on the side facing ground zero and over the two entries - indicative of blast-wind scouring of earth cover over a full-scale shelter by a megatcn explosion.

The most surprising damage is shown by Figs. 9.6 and 9.7. Obviously, th- dry earth moved ("flowed") away from the middle of the shelter and toward the two ends of the shelter. Apparently the pressures on the ends of the shelter were decreased as compared with the pressures on the 


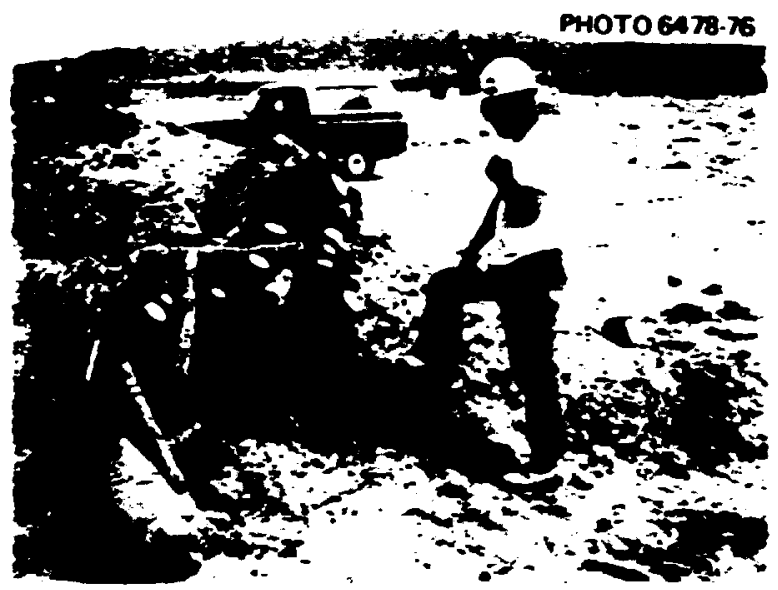

Fig. 9.6. Collapsed entrance facing away from ground zero, at 15 pst. The blast winds had scoured away most of the covering earth, and the earth had "flowed" away from the center of the shelter, pushing the upper part of the entry in a direction perpendicular to the radius from ground zero.

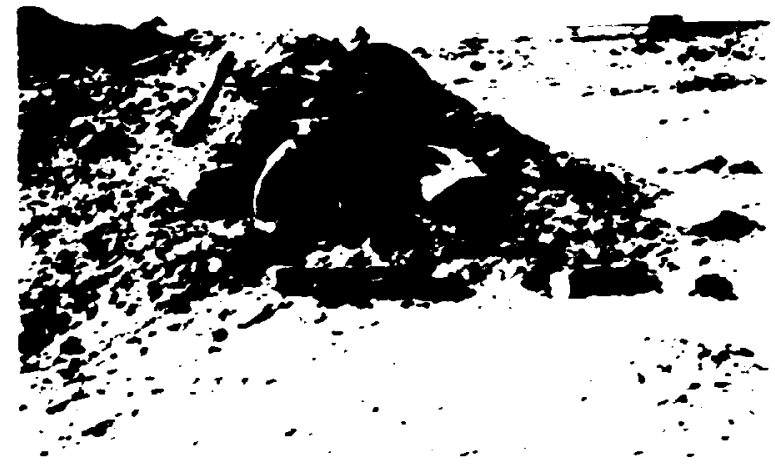

Fig. 9.7. Postblast view of the entry of the Ridge-Pole Shelter facing ground zero, at $15 \mathrm{psi}$. Note the scattered potato-sack sandbags that had been placed to retain the earth over the entry. Earth "flow" had pushed all but the base of the entry away from the middle of the shelter, leaving none of the entry walls perpendicular.

center, both by the lack of refiected overpressures at the ends and the lowering of pressures at the ends caused by Bernouli effects, where the velocities of the blast winds were increased as the winds passed around the ends of the obstructing shelter.

The three fireplace-size logs (see Fig. 9.7) in front of tire entrance facing ground zero, and also the two poles pictured resting on the side of the shelter, had been carried by the blast winds from where 
they had been stacked before the test at the 70-psi range, $315 \mathrm{ft}$ from where they came to rest. Note the identifying spot of paint on the end of the $\log$ on the right.

The overpressure inside reached only $3 \mathrm{psi}$, due to the sall size of the semicollapsed entryways, the relatively large volume of the main room, and the relatively short time (about $80 \mathrm{msec}$ ) that the overpressure outside remained above 3 psi.

\subsubsection{At 5.8 psi. As anticip̌r:ted, this Ridge-Pole Shelter vas} undamaged as regards its pole frame. Heasurements showed the ridge pole to be unmoved. However, $f$ to $12 \mathrm{in}$. of dry, sandy earth was removed from the ridge, partly due :o blast-wind scouring and partly due to shock effects having broken five holes in the 4-mil polyethylene where the thin plastic covered the rough ends of the wall poles. Some dry, sandy earth hac fallen through these holes, but no part of the roof was wholly uncovered. The overpressure measured inside was 2 psi.

\subsection{Conclusions ana Recommendations}

9.4.1. Due to the amount of dry shielding earth that would be removed by the blast winds produced by the sizes of nuclear weapons that menace the United States, and also due to the damage that aboveground shelters built in wooded areas would suffer from blast-hurled trees, the practicality of Ridge-Pole Shelters for protection against both blast effects and fallout is severely limited. (If the earth is wet, however, blast-wind scouring by 1-kiloton blast winds at the 16-psi overpressure range removes a negligible thickness of sandy earth from a shelter with the same slope and orientation of roof. ${ }^{1}$ )

9.4.2. Before covering this type of shelter with thin plastic preparatory to covering with earth, the ends of its poles should be covered with cloth, rugs, or other stronger material in order to prevent the sharp edges or splinters on the ends of poles from causing the plastic to be torn when being covered with earth or subjected to blast stresses. 
10. DOOn-COVTRED TRENCH SHELTFRS AT 31 AND 15 pS1

\subsection{Purpose}

Most separate Anerican homes have enough interior doors to roof a trench shelter for the occupants and thus provide then with much better protection against fallout radiation and fire than do the great majority of homes. In a prior DNA blast test, a Door-Covered Trench Shelter w. s essentially undamaged at 5 psi. Therefore, we tested this simple fallout shelter at the predicted 30- and 15-psi overpressure ranges. The test at 30 psi was carried out to learn whether or not earth arching would prevent the collapse of the hollow-core interfor doors roofing a trench dug in almost rocklike earth - not to estimate the ultimate survivability of persons exposed to 30-psi blast effects in a very snall open shelter.

\subsection{Construction}

The Door-Covered Trench Shelters at 31 and 15 psi were of identical construction, as shown by Fig. 10.1. However, a greater thickness of earth was mounded over these shelters, about $2-1 / 2 \mathrm{ft}$, than shown in this drawing. We found that a hollow-core interfor door can withstanc being covered with earth many feet thick, since it: yields under loading, and protective earth arching develops in earth mounded over it.

\subsection{Test Results}

10.3.1. The shelter at $31 \mathrm{psi}$ was a total failure. Earth arching over the doors did not prevent them from being broken in at this high overpressure. Figure 10.2 shows the depression resulting from this collapsed shelter, photographed eight days after the blast. Note the large amount of sand that had been blown into this depression during these postblast eight days. In the desert outside the blast-devastated area, the grass and desert shrubs prevented any consequential blowing of sand and dust during these same eight days. Open entries serving as ventilation openings had large amounts of sand blown into them, Indicating a potential fallout-entry problem in blast-devastated areas. 


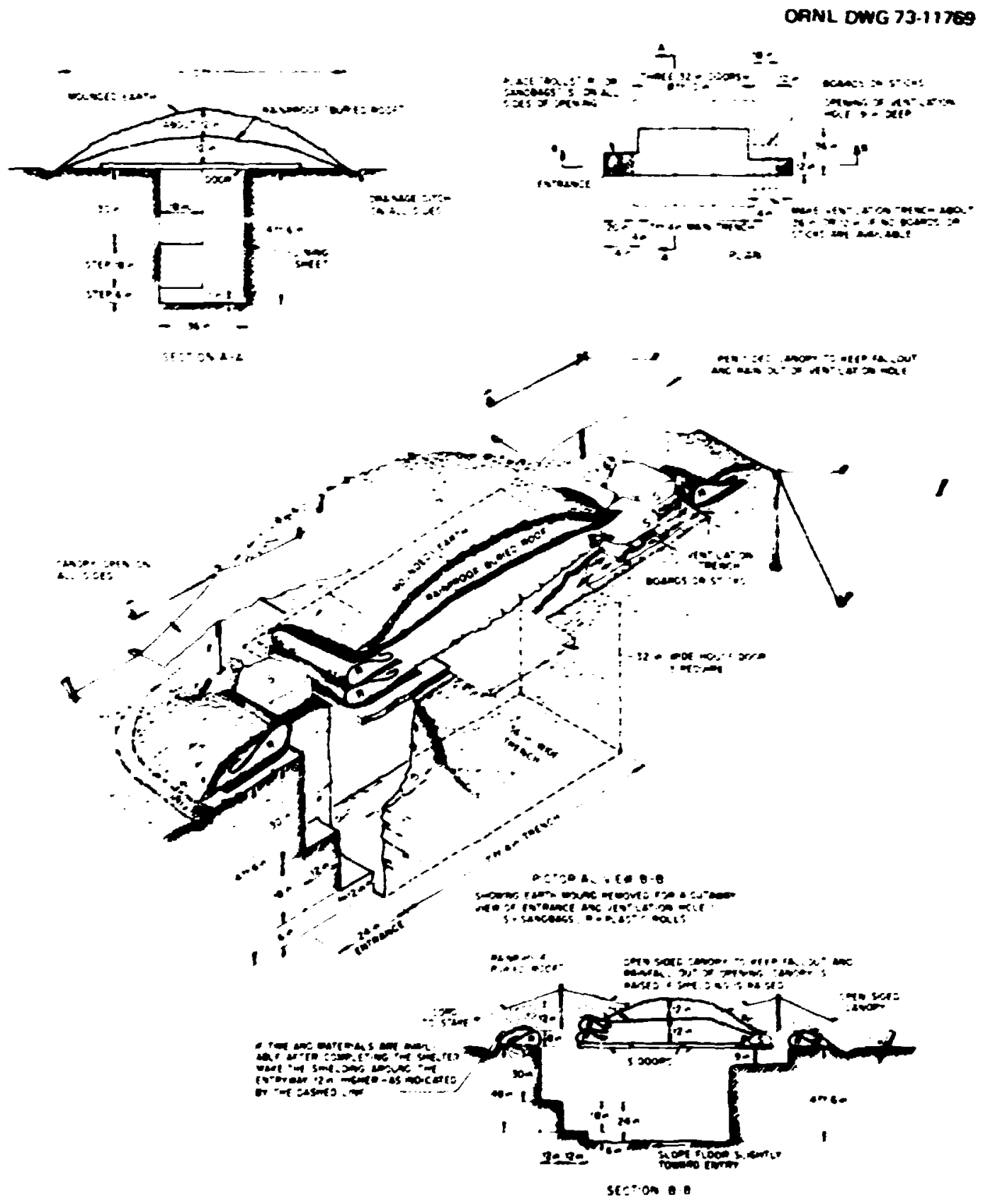

F18. 10.1. Door-Covered Trench Shelter tested at 31 and 15 psi. 


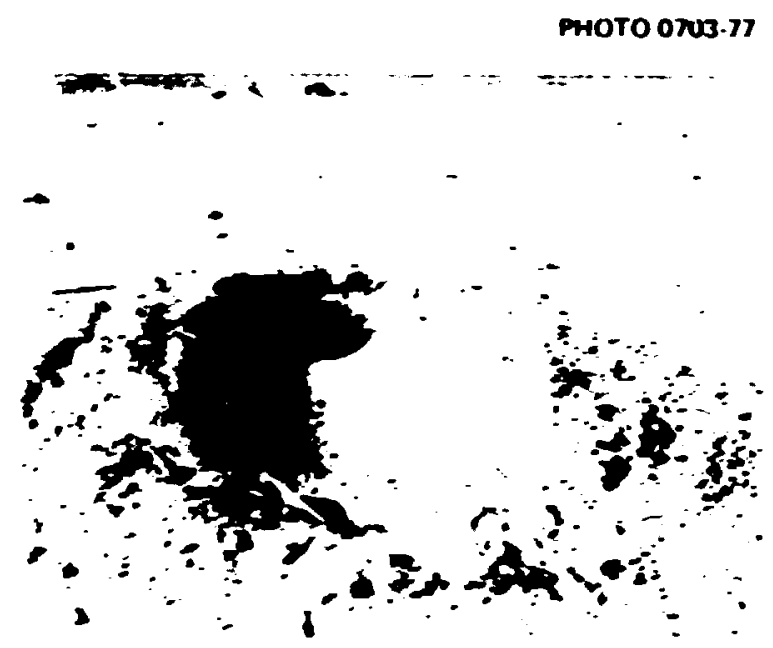

F12. 10.2. Photo of Door-Covered Trench Shelter at $3 i$ psi taken efght days after the blast. The doors were smashed in. Note the sand accumlation in the right side of the hole, indicative of the probability of dangerous anounts of fallout being blown into entries used as ventilation openings in blast-devastated areas.

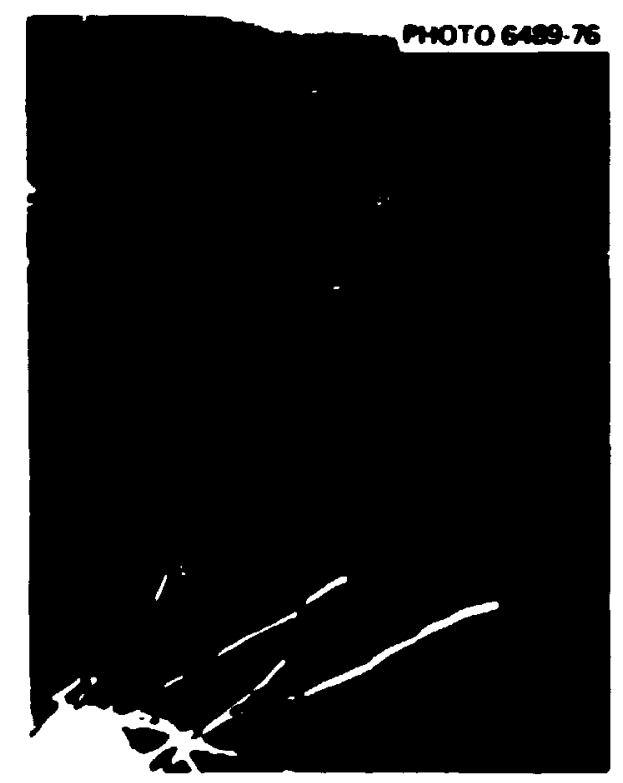

P18. 10.3. Postblast interior of Door-Covered Trench Shelter at $15 \mathrm{psi}$. Large chunks of earth were knocked of $f$ the walls. Between 16 and 24 days after the blast, the partly broken doors broke completely.

10.3.2. At 15 gst the roof 1 ng doors were cracked but not broken In (see P1g. 10.3). However, much $r$ ird callche was broken of $f$ the walls. The overpressure measured inside the shelter was 5 psi, high enough to break some occupants' eardruns. 


\subsection{Conclusions and Recomendations}

10.4.1. If subjected to the longer-duration overpressures and greater anplitudes of sround wotions caused by strategic weapons, DonrCovered Tr: ich Shelters would afford obviously inadequate blast protection at overpressure ranges considerably less than 15 psi.

10.4.2. In blast-devastated ateas, the problen of fallout particles being blow into shelters dependent for their air supply on ground-level openings could be sericus.

\section{ChINESE "MAN" SHELTER AT 20 psi}

\subsection{Purpose}

In the first Chinese handbook ${ }^{7}$ on nuclear defense that cane into our hands, we say the shelter illustrated by fig. 11.1. Previously, we had never seen or conceived a blast shelter of this desig or one built of such thin poles. If such thin poles could safely be used, it would reduce the labor of obtaining the poles for an expedient blast shelter - one of the chief constraints on the practicality of such shelters. Therefore, we devided to blast test th.is Chinese design.

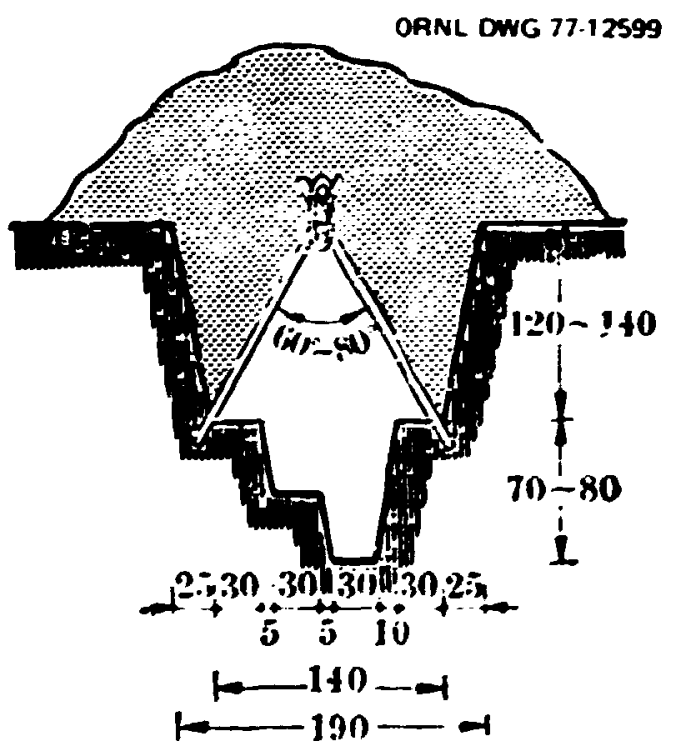

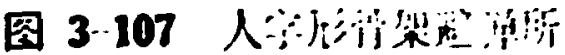

Fig. 11.1. Chinese "Man" Shelter tested at 20 psi. This shelter is called "Man" Shelier in a Chinese civil defense handbook because a cross section of its frame resembles the Chinese character ", " for "man." 


\subsection{Construction}

The main roon was $10 \mathrm{ft}$ long. It was made in a trench with two shelves, a bench, and a 1-ftuide foot trench dug into the hard caliche. The sloping wall poles were first cut 6 ft by 6 in. long, but later had to be reduced about $6 \mathrm{in}$. in length because their loser ends could not have been dug into the rocklike earth without breaking off large chunks of the wo shelves on which the wall poles rested. The two sall poles, one below and one above where the wall poles crossed at the top of the frane, were encircled tightly with a single strand of No. 9 wire between each adjacent wall pole.

The 10-ft-long main room (see Figs. 11.2 and 11.3) plus a 5-ft-long horizontal entryway required 28 poles on each side, averaging about 3 in. in dianeter, including bark. The tops of these poles averaged about 2-1/2 in., excluding bark. The horizontal entryway was of the same design as the wain room, except that its entire floor was at the same level as the shelves and the bottons of the wall poles of the anin room. It led to the vertical south-end entry that, for lack of a Chinese drawing, we designed and built using the triangular construction piciured in Figs. 11.2 and 11.4 . The poles of the vertical entry averaged I little over $3 \mathrm{in}$. In diameter, including bark. Ajove the $30 \times 30 \mathrm{in}$. opening at the outer end of the horizontal entryway, the inside of the vertical entry was an equilateral triangle 39 in. on a side - big

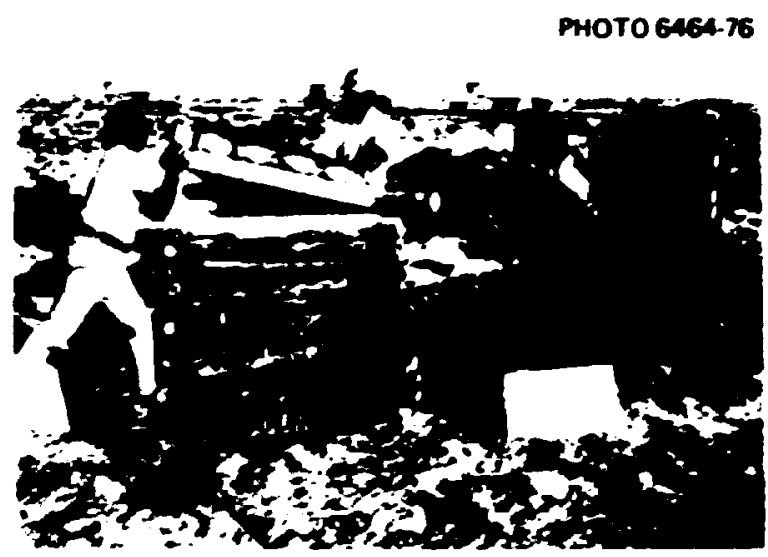

Fig. 11.2. Completed frame of Chinese "Man" Shelter tested at $20 \mathrm{ps} 1$. In accord with the Chinese drawing, the poles of the main room averaged only about $3 \mathrm{in}$. In diameter. The triangular entries and triangular blast doors were of ORNL designs. 


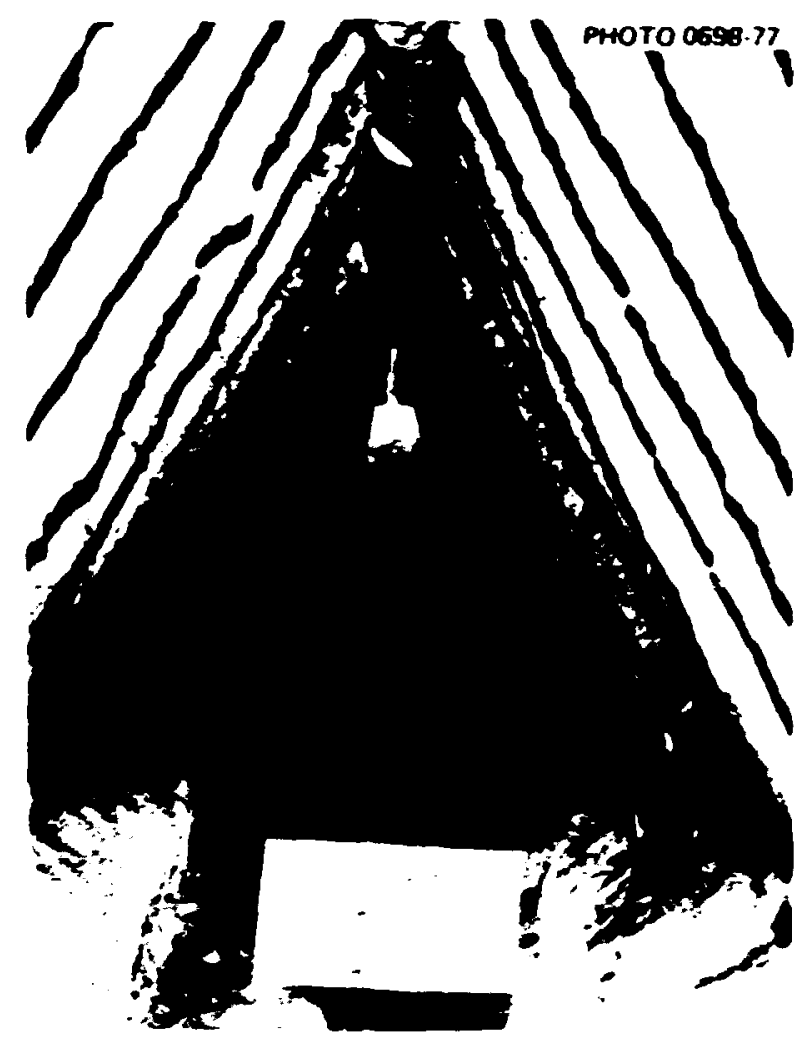

Fig. 11.3. Undamaged interior, showing earth bench on one side and roof deflection gauge on post.

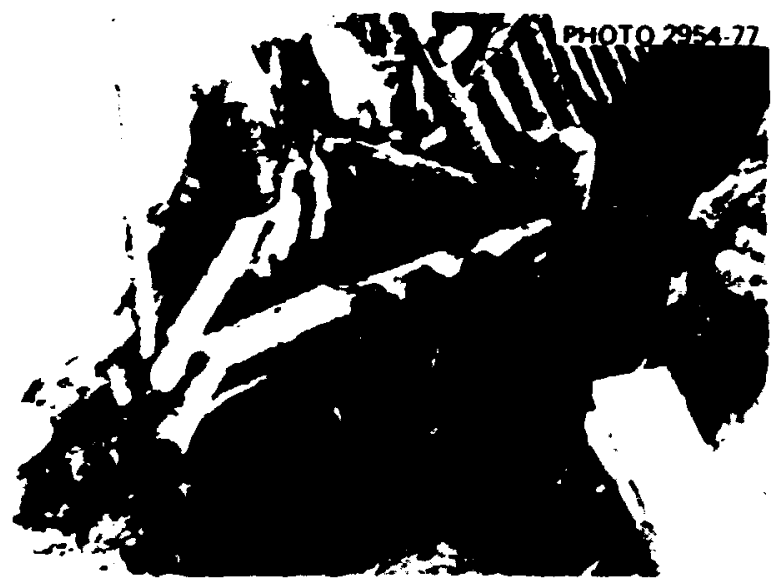

Fig. 11.4. The lower part of the vertical triangular elltry is pressed horizontally against two pairs nf vertical posts. Each pair is wired tngether. The two pairs are held apart by two horizontal spacer poles tuenailed in place to frame the rectangular opening between the horizontal and vertical parts of the entry. The pairs of vertical posts are pressed against two horizontal poles (the uppermost is shown) that in turn press against both the outermost two poles of the horizontal part of the entry and the earth in two slots dug in the sidewalls of the excavation. 


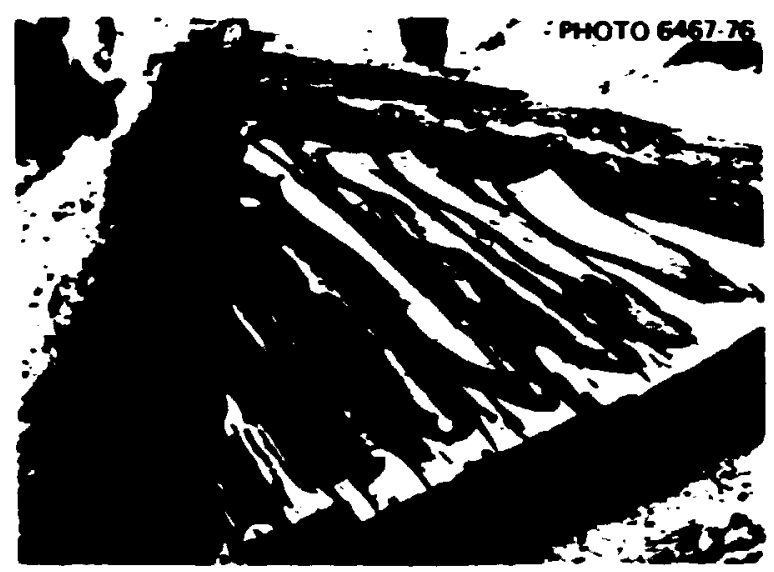

Fig. 11.5. Posttest undamaged triangular blast door, made of three 5-in.-dian peeled poles covered with seven 4-in.-diam peeled poles. Between these covering poles were six $2-i n$. - widz ventilation slots, protected by six flap valves made of strips cut from woril tire treads.

enough for a big man (see Figs. 11.2 and $J 1.4$ ). The five uppermost poles averaged $4 \mathrm{ir}$. In diameter, and the top three were notched and nailed together so as to make a plase on which the blast door could be closed snugly.

The blast door was very similar to the triangular blast doors on the Log-Covered Trench Shelters described in Sect. 6, except that the three frame poles of the door were smaller in diameter, and the door had six open slots and six flap values, as shown in Figs. 11.5 and 11.6. To prevent the door and the uppermost poles of the triangular entry from being pulled up and blown away during the negative pressure phase of an explosion, the uppermost poles were wired securely to poles about $3 \mathrm{ft}$ lower down the entry. 


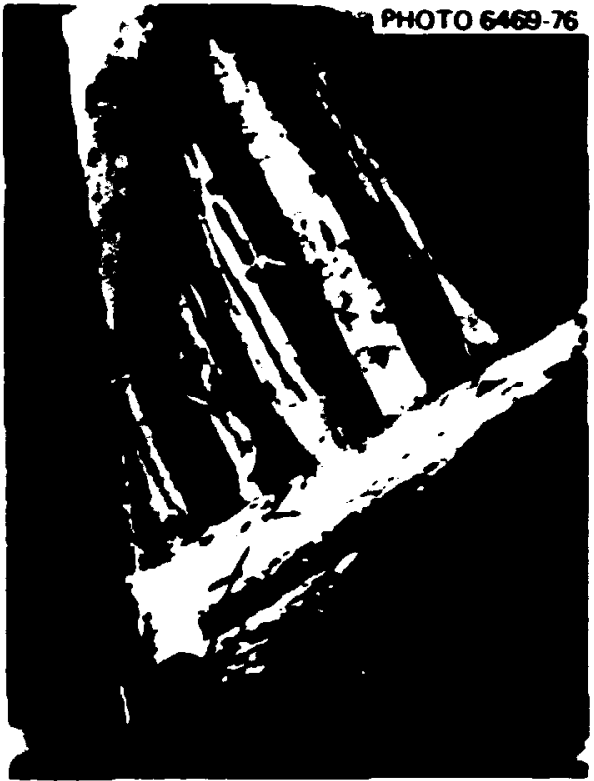

Fig. 11.6. Undamaged triangular blast door, partly open, and viewed looking up the side of the triangular entry to which the door was hinged.

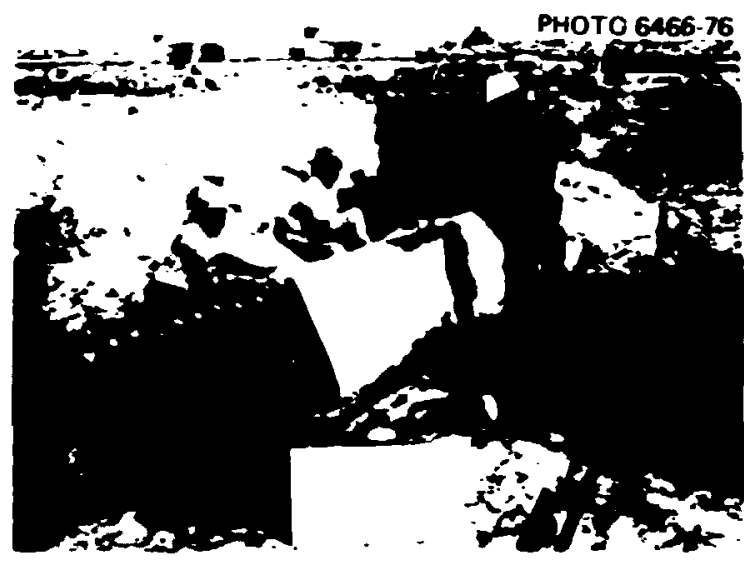

Fig. 11.7. Covering the limb-covered pole frame with bed sheets. Salt cefar limbs had first been placed crosswise over the lightly constructed pole frame.

Figure 11.7 shows the covering of the shelter frame, except for the mounding of the shielding eartin. Due to a construction error, the earth was mounded $4 \mathrm{ft}$ deep above the tops of the wall poles, rather than the approximate $3 \mathrm{ft}$ shown by the Chinese drawing.

The outer (north) entry was ruggedly constructed of 6-in.-diam vertical poles, with interior triangular braces. Its blast door was practically identical to the door on the ORNL-designed "Chinese" entry to the south end of the shelter. A :ectangular expedient shelter ventilating pump (a $20 \times 24$ in. KAP) was installed in a makeshift frame placed in the horizontal crawlway leading to the north entry.

\subsection{Test Results}

Contrary to our predictions, this lightly constructed shelter, tested closed, was undamaged by blast effects. The undamaged interior is pictured in Figs. 11.3, 11.8, and 11.9 .

The triangular blast-protector logs around the doors, each $8 \mathrm{ft}$ long and 7 to $8 \mathrm{in.}$ in diameter, were moved away from ground zero, so 


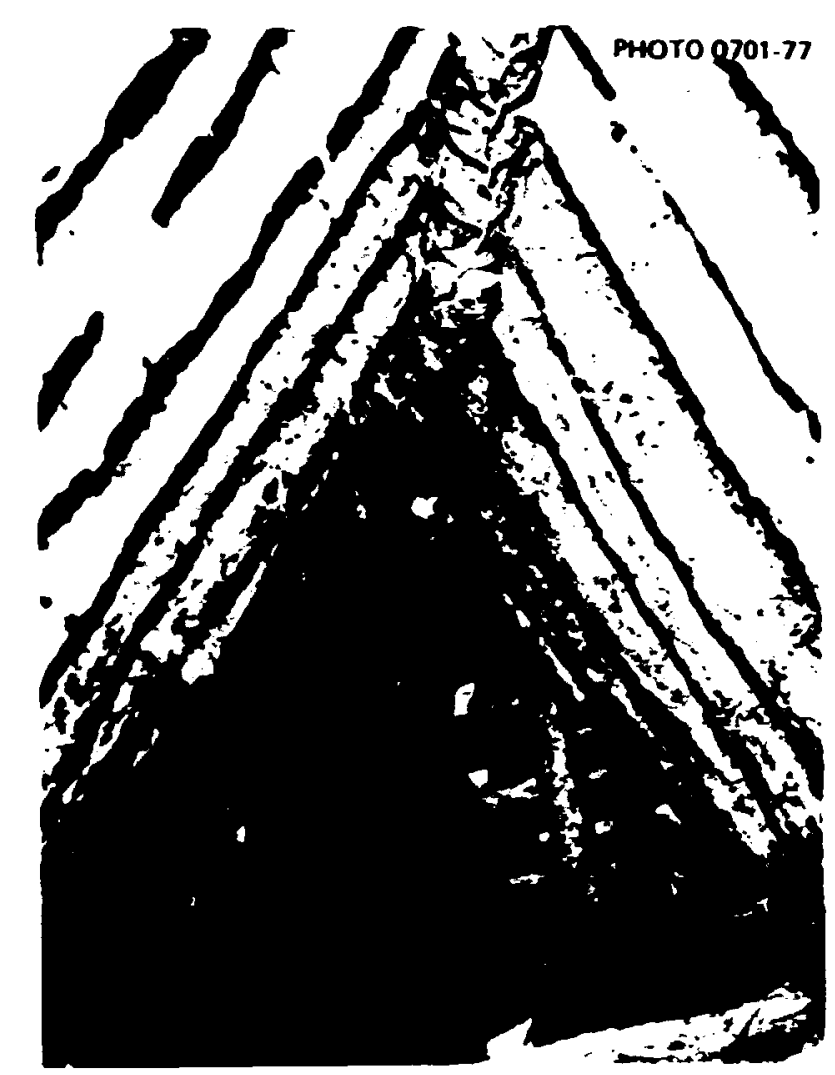

Fig. 13.8. Posttest view of opening at bottom of triangular vertical encry, undamaged by 20 -psi blast effects.

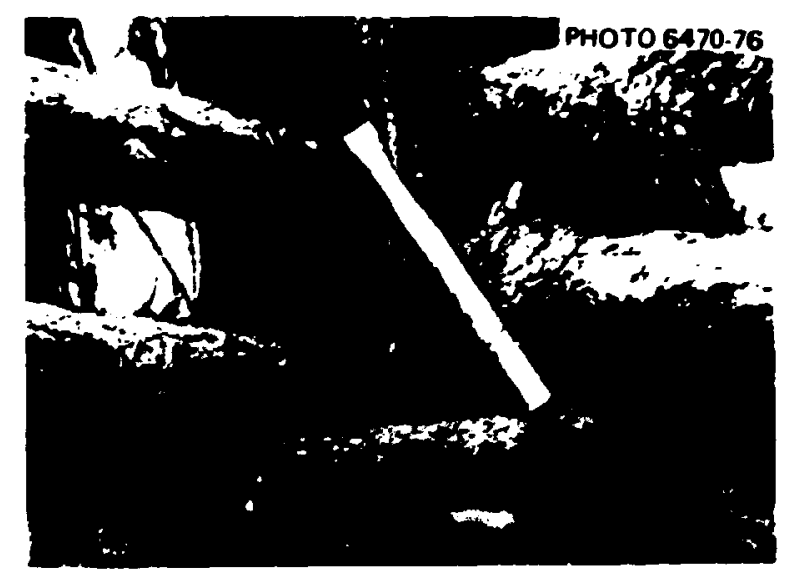

Fig. 11.9. Postshot condition of the lightly constructed triangular vertical entry. The hammer rests on a step pole. Earth arching prevented the ylelding bed sheet outside from being torn.

that a 108 pressed against the blast-door hinges of each door (see Fig. 11.5). Both doors, however, could be opened. The blast winds scoured away about 8 to $10 \mathrm{in.}$ of dry earth from around the six logs. 
The blast valves on both doors obviously closed properly; a pressure rise of only 1 psi was recorded in the center of the shelter. The subsequently open valves permitted enough sand and dust to fall into the entries to have constituted a health hazard if heavy faliout had been on the ground outside. The ventilating pump and its flimsy frame were damaged slightly, but required unly about 10 min to repair before postshot testing.

The undamaged shelter frame was moved only slightly. The top of the roof was permanently depressed $1-5 / 8$ in. and pushed $3 / 4$ in. away from ground zero.

\subsection{Conclusions and Recommendations}

11.4.1. The Chinese "Man" Shelter, if built with the ORNL-designed triangular vertical entry and expedient blast doors, is a good example of the blast protection attainable by properly building a lightly constructed shelti: that yields under blast loading so as to attain effective earth arching in an adequately thick earth covering.

11.4.2. i.e lack information concerning the magnitude and duration of the earth pressures produced by the blast on the wall poles - pressures that tend to collapse this $i$-frame structure. Therefore, we are unable even to hazard a prediction as to whether or not this closed shelter would survive the blast effects of a megaton weapon at the same 20-psi overpressure range, producing greater and much longer-lasting overpressures at depth, and ground waves of much greater amplitude.

11.4.3. During a rapidly escalating crisis, in many wooded areas the most difficult poles to supply in adequate numbers at shelterb'ilding sites would be the long, straight, stout poles required to make rectangular entries to blast shelters. Therefore, triangular blast entries made of short, light poles and triangular expedient blast doors should be tested at higher overpressure and longer duration.

\section{RUG-COVERED TRENCH SHELTERS AT 1.5 AND 5.8 psi}

\subsection{Purpose}

Tarp-Covered Trench Shelters had been undamaged by heavy static and moving loads, including a 6-ton backhoe driven over the earth 
covering a shelter of this type roofed by a coiton tarp. 11 Since a cotton tarp is not as strong as a piece of typical wall-to-wall carpeting made largely of strong synthet fr fibers, we anticipated this shelter would withstand the blast at the 15-psi overpressure range, by facilitating earth arching.

\subsection{Construction}

Figure 12.1 shows the principal design elements of a Rug-Covered Tranch Shelter. The two models tested at DICE THROW had main-room
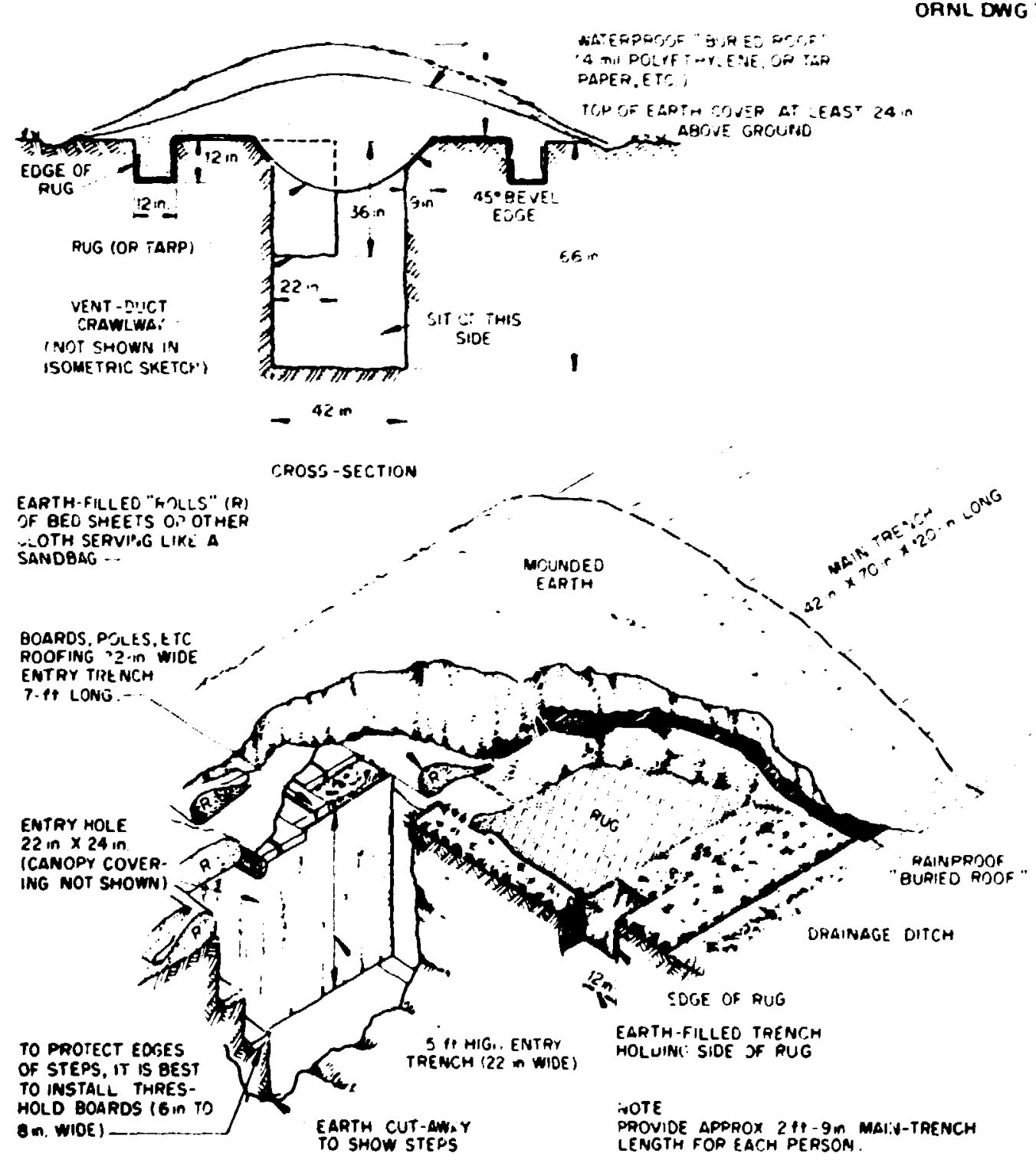

Fig. 12 1. Construction of Rug-Covered (or Tarp-Covered) Trench Shelter. 
trenches $40 \mathrm{in.}$ wide, $6 \mathrm{ft}$ deep, and $11 \mathrm{ft}$ long. The roofing rugs wert each $12 \mathrm{ft}$ wide by il ft long. These rugs had a doutle-laminated jute backing over nylon - typical low-cost wall-to-wall carpeting. No difficulties were experienced in covering the rugs with earth to a depth of $48 \mathrm{in}$. over the midline of the trench, nor in completing the 20-in.wide entrances at each end (see Figs. 12.2 arid 12.3).

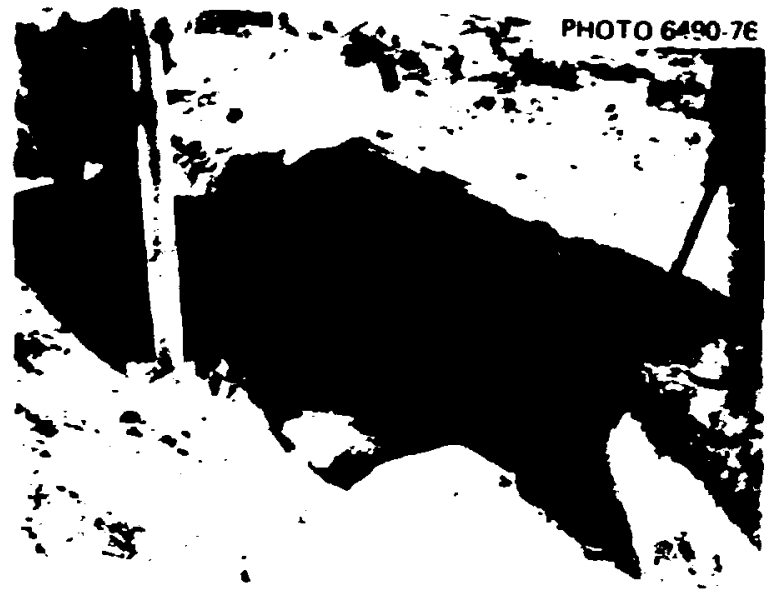

Fig. 12.2. Tamping earth over efige of a side trench of Rug-Coverad Trench Shelter at 15 psi.

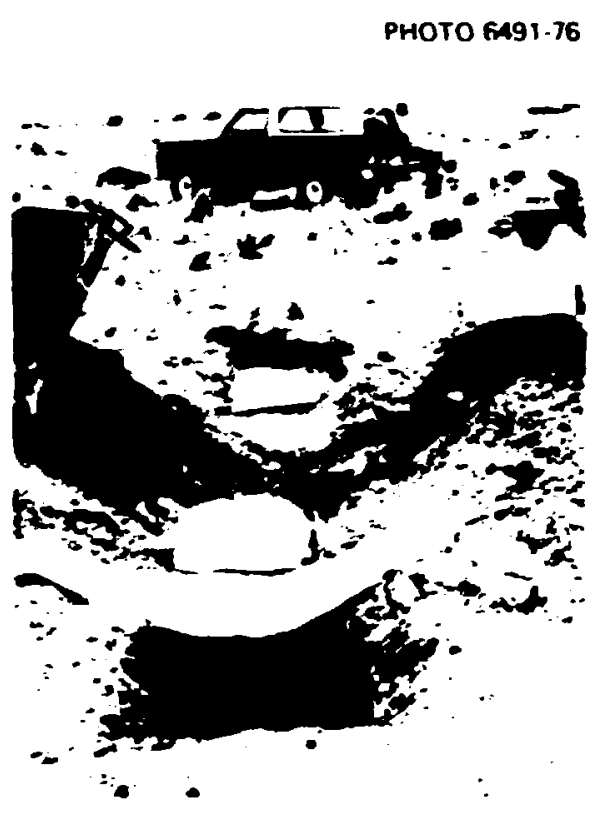

Fig. 12.3. Dumping earth on side of ruz before mounding earth $4 \mathrm{ft}$ deep along centerline. An earth-filled bed-sheet "rol;" and a pillowcase "sandbag" retained earth at each entry, pictured prior to completion.

\subsection{Test Resulis}

12.3.1. At 15 psi, the rug was torn lengthwise on one side from end to end, and the mass of overlying earth fell into the trench. This complete faflure is shown clearly by Fig. 12.4 .

12.3.2. At 5 psi, the rug was not torn, but the ground shock loosened it from the earth holding one of its edges in a side trench. 


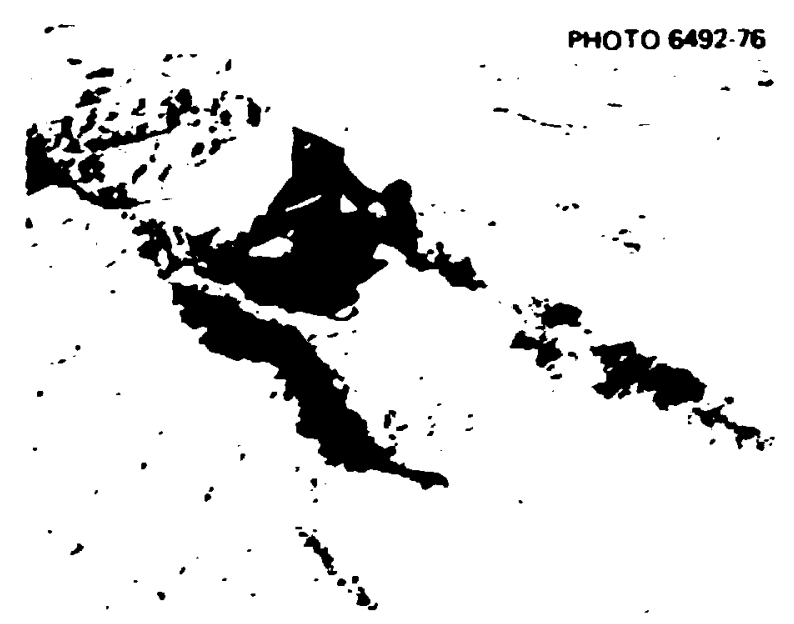

Fig. 12.4. Demolished Rug-Covered Trench Shelter at 15 psi. The edges of the rug were not pulled loose by blast effects; it was torn lengthwise.

As a result, the whole intorn rug and the mass of earth above it fell into the trench, to within about $18 \mathrm{in.} \mathrm{of} \mathrm{the} \mathrm{trench} \mathrm{floor.} \mathrm{At} \mathrm{this}$ point, earth arching and the strength of the rug stopped the dowmard fall. Occupants sitting in the trench would have been crushed.

\subsection{Conclusions and Recommendations}

12.4.1. A Rug-Covered Trench Shelter definitely should not be built in areas likely to be subjected to blast effects.

12.4.2. A Rug-Covered (or Tarp-Covered) Trench Shelter shouid only be built for fallout protecti a, in an area where the earth is very stable, by persons lacking other materials with which to roof an expedient trench shelter.

\section{SCALE MOUL'TS OF SHELTERS}

\subsection{Purpcse and Construction}

In order to save money and to compare the resistance to blast effects of full-scale shelters with that of reduced-scale shelters, the scale models listed below were tested. All scale models were built of materials as similar as practical to those of their full-scale counterparts, and linear scaling of all dimensions was used in all cases. 


\subsection{Test Results}

13.2.1 One-half-scale Rug-Covered Trench Shelters at 15 and 5 psi. Both shelters were undamaged by the blast effects, whereas their fullscale counterparts failed at the same overpressure ranges. The canvas used to roof the one-half-scale models was approximately one-half as strong as the wall-to-wall carpeting used to roof the full-scale shelters. For the one-half-scale models, a fabric only one-fourth as strong should have been used, since the weight of earth supported by a 1-ft-wide segment of tine roofing fabric (measured along the edge of the trench) of the one-half-scale model is one-fourth as great as the wefght of earth supported by a l-ft-wide segment of the roofing fabric of the full-scale shelter $(1 \times 1 / 2 \times 1 / 2$ vs $1 \times 1 \times 1)$. But even if we had selected roofing fabric only one-fourth as strong for the one-half-scale model, scaling would not have been satisfactory because the strength of the earth of the unsupported walls would have remained the same in both models, whereas the full-scale model to be equally strong would require earth having twice the resistance to shearing and tenstle stresses.

Due to an oversight, samples of the rugs and canvas used to roof shelters were not preserved for matertals laboratory testing. The celative amounts of stretch or yield of a fabric before tearing is probably more important than its ultimate tensile strength as a determinent of its value for roofing a blast-shelter trench.

13.2.2 Unshored earth walls of trench shelters. In all cases, at the same overpressure ranges the unsupported earth walls of small-scale trench shelters and of small-scale open trenches were less damaged by blast effects than were the corresponding walls of large-scale trench shelters and of large-scale open trenches. This was due to the fact that the volume of earth tending to be sheared off a trench wall by gravity and ground-shock for'es increases as the cube of the increase in scale, whereas the area of the surface of the potential shearing-off of this vulume increases as the square of the increase in scale. As a result of this difference, ff we double all linear dimensions of a half-scale trench, then in the case of the full-scale earth wall a unit area of the 
surface of potential shearing is subjected to twice the unit stresses to which a corresponding unit area of the half-scale earth wall is subjected. Therefore, the full-scale trench wall fails first.

13.2.3 One-half-scale Chinese "Man" Shelter at 31 psi. This closed shelter (Fig. 13.1) was a one-half-scale counterpart of the Chinese "Man" Shelter tested at 20 psi, ex-ept that it had only one entry and had only one blast-protector 108 , which was $10 \mathrm{in.}$ in diameter and secured by stakes.

The blast tore loose the blast-protector log. The blast winds, theoretically peaking at about $670 \mathrm{mph}$, hurled this $\log 180 \mathrm{ft}$, where it struck the side of the Ridge-Pole Shelter. About $10 \mathrm{in.}$ of dry earth was scoured from around its entry. The earth shelves on which the lower ends of its side poles rested were cracked, but not broken of $f$. About 2 in. of powdery caliche earth accumulated on: the fluor. The height of the shelter rcof was. reduced only $7 / 8 \mathrm{in}$.

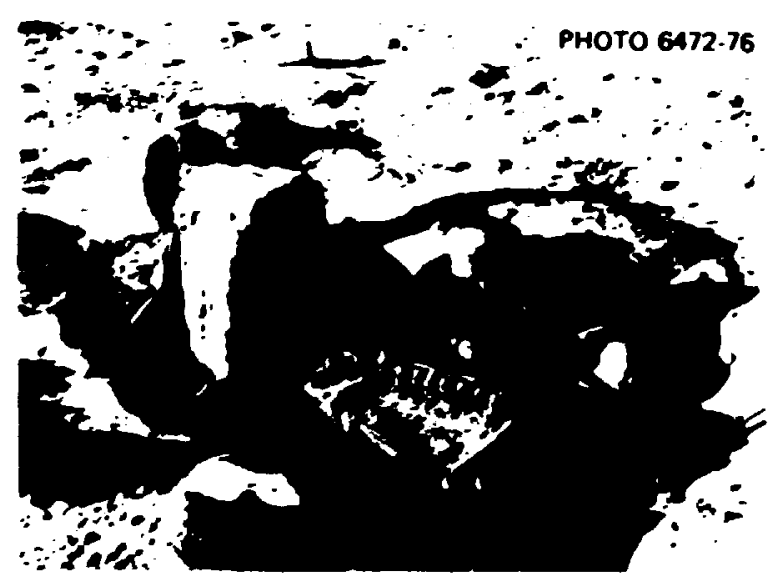

Fig. 13.1. One-half-scale Chinese "Man" Shelter tested at 31 psi with its triangular blast door closed. Before being covered with earth mounded as high as the blast door, the whole sheltar was covered with 4-mil polyethylene.

13.2.4 One-tenth-scale Chinese "Man" Shelter at 31 pst. This onetenth scale model consisted only of a main room, closed at both ends with "poles," with its top at ground level. The frame was undamaged, but had been pushed finto the sandy earth 2 in., reducing the celling height of the room from $4-1 / 4 \mathrm{in}$, to $2-1 / 4 \mathrm{in}$. (see Fig. 13.2). If a full-scale shelter built in soft earth had its poles proportionally 


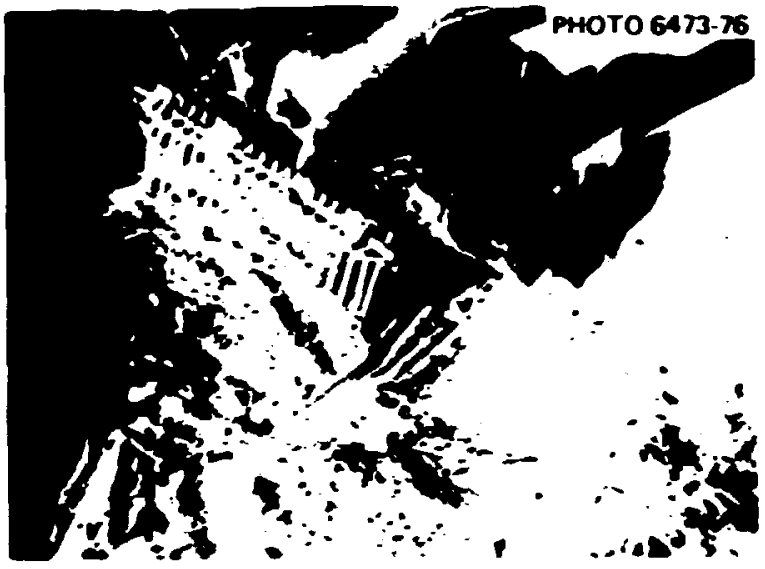

Fig. 13.2. One-tenth-scale room of Chinese "Man" Shelter at 31 psi, photographed postcest. The frame had remained adequately covered, was undamaged, but had been pushed about halfway into the ground.

pushed down into the earth b; the 31-psi blast overpressure from a 1-megatin explosion, with its duration of overpressure ten times as long as from a 1-kiloton explosion, the intact survival of the shelter frame would be unimportant to occupants of this shelter.

\subsubsection{One-hali-scale Log-Covered Trench Shelter at 53 psi. This} closed shelcer consisted solely of a two-level room and a horizontal entry trench, counterparts of the acijacent full-scale Log-Covered Trench Shelter. Both of these shelters were built to compare the effectiveness of roofing a trench with poles laid on the surface of the ground as iliustrated in Russian civil defense handbooks, as compared with the recommended Chinese procedure of placing the roofing poles on shelves well below ground level (see Fig. 13.3).

The blast damage suffered by both parts of this closed shelter indicated that occupants probably would have been injured, but was less serious than the damage suffered b; its full-scale counterparts tested at 5.3 and 31 psi. In the Russian half, the upper parts of the earth walls were broken of $f$, and the unbroken roof poles came to rest sloping, 


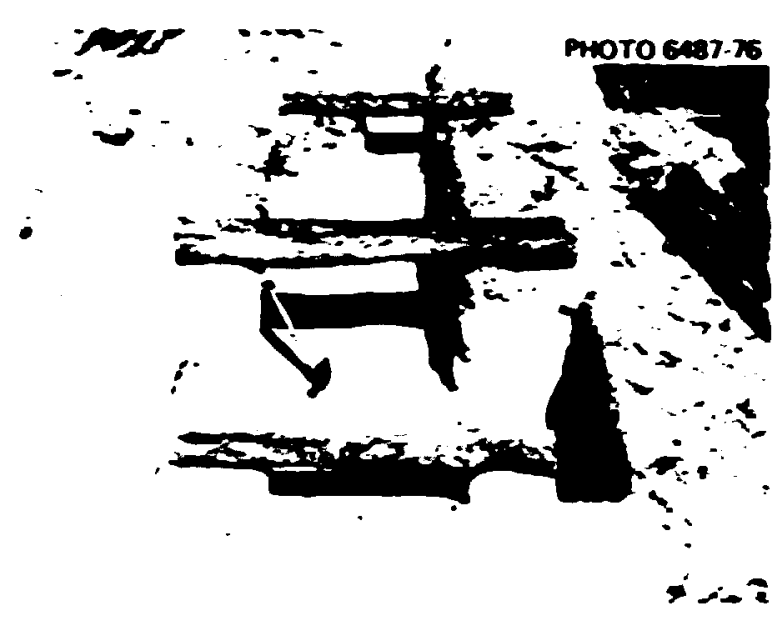

Fig. 13.3. Construction of one-half-scale Log-Covered Trench Shelter at 53 psi. The Chinese way of placing roofing poles below ground level is shown in front; the Russian way, to the rear.

with a reduction of $3-3 / 4$ in. in widceiling height. In the Chinese half, the roof poles remained horizontal, although they were lowered $2-1 / 4$ in. in the center.

13.2.6 One-tenth-scale Ridge-Pole Shelter at 15 psi. Unlike its adjacent full-scale counterpart, the entryways to this shelter were undamaged. However, as shown by Fig. 9.5, the earth covering the side of its frame facing ground zero and the tops of its entryways was complete?y removed.

13.2.7 One-tenth-scale Sma11-Pole Shelters at 53, 106, and approximately 180 psi. The shelter at 53 psi was undamaged, as was its full-scale counterpart at 53 pst. The shelter at 106 psi failed; one of its two vertical entries was wrecked, and lethal overpressures apparently entered through its smashed entry (see figs. 13.4 and 13.5). 


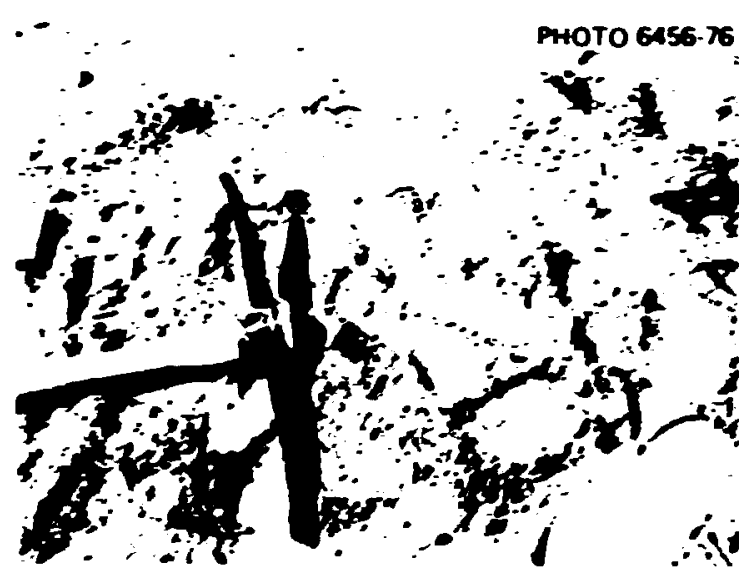

Fig- 13.4. One-tenth-scale Sazli-Pole Shelter, pretest at 106 psi. Earth was mounded over this shelter at slopes of about $10^{\circ}$ to minimize blast-wind scouring. Only the plywood blast doors are visible.

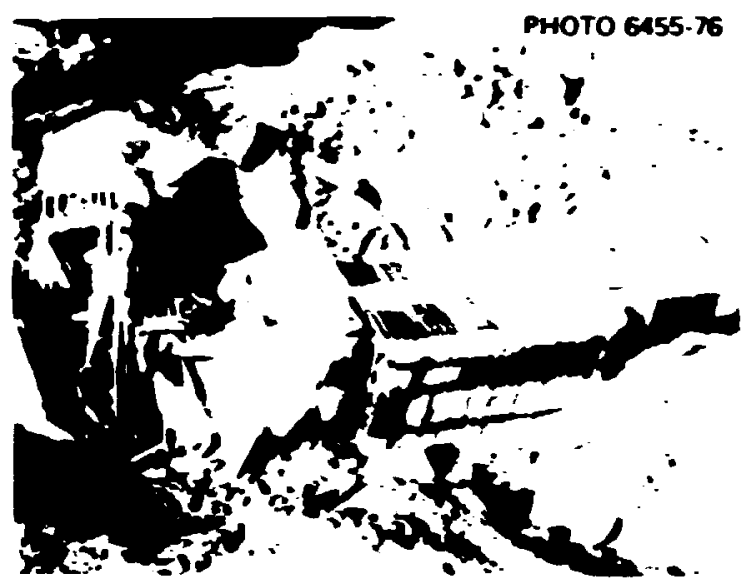

Fig. 13.5. One-tenth-scale Small-pole Shelter, posttest at 106 psi, show after being carefully uncovered.

Neither of the 6-in.-deep earth covers of these one-tenth-scale shelters was seriously wind scoured. By contrast, their full-scale counterpart at $53 \mathrm{psi}$, shielded by an earth mound with slopes of $36^{\circ}$, lost over 8 to 12 in. of cover due to blast-wind scouring. However, the shielding earth over the one-tenth-scale models was mounded with slopes of only about $10^{\circ}$. and the wind velocities a few inches above the quite rough ground were not as high as those striking the 5-ft-high wound over the full-scale shelter.

At the approximately 180-psi overpressure range, a one-tenth-scale model of only the main room of a Small-Pole Shelter, tested closed and covered with 6 in. of unmounded sandy soll, survived. However, the wall poles were pushed down about one-third their heights, and the lower cross-bracing "-. : Her" iroke, with poles left sticking upward into the living space, wi.lch would have injured or killed most occupants. At these overpressures it will be necessary to underlie the shelter with a floor Identical to the roof, and probably to provide a crushable material, such as branches, under and around a full-scale shelter. 


\subsection{Conclustons}

13.3.1. The successful testing of a reduced-scale shelter does not justify an assipption that its full-scale counterpart vill survive as vell in the same blast enviroment, especially under the dynanic loadings produced by large explostons.

13.3.2. When the critical stresses in full- and reduced-scale test structures (including stresses in earth banks subject to failure by shear) are induced by gravity and/or the acceleration or deceleration of asses, these stresses in the oodel are reduced by the scale factor.

13.3.3. T'sts of sall-scale shelters wy be helpful in selecting the cost pronising of several designs for expensive full-scale testing.

\section{BLAST-HURLED DEBRIS}

\subsection{Purpose}

Blast tests have very rarely involved simulating the conditions of urban, suburban, or wooded areas as regards the danage likely to be caused by blast-hurled debris. Structures that could easily be danaged by heavy projectiles have frequently survived shock waves and blast winds because no aterials to simulate houses and trees vere placed between tham and ground zero (see ref. 3 for examples). Saall expedient shelters, especially aboveground types and shelters with saall, steeply sloped earth coverings, could be danaged or destroyed by blast-hurled heavy projectiles such as tree trunks or the parts of houses.

Therefore, to get at least a feeling for the magnitude of this neglected problem, ve secured permission to expose to the blast some fireplace-sized logs, leftover luber, a 14-ft-high complete trae "planted" securely in the hard callche, and three 16-ft $2 \times 4$ 's also "planted" securely. Host of the logs were stacked in a woodplle at the approxtately 70-psi range, with the logs pointing toward ground zero. Six logs averaging $8 \mathrm{in}$. In diameter were placed on top of the 5-ft-high wound of earth over shelters at $53 \mathrm{psi}$. The $10 \mathrm{gs}$ and boards were marked with paint of different colors, for posttest identification. 


\subsection{Test Results}

The shock wave and blast winds hurled this debris farther than the standard blast wind velocities and theoretical calculations would lead one to believe. Most of the fireplace-sized logs cane to rest 240 to $360 \mathrm{ft}$ from their starting positions, and seven were airborne between 360 and $640 \mathrm{it}$. The farthest airborne, a S-in.-dian, 18-in.-long stick, cane to rest $640 \mathrm{ft}$ fron the woudpile. Fourteen logs struck the 5-fthigh wound over the log-Covered Trench Shelter at 53 psi and were embedded in the sof $t$ earth, as pictured in Fig. 14.1. Of the 73 pieces of blast-hurled debris that were found, 33 pieces were hurled between 240 and $360 \mathrm{ft}$ and cane to rest between approximately the 19- and 13-psi overpressure ranges.

The 14-ft-high tanarisk (salt cedar) tree, cut and "planted" two days before and still in full leaf, was broken of $f$ at the ground. Apparently, it was broken into very small pieces, and the pieces carried far away, since we were unable to find any part of this tree. The three vertical $2 \times 4$ 's were each broken into two or more pieces, some as short as 2 ft long.

Two of the small logs were hurled end-on into the earth ban', over the shelters at 53 psi and punched into the bank about 15 in. deep, measured from the preblast surface of the mound (see Fig. 14.2). Most

PHOTO 2653.77

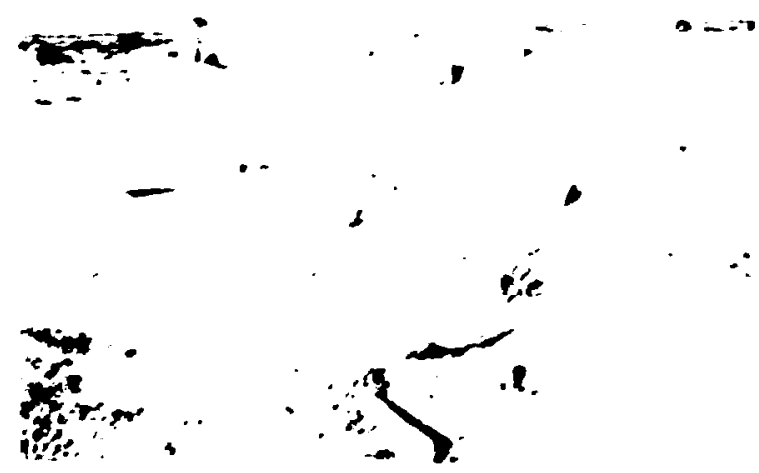

Fig. 14.1. Some of the fireplace-size logs i.:urled from a woodpile and embedded in the 5-ft-high mound at $53 \mathrm{ps} 1$. Apparently, the blast winds of the negative phase had uncovered the two small logs in the foreground and moved them toward ground zero. 


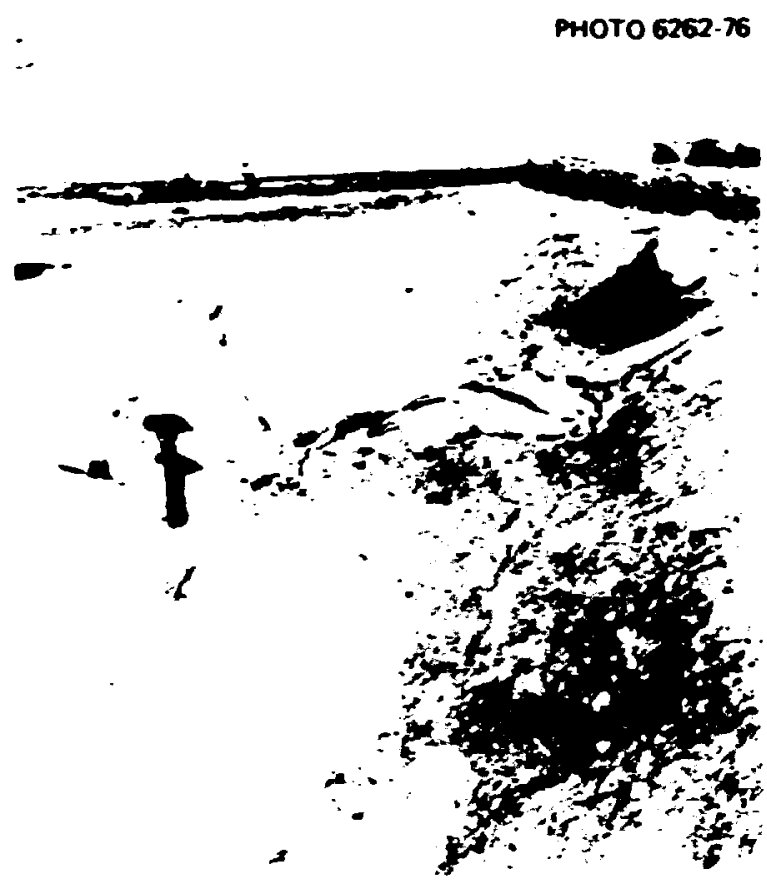

Fig. 14.2. Posttest condition of the side facing ground zero of the 5-ft-high mound of earth over Log-Covered Trench Shelter at 53 psi. The log sticking out of the mound had been hurled by the blast winds. The caivas had been covered with about $4 \mathrm{in}$. of earth, in a marginally successful attempt to reduce blast-wind scouring.

of the logs apparently bounced upward on hicting this bank (that sluped at about $36^{\circ}$ toward ground zero) and were swept higher upward by the turbulent blast winds. None hit a blast-protector $\log$ around a blast door. Some came to rest when they struck sheiter mounds farther from ground zero, as shown in Fiz. 9.7.

\subsection{Conclusions and Recommendations}

14.3.1. Blast-hurled debris would constitute a serious hazard to most expedient shelters built in areas of the types where most Americans live or would evacuate into during a nuclear crisis, if these areas were subjected to severe blast effects.

14.3.2. For reasons explained in Sect. 18, it is extremely dffficult to estimate from this evidence (based on a 1-kiloton air blast) the much greater hazards from blast-hurled debris 1 ikely to result at the same overpressure ranges from strategic nuclear weapons. 


\section{BLAST-WIND SCOURING}

\subsection{Purpose and Method of Measurements}

Blast-wind scouring of dry earth mounded over expedient shelters at the usual slopes results in serious degradation of the fallout protection af forded. 9,10 In order to obtain data indicative of the depth of blast-wind scouring from various slopes of mounded earth, at DICE THROW we measured tire depths of dry, sandy earth. scoured from around fixed sheiter entries and blast-protector logs, and also from around lines of 12-in. steel spikes driven into mounds at the 53-, 31-, 20-, and 15-psi overpressure ranges. Fach line of four to seven spikes was on a radius from ground zero and extended from near the base of a mound to its top. The painced heads of these spikes were at the surface before the blast. Slope angles were measured with a Brunton pocket transit.

\subsection{Test Results}

The blast-wind scouring was more severe than anticipated. Most of the 12-in. spikes were blown away and lost, in spite of a search that involved raking. All spikes were lost from the 5-ft-high mound at 53 psi. (We should have used steel rods driven several feet into the ground.) Table 15.1 summarizes the measured and estimated depths of blast-wind scouring.

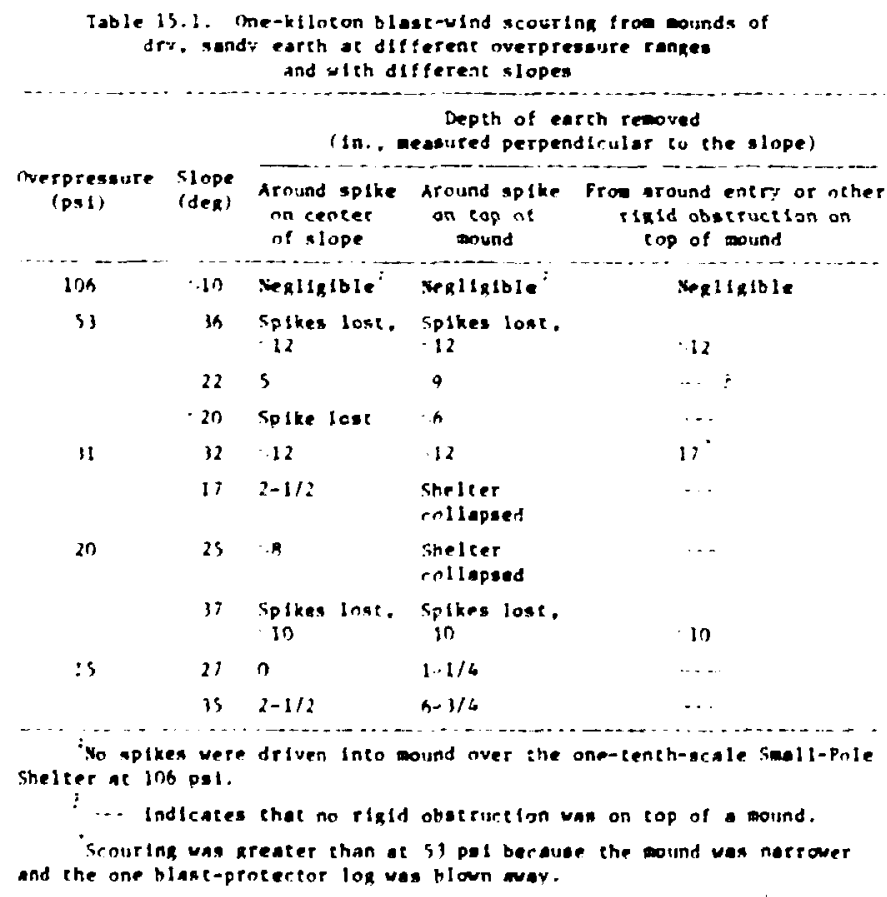




\subsection{Conclustions and Recommendations}

15.3.1. In order to prevent serious degradation of the fallout protection afforded by a shelter covered with dry, sandy earth if subjected to blast-wind scouring from a large nuclear explosion at overpressure ranges greater than about $30 \mathrm{psi}$, it appers prudent to mound earth over the shelter with slopes no $g_{i}$ eater than about $10^{\circ}$.

15.3.2. The effects of blast-wind scouring on different solls, mounded at differer.t overpressure ranges and with different slopes and tested while wet, damp, and dry, should be determined by blast tests.

\section{EXPEDIENT WATER STORAGE}

\subsection{Purpose}

For a shelter to be occupied for weeks in an area of severe fallout hazards, adequate drinking water must be avallable close at hand. The survivors in areas likely to be subjected to both blast effects and heavy fallout should not depend on normal sources of drinking water or on water stored fin containers likely to leak as a result of blast effects. Therefore, we conducted the first blast tests of simple, Inexpensive expedient means for storing many gallons of water per shelter occupant.

\subsection{Construction and Test Results}

16.2.1 Water stored in plastic bags lining cylindrical pits in the earth. ${ }^{12}$ As anticipated, lined cylindrical pits proved to be the most blast-resistant way to store water outside of blast shelters (see Fig. 16.1). Ordinary 30-gal polyethylene trash bags were used for waterproof 1iners. One bag was placed inside another, since a very small fraction of polyethylene bags not made for water storage have pinhole leaks. Each cylindrical pit was dug so as to have a diameter about 2 In. smaller than the diameter of 1 ts waterproof 1 iner bag, when its liner bag was inflated.

The best way to keep the upper edges of the pit-1ining bag from slipping into a pit is 1llustrated by Fig. 16.2: make a circular wire hoop the size of the mouth of the bag, and tape it into the mouth. 
ORNL DWG 77-10123

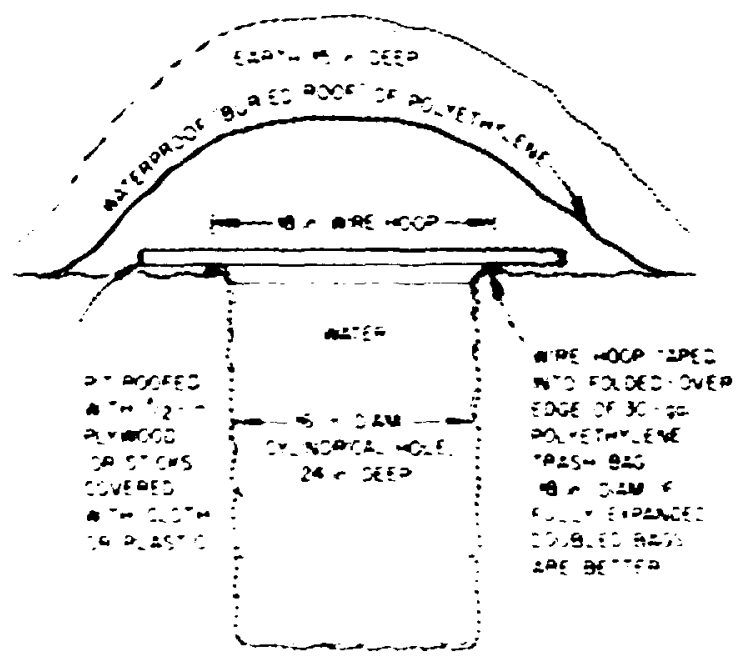

Fig. 16.1. Vertical section of cylindrical vacer storage pit lired with waterproof plastic bag, or two bags.

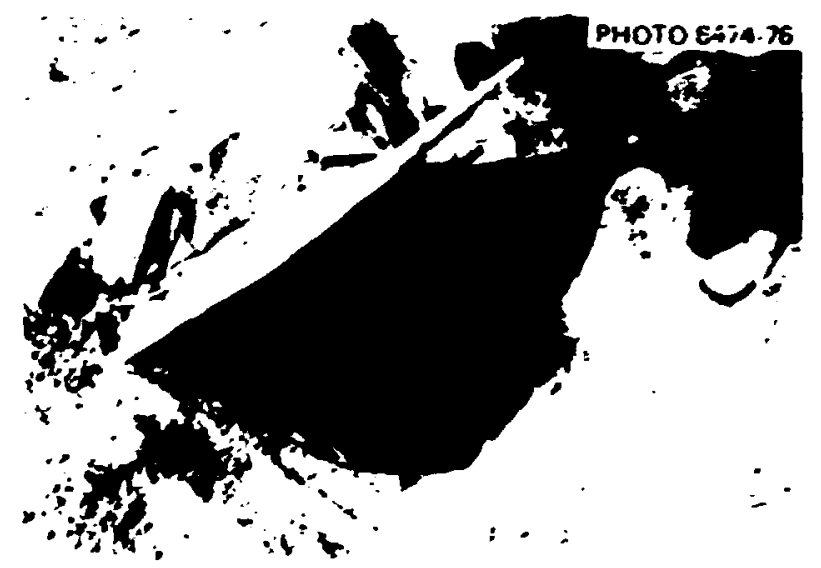

Fig. 16.2. Cylindrical water storage pit lined with two polyethyiene trash bags. After exposure to blast effects at 20 psi, this pit was undamaged and stijll full of water.

This method was used in the water storage pits at the 20- and 6.7-psi overpressure ranges. At the 53-psi range, the upper edges of doubled bags were satisfactorily held in place merely by sticking six 4-in. nails through the turned-under eiges of the bags and into the very $\mathrm{f} i \mathrm{rm}$ earth.

Before the test, the lined pits, each aoproximately 2 ft deep, were filled almost fuil and then roofed and covered as illustrated by Fig. 16.1. Each 1 fined pit contained about $20 \mathrm{gal}$ uf water. The earth cover 
was sufficiently thick to result in very effective earth arching under tne blast loadings; both plywood pit roofs were cracked bu not broken. None of the threc storage pics developed leaks. Even at the 53-psi ranye, the blast effects resuited in no caving of the pit wall.

The storage pit at 53 psi, which after the blast was left partly open to the dry desert winds, showed onlv 47 luss of water after eight days. At the 20-psi range, after 24 days during which the pit was left completely open to the dry desert winds, it was about $70 \% \mathrm{full}$; and at 6.7 psi, the covered pit had lost only about $4 \%$ of its water -fter 24 days.

16.2.2 Wacer scored in one or two plastic bags used to line a smaller fabric bag or an ordinary pillowcase. This method can be usfd to transport and sture quita large volumes of water. "' Two burlap potato bags, each lined with two 2 -gal polyethylene crash bags, were each filled with ahnut $10 \mathrm{~g}: 31$ of water.

One of these expedien: ...ricainers was tested inside the Small-Pole Shelter at the 53-psi overpresiure range. Its mouth was tied shut with a 1/4-in. cord, one end of which was then tied to a niil driven into a wall poie of the shelter, about a foot above the top of the water bag. This cord kept the mouths of the burlap bag and its double lining bags above the level of the water inside. This water storage was unaf fected by the quite severe ground shock inside the cios,pd shelter.

Inside the open fussian Pole-Covered Trench Shelter at 6.7 psi, an identical water stnrage container was undamaged by tite shock wave and blast winds that entered through the open otairway.

16.2.3 Water stored in plastic-1ined trenches. Figure 16.3 is a postsho. photo showing a lined watar storage trencli at 6.7 psi. This trench was dug $8 \mathrm{ft}$ long, $27 \mathrm{in.} \mathrm{wide,} \mathrm{and} 30 \mathrm{in}$. deep, and had been lined with a 10-ft-wide sheet of 4-mil polyethylene, with its edges secured in small, earth-filied ditches. About 200 gal had filled it to within about 6 in. of the top. The pit fiad then been covered with the pictured 3/4-1n. plywood sheets. Earth had next been mounded about 30 in. dee; over the plywood, incorporating a waterproof "buried roof" to keep 


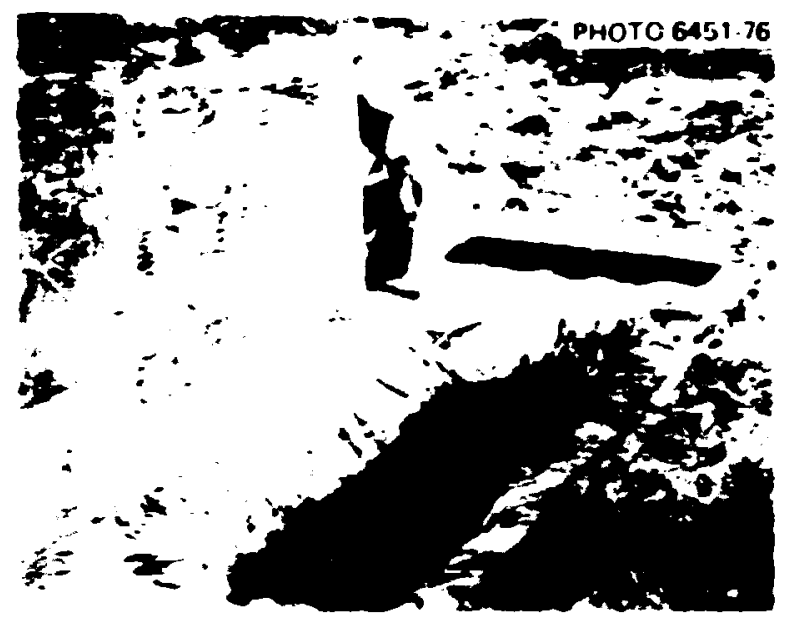

Fig. 16. : Postshot view of plastic-lined water storage pit at the 6.7-psi overpressure range.

out fallout-contaminated raimater. The resulting cross-sectional profile was similar to that shown in Fig. 16.1.

Ground shock resulted in some earth caving of the edges of the long sides of the trench, but no puncturing of the plastic lining resulted. Eight days after the blast, this sidewall caving had increased, but the trough still held a calculated 190 gal of water.

At the 20-psi range, a similar lined water storage pit was badly damaged by sidewall caving, although earth arching saved its roof. Before it could ie examined after the blast, almost all of its approximately $200 \mathrm{gal}$ of water had leaked oui.

\subsection{Conclusions?}

16.3.1. If blast is expected in a sheiter area, plastic-lined cylindrical pits, filled almost full and protected from blast and contamination as fllustrated in Fig. 16.1, would usially be the most practical method of expedient water storage.

16.3.2. Inside blast shelters, sufficient water for several days should be stored in fabric bags lined with larger plastic bags. 


\section{EXPEDIENT VENTILATION OF BLAST SHELTERS}

\subsection{Purpose}

Expedient shelters that afford good protection against both blast and fallout have sall entries, usually vertical. Such entries result In inadequate natural ventilation when a wind is not blowing. In hot weather, espectally if it is humid, even with a breeze outside, a fully occupled shelter can become dangerously or lethally hot and humid. Furthermore, we recognized that afr intake and afr exhaus t openings at ground level, If used for afr supply in a blast-devastated area contaminated with heavy fallout, might have dangerous amounts of fallout blown into them (see Fig. 10.1).

The problem of pumping suffictent atr through expedient blast valves of the types described earlier In this report needed investigation.

\subsection{Observations, Construction, and Test Results}

Intermittently during the three weeks following the main event, we observed the amount of sand and dust that was added to the amount that came through the poorly positioned blast valves in blast doors. Although in an area of very heavy fallout the amount that entered through these valves could prove serfous, much more fell into the open entries of the shelters not partially protected by blast doors and the blastprotector logs around them.

The Small-Pole Shelter at 53 psi, which had solld plywood doors that had to be left partly open to secure adequate ventilation, presented a special problem. In an attempt to keep sand particles out, we built an improvised 1-ft-high "wall" of sticks covered with polytihylene around the vertical entry, inside the blast-protector logs, and over the whole entry we erected an expedient tent. These measures reduced by about $60 \%$ the amount of sand subsequently blown into the shelter. However, If the area had been covered with heavy fallout, it would have been impractical to work outside the estimated 20 or $30 \mathrm{~min}$ required to install twe "wa1ls" and two tents, even if all parts of the "walls" and tents had been carefully made to fit around and over the two shelter doors before tha blast, and were stored inside the shelter for postattack use. 
Oentilation tests, using expedient kiPs and naking air velocity neasurements itit a bast ings anemoneter, yielded the following results:

17.2.1. In the Lop-Covered Trench Shelter at 53 fsi, using a 20-in.wide - 36-in.-high kAf (see fig. 17.1), $\$ 12 \mathrm{cfm}$ was pumper through the she!ter when its blast doors were open; $177 \mathrm{cfm}$ was pumped through the shelier with its two blast doors closed, with the air flowing through the blast valyes. In each case a deduction was made for the small measured volume of air that moved through the shelter during times when the wind was blowing outside. Hach door had blast valves with openings toraling about $80 \mathrm{in.}$ in cross-sectional area.

17.2.2. In the Chinese "Mar" Shei:er at in psi, using a 20-in.wide, 24-in.-high KAP (see Fig. 17.2), with the two triangular blast doors open, $350 \mathrm{cfm}$ was pumped through the shelter with the blast docrs open; $240 \mathrm{cfm}$ was pumped through the blast valves with the blast onors closed. Fach door had valves with openings totaling about 115 ir.: A gusty wind outside made these post test measuremonts less reliable, probably on the high side.

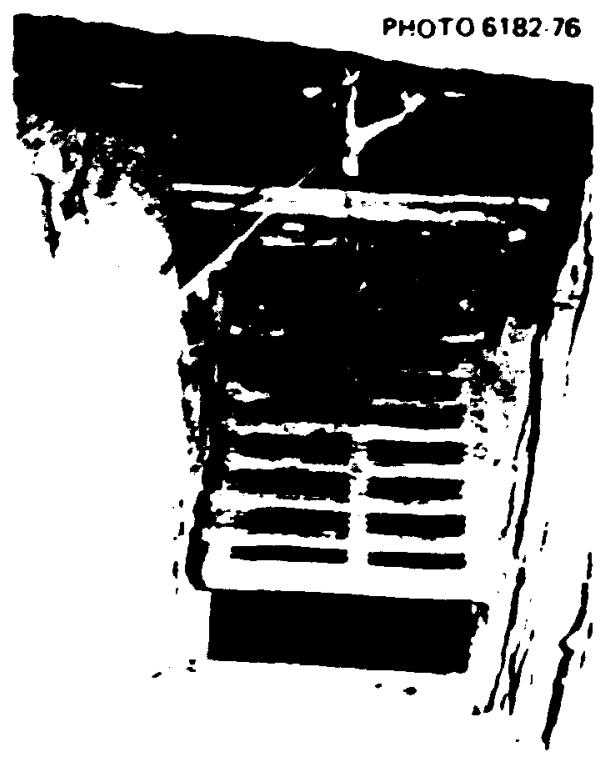

Fig. 17.1. Expedient sinelter ventilating pump (a $20 \times 36$ in. KAP) in an entry of the Lor-Covered Trench Shelter at 53 psi. Tested preblast, it pumped $177 \mathrm{cfm}$ through the valves of the two closed blast doors and $412 \mathrm{cfm}$ with the docrs open. This entry was demolished by blast effects. 


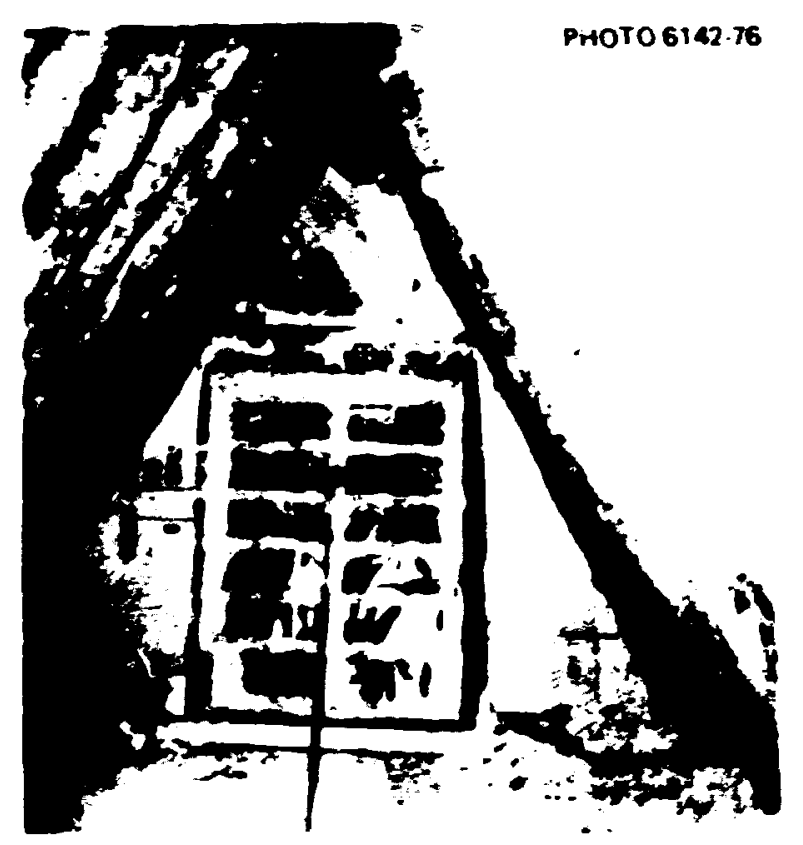

Fig. 17.2. Expedien: KAP (20 x $24 \mathrm{fn}$.$) tested in the Chinese "Man"$ Shelter at 20 psi, after the blast.

:7.2.3. In the Small-Pole Shelter at $53 \mathrm{psi}$, using a 29-in.-wide $\times$ 36-in.-high KAP when there was no wind outside, $861 \mathrm{cfm}$ was pumped through the shelter while the two solid blast doors were each open about $1 \mathrm{ft}$, providing two openings each about $5 \mathrm{ft}^{2}$ in cross-sectional area. The fallout-protective "walls" and expedient tent were around and over the air intake entry during this test. (A similar test conducted before the blast, but with the doors completely open, resulted in a measured airflow of $876 \mathrm{cfm}$, see Fig. 4.6.)

\subsection{Conclustons and Recommendalions}

17.3.1. Blast valves in blast doors are impractical. If valves of the type tested are mounted in separate vertical ventilation shafts, as was done in the ORNL tests In DNA's MIXED COMPANY main event, the entry of fallout particles appears likely to be reduced below dangerous levels. Ways to build expedient ventilation shafts that do not require heavy lumber should be developed and tested.

17.3.2. Except in extremely hot and iumld weather, an air supply of about $10 \mathrm{cfm}$ per shelter occupant, is enough to maintain tolerable 
conditions during continuous occupancy for several days. Therefore, even a KAP as small as $20 \times 24 \mathrm{in}$. would usually prove adequate for a 15-man shelter protected by blast valves having total openings as large as those of the biast valves tested in DICE THROW (around $100 \mathrm{in.}^{2}$ ) but installed in separate air intake and air exhaust ventilation shafts.

17.3.3. Simple, expedient equipment to enable shelter occupants to raise ventilation air intake and afr exhaust openings above ground level after the blast, and at the same time to quickly seal of the rest $c^{*}$ the entries, should be developed and tested.

17.3.4. For use in prefabricated blast shelters or in blast shelters that may be built in normal times or during slowly worsening crises, ventilation pipes that are installed with their upper ends safely below the earth until after the blast, and that can be raised by a jack above ground level after the blast, should be developed and blast tested. (Since DICE THK $W$, we have designed and built a prototype of such an extendable ventilation pipe, and also a manually operated, homemade suction pump capable of pumping around $60 \mathrm{cfm}$ through a $3-$ or $4-1 \mathrm{n}$. pipe.)

\section{LIMITATIONS OF THESE DICE THROW TESTS}

Caution should be used in extrapolating from the results of these DICE THROW tests to estimate the survivability of expedient shelters especially those built in typical urban, suburban, or wooded areas - if subjected to the blast effects of a large nuclear weapon, for the following reasons:

\subsection{Limitations Due to Size}

This blast was small, with air-blast effects roughly equivalent to a 1-kiloton nuclear explosion. At locations receiving the same peak overpressures from a multimegaton surface burst, mush more severe blast effects would result:

18.1.1. The duration of the overpressures and the dynamic overpressures would be much longer (20 times as long from an 8-megaton explosion), 3 and the energy transmitted to structures on and below the surface could be many times greater. At the same maximum overpressure ranges, the 
resulting destructive effects from an 8-megaton explosion on deeply bursed parts of shelters and the unshored earth walls of shelters would be greater. Also the earth-f low phenowena observed (to a relatively minor extent in some of these DICE THROW tests) would certainly increase in some areas.

18.1.2. The damages due to ground shock would be more extensive due to the greater amplitude of the ground wave and (in the case of an 8-wegaton burst) to the twenty-fold greater distances from ground zero to a given overpressure range. These greater distances usually would permit the ground shock to arrive at the ranges of interest up to hundreds of milliseconds in advance of the air shock wave; this difference between arrival times would cause the shelter roof supports to be accelerated upward before any dowmard forces from the airborne shock wave could cause dowmard movement of the earth covering a shelter. The vertical amplitude of such initial ground-shock (ground-wave) effects can be several inches, and the inertial mass response of the earth covering $a$ shelter roof would thus cause the roof members to be bowed downuard, to an extent not observable in high-explosive tests of similar sheliers at similar overpressure ranges.

18.1.3. Earth scouring of aboveground mounds by the blast winds (that from an 8-megaton explosion would blow for about 20 times as ing as from this "1-kiloton" DICE THROW shot) could be much greater, depending on the contour of the mound. Especially if the shielding earth were dry, such long-duration blast winds could biow awey much of the shielding earth mounded above ground level over a shelter, possibly reducirig its usefulness as a fallout shelter.

18.1.4. Blast-hurled heavy projectiles - including the trunks of large trees and parts of houses and other structures - can be accelerated iy a l-kiloton explosion to velocities only a small. fraction of those to which the same objects, if at the same overpressure range, would be propelled by a multimegaton explosion. Persons estimating blast damage should remember that an object's kinetic energy varies as the square of its velocity. Furthermore, a hurled object having linear dimensions ten times as large as those of a small object having the same velccity, 
densit $\because$, and relative proportions, and impact ing in the same relative position on a fixed object, delivers ten tioes the amount of energy per square inch of impact area. Therefore, the imoact damage to be expected from large objects accelerated by a multimegaton blast cannot be accurately estimated from the results of experiments like those at DICE THROW nor from the damage caused by blast-displaced heavy objects at Hiroshima and Nagasaki.

\subsection{Blast Tests of Scale Models}

Blast tests of scale models of shelters can give misleading results regarding the survivability of full-scale shelters subjected to the same blast effects. In the DICE THROW tests, all of the reduced-scale models of shelters withstood blast effects better than the corresponding fullscale sheltcrs. For example, both of the half-scale Rug-Covered Trench Shelters tested at the 15- and 5.8-psi range were undamaged, whereas both full-scile models failed at the same overpressure ranges.

\subsection{Earth Stability}

The earth was extremely stable in the DICE THROW test area. it almost all of the ORNL DICE THRO' shelter sites, at depths of only a few inches the sandy desert soil changes to very stable caliche. At the 53and 31-psi ranges, the hardness of tinis soil, largely composed of sand grains cemented together with gypsum, approached that oi a ver, sof limestone rnck. Thus if shelters were built in typical inhabited areas.. Ehat have much less stable soils and were subjected to blast effect; similar in magnitude to those at DICE IHROW, the collapse of the unshored walls of trench shelters, the pressures exerted on deeply buried parts of shelters, and the earth flow effects would all have been more pronounced and damaging.

\subsection{Fire Dangers}

18.4.1. The dangers from fires, carbon monoxide, and toxic smokes that would result from the thermal pulse and secondary blast effects of 
a nuclear explosion were not simulated at DICE THROH. Designers, advocates, and bullders of shelters should become more aware especially of the dangers from carbon monoxide in blast-devasted areas. Soviet civil defense handbooks prudentiy state that in the "zone of total destruction" (the zone within the 7-psi contour) "the rubb!e only smolders."

Persons concerned with blast shelters should also be infcrmed that even in areas of World har II mass fires, where less carbon monoxide was produced than if these same urban areas had been subjected to nuclear blast effects, often the majority of fatalities suffered by the occupants of shelters were caused by carbon monoxide. Thus some $70 \%$ of the 5000 persons who lost their lives in the well-prepared German city of Kassel were "asphyxiated, the greater part of them by poisonous carbon monoxide fumes." 18

18.4.2. Whenever practical, shelters should be built well removed from bulldings, flammable woods, and other readily ignitable material., and the parts of shelters that are flammable and may be exposed to thermal pulse should te covered with a heat-reflective and/or fireretardant coating. One of the means advocated in both chinese and Russian civil defense handbooks for preventing thermal pulse or a nearby fire from igniting exposed flamable parts of expedient shelters is to paint these parts with a thick coating of slaked lime. 5,17 The World War II fire bombing of Kassel was less effective than in other German cities in producing fire storms because the roof timbers had been so treated. 1 is

18.4.3. ORNL tests of this method included painting half of a dry, debarked 108 with a paste of slaked lime and then exposing the whole $10 \mathrm{~g}$ to intense radiant heat from a very hot fire. The unpainted half burst into flames before the painted white part began to smoke much. If lime or white cement is not avallable, coating exposed wood, sandbags, etc., with ordinary rieat iment, plaster, or even clayey mud should prove useful. Figure 18.1 illustrates blast-protector logs being quickly whitewashed. If water is available, keeping the exposed flamable parts of an calth-covered shelter wet, or even damp, w11l prevent their ignition by therma! pulse. 


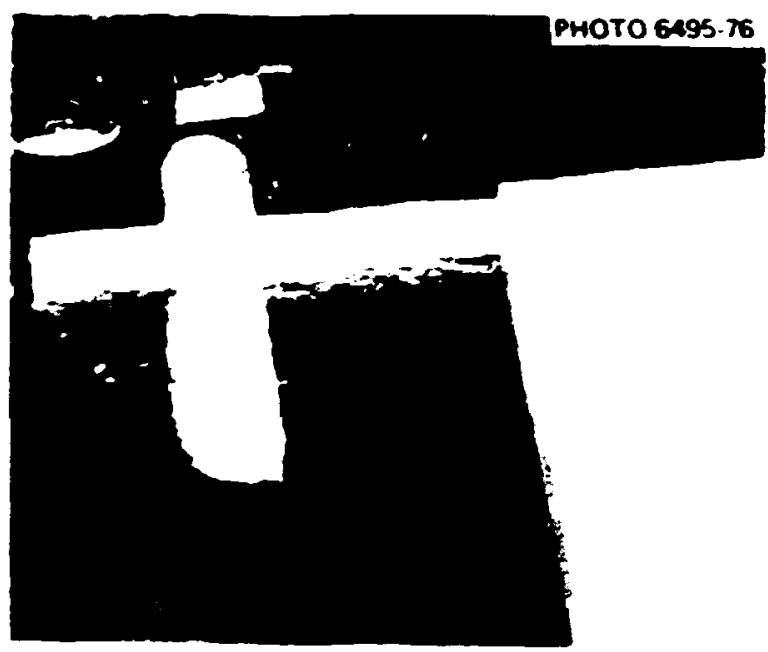

Fig. 18.1. Parts of a blast door and its blast-protector logs whitewashed with a thick slaked-lime paste. This is a proven effective means for making wood much more difficult to ignite.

\section{PRINCIPAL CONCLUSIONS AND RECOMMENDATIORS}

19.1. Expedient shelters of the types tested - especially if the ones with shored walls are equipped with blast doors - would af ford better protection against the blast and fire effects of nuclear weapons and much better fallout protection than do all but a small fraction of existing buildings.

19.2. Ground-shock effects - not overpressure effects - would cause the fallure of most expedient sheltars with sufficient earth covering to assure effective earth arching. (In order to assure effective earth arching, the earth covering should be at least one-half as thick as the free span of the shelter roof. Also the roof and/or the whole structure must yfeld when loaded - thus causing the resultant earth arching around the structure to bear most of the load.)

19.3. Even in very stable ground, unshored trench shelters with cellings about $6 \mathrm{ft}$ high would be unsafe if subjected to the blast effects of large nuclear explosions at overpressure ranges of more than about 7 psi. Shelters of this same type with ceilings about 4-1/2 ft high would become unsafe at overpressures above 10 or $12 \mathrm{psi}$.

19.4. When roof cover is adequate to assure earth arching, flexible poles considerably smaller in diametex than those used to roof the ORNL shelters tested at DICE THROW should prove adequately strong. 
19.5. Shelters likely to be subjected to blast effects should be built, whenever practical, with their roofs far enough below ground so that the tops of their entrances are no more than a foot above ground level. This positioning would greatly reduce blast damage and the removal of shielding earth by blast winds.

15.6. Expedient blast doors - especially doors made of poles and of triangular design - can be readily built strong enough to withstand as severe blast effects as the strongest expedient shelters tested to date. These doors should be blast tested while not protected by blastprotector logs, to determine whether such protection is essential.

19.7. Since the ground shock and earth flow effects from large nuclear weapons were not well simulated by the DICE THROW blast, expedient shelters and their life-support equipment should be tested under conditions more representative of large yields. The Air Force Weapons Laboratory's 125-kfloton dynamic air-blast simulation (DABS) test planned for March $: ? 9$ should provide a longer-duration blast environment more closely approaching that of the larger yields of interest.

19.8. Means for assuring adequate and safe ventilation-cooling of shelters after they have been subjected to severe blast effects is the most neglected essential component of shelter design. Future design and blast testing should include simple air intake and air exiaust openings of types shelter occupants couid raise above ground level after the blast and that would cnable them to pump sufficient air through their shelter while excluding dangerous amounts of fallout. 


\section{REFERENCES}

1. Cresson H. Kearny and Conrad V. Chester, $\Xi 2:$ Tests Execient

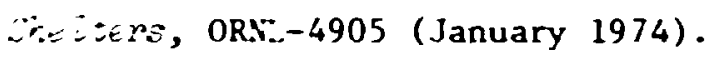

2. R. W. Manweiler, C. V. Chester, and C. H. Kearny, Ueasuremert :"

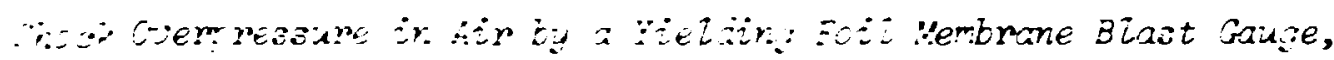
ORNL-4868 (September 1973).

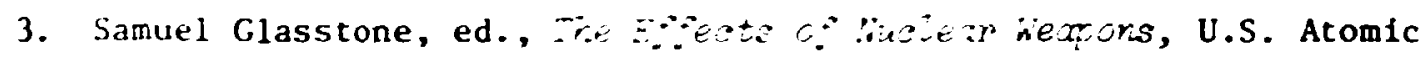
Energy Commission, U.S. Government Printing office, Washington, D.C. (April 1962).

4. C. H. Kearny, "Hasty Shelter Coust:urtion Studies," Annual Prorress

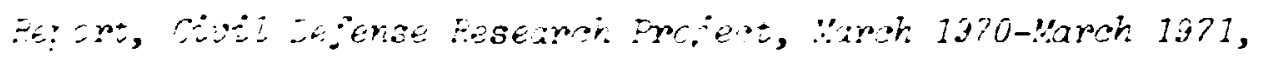
ORNL-4679 (March 1972).

5. Exercise Laboratory Shelter: $\therefore$ tox $\therefore:$ icr. Erort, Headquarters XVIII Airborne Corps and Ft. Bragg, Ft. Bragg, N.C. (December 1972).

6. P. T. Egorov, I. A. Shyakhov, and N. I. Alabin, Civi Defense, Escro, 1.7\%, ORNL/TR-2793 (December 1973).

7. G. A. Cristy and C. H. Kearny, Exretient Sheiter Handioot, ORNL-4941 (August 1974).

8. C. V. Chester and R. O. Chester, "Analysis of Effects of Nuclear Weapons Overpressures on Hasty Pole Shelters," Annua? Progress

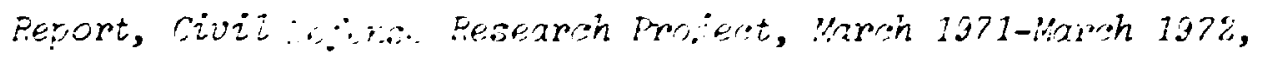
ORNL-4784 (December 1972).

9. Archie P. Flynn, geration Eustor, WT-359, Federal Civil Defense Administration, Washington, D.C. (March 1952).

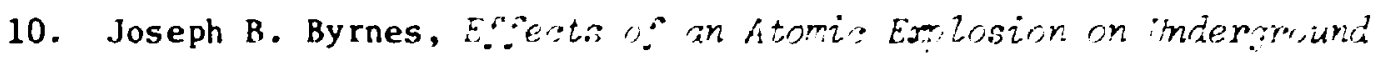
and Baserent Tupes of Hore Cheiters, WT-801, Federal Civil Defense Administration, Washington, D.C. (October 1953).

11. Lawrence Dresner, "Peak Overpressure at the Foot of a Vertical Wall Facing an Afr Blast," .T. Ar, P. Phs. 40(4): 1945-49 (Mar. 15, 1969).

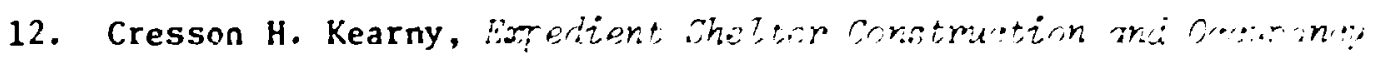
Exeriments, oRNI-5039 (March 1776). 


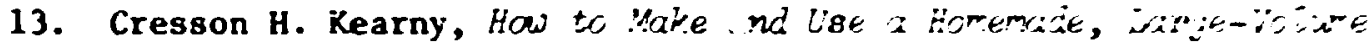
Efficient Sheltor-Ventilating Frow, the learn: fir Fur, ORNL/TM-3916 (August 1972).

14. N. I. Akimov et a1., Civil refense, Mos zow 13\%3, ORNL/TR-2306, ed. J. S. Gallar and C. H. Kearny (Apr 11 1971).

15. v. I. Molodykh et al., Antiradiation Sheiters in Ruml Areas, Moscow 1972, ORNL/TR-2745, ed. Cresson $H$. Kearny and Joanrie S. Gailar (October 1973).

16. G. K. Kotlukov et al., Civii Defense, Hoscow 1976, translated by Defense Civil Preparedness Agency, Washington, D.C. (1977).

17. Chinese Civil Defense, ORNL/TR-4171, ed. C. V. Chester and C. H. Kearny (August 1977).

18. David Irving, The Destruction fresten, William Kimber, London, 1963. 